San Jose State University

SJSU ScholarWorks

Dissertations

Master's Theses and Graduate Research

Summer 2018

\title{
Analyzing Student-Teacher Relationships of Cariño and Confianza and Their Impact on Academic Engagement by Latino Males
}

Nereida Robles Vasquez

San Jose State University

Follow this and additional works at: https://scholarworks.sjsu.edu/etd_dissertations

\section{Recommended Citation}

Vasquez, Nereida Robles, "Analyzing Student-Teacher Relationships of Cariño and Confianza and Their Impact on Academic Engagement by Latino Males" (2018). Dissertations. 25.

DOI: https://doi.org/10.31979/etd.bw49-v8cz

https://scholarworks.sjsu.edu/etd_dissertations/25

This Dissertation is brought to you for free and open access by the Master's Theses and Graduate Research at SJSU ScholarWorks. It has been accepted for inclusion in Dissertations by an authorized administrator of SJSU ScholarWorks. For more information, please contact scholarworks@sjsu.edu. 
MALES

\author{
A Dissertation \\ Presented to \\ The Faculty of the Educational Doctoral Program in Educational Leadership \\ San José State University \\ In Partial Fulfillment \\ of the Requirements for the Degree \\ Doctor of Education
}

by

Nereida Robles Vasquez

August 2018 
(C) 2018

Nereida Robles Vasquez

ALL RIGHTS RESERVED 
The Designated Dissertation Committee Approves the Dissertation Titled

ANALYZING STUDENT-TEACHER RELATIONSHIPS OF CARIÑO AND CONFIANZA AND THEIR IMPACT ON ACADEMIC ENGAGEMENT BY LATINO

MALES

by

Nereida Robles Vasquez

APPROVED FOR THE EDUCATIONAL DOCTORAL PROGRAM IN EDUCATIONAL LEADERSHIP

SAN JOSÉ STATE UNIVERSITY

August 2018

Marcos Pizarro, Ph.D. Department of Mexican American Studies

Roxana Marachi, Ph.D. Connie L. Lurie College of Education

Angela Meeker, Ed.D. Santa Cruz City Schools District 


\section{ABSTRACT \\ ANALYZING STUDENT-TEACHER RELATIONSHIPS OF CARIÑO AND CONFIANZA AND THEIR IMPACT ON ACADEMIC ENGAGEMENT BY LATINO MALES}

by Nereida Robles Vasquez

Latinos attending California's public schools often feel disconnected, unwelcome, and unsafe. This qualitative interview study uses the grounded theory approach to provide a platform for the voices of Latino male high school students to explain their experiences. This approach allows for understanding of why a large number of them are transferred from their schools to alternative settings which in turn greatly limit and often prevent them from continuing their education. Many describe experiences of rejection and hostility causing them to drop out, or to have no interest in furthering their education. Findings illustrate the impact of their perception of Required Caring [Cariño Laboral] versus Authentic Caring [Auténtico cariño], and the development and/or lack of development of Respect [Respeto] and Trust [confianza] as students of color and as human beings. These findings support the urgent need for training of school leadership to reflect on their practices and approaches in order to recognize that their Latino male students' perspectives could create a culture of mistrust, fear, and ultimately separation. This adequate training would provide a substantial effort to begin paying down the educational debt that we owe to students of color. 


\section{ACKNOWLEDGMENTS}

I dedicate this dissertation to my father Atilano Robles Celis and to my nephew and godson, David Abraham Robles. To my father for instilling in me a strong work ethic, love for learning, and the consistent drive to reach my goals; dedicating his entire life as an educator in rural villages. To David Abraham for his short but significant role in my life, which encouraged me to learn about the challenges Latino male youth encounter in the educational system. To ALL the youth (my heroes, warriors, and inspiration) I have worked with for the past twenty years. With much love to my daughter Chanel, and nieces/nephews: Lindsey, Kristen, Jenny, Kim, Gabby, Edgar, Quetzal, Milan, Samuel; and my sisters and teachers: Fe, Coco, Chele, Silvina, Panuncio, Rey, and also my mother and greatest teacher, Natividad Vasquez Celis. To ALL my professors in the doctoral

program. To my dissertation committee, Dr. Angela Meeker, Dr. Roxana Marachi, and Dr. Marcos Pizarro. To mi maestro, Marcos Pizarro, who for three years based on confianza, cariño, and respeto, guided and supported me in finishing this dissertation. With gratitude to Lisa Storer, who has never doubted my ability and determination. To educators Curt Coleman, Carol Swain, June Reuben, Mickey Mood, and Genene Oviatt. Lastly, to the twenty students who taught me the difference between auténtico cariño and cariño laboral; they helped me understand the difference between the meaning of trust and care for a student, and for a Latino growing up in the United States. 


\section{TABLE OF CONTENTS}

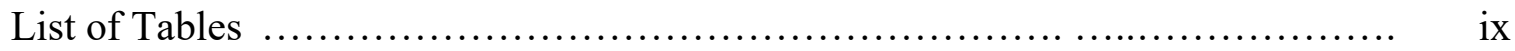

List of Figures ..................................................................... xi

Chapter One: Purpose of the Study ..........................................

The Educational Equity Problem/Issue..................................... 1

Why am I Focusing on Latino Males? .................................... 3

Overview of Existing Knowledge on the Issue .............................. 6

Gaps in Existing Knowledge Related to my Research Questions.................. 10

Research Questions ................................................. 10

Explanation of Methods .................................................. 11

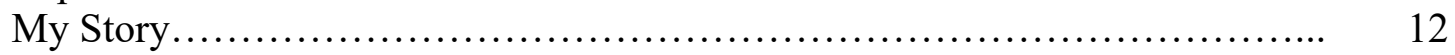

Potential Implication of the Dissertation Study ............................. 16

Definition of Terms................................................... 18

Chapter Two: Literature Review ................................................... 21

Teacher: Institutionalized Racism.......................................... 21

Teacher: Power and Privilege .................................................... 23

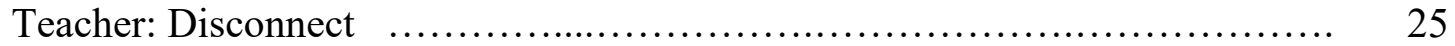

Teacher: Lack of Understanding …............................................ 28

Teacher: Deficit Thinking ............................................... 28

Teacher: Low Academic Expectations $\quad$............................................ 29

Student: Cultural Identity and School...................................... 31

Student: Cultural Identity in Other Communities .......................................... 33

Student: Language Identity at School ..................................... 34

Student: Opportunities to Talk......................................... 35

Student: A Need to Belong........................................................... 37

Dropout Rate ........................................................ 38

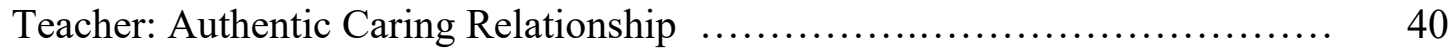

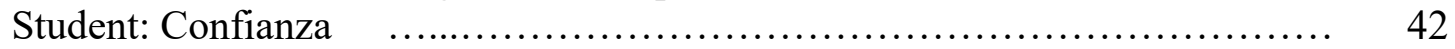

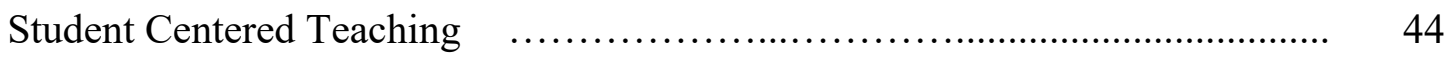

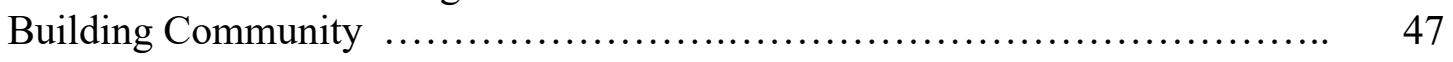

Conclusion............................................................. 47

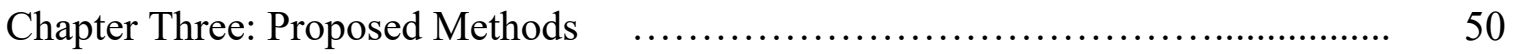

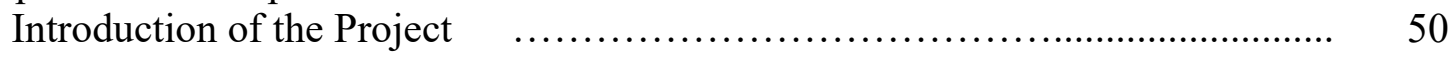

Specific Variables That Are Being Analyzed for Relationships........................... 51

External Factors: Teachers Beliefs, Expectations, and Behaviors ................ 53

Outcome Factors: Academic Motivation and Academic Engagement............ 53

Pilot Sample ......................................................... 57

Contextual Analysis -Study Sites (EHS and AHS) ................................. 58

Why I Chose EHS ..................................................... 59 
Brief Description of the Continuation School .................................. 60

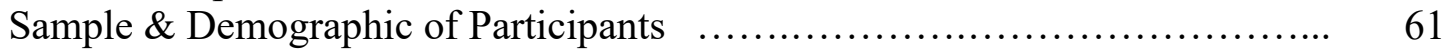

Insights from Stakeholders................................................ 62

Why this Sample was Most Appropriate for Answering My Research

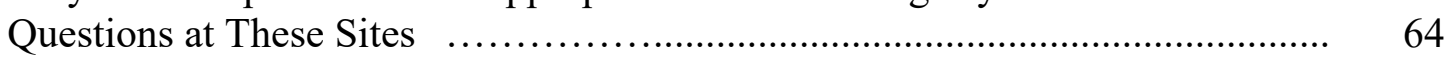

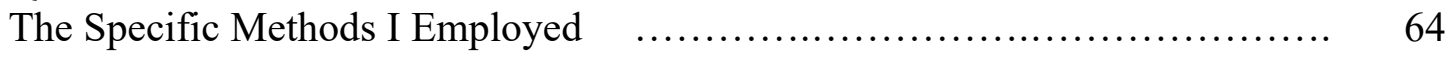

The Specific Components of the Data Collection Tools and How They

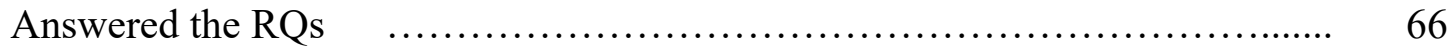

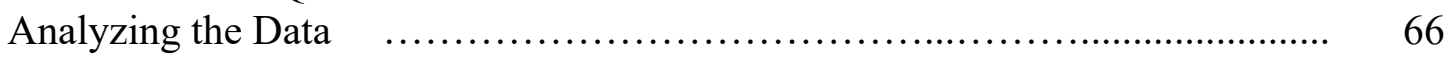

Limitations of the Data Collection.......................................... 67

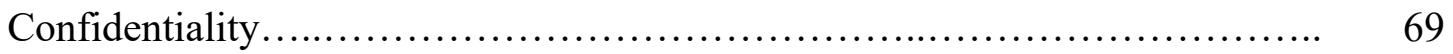

Role of my Positionality............................................... $\quad 70$

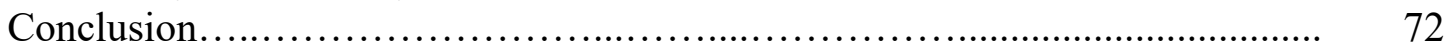

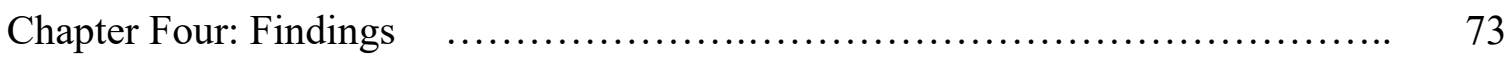

Background Related to Participants and Their School Placements............... 74

Background: Description of Students .............................................. $\quad 76$

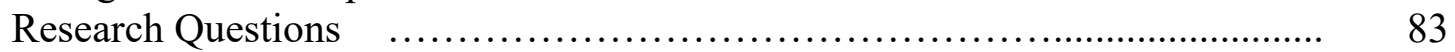

Participants' Perceptions of Their Teachers' Beliefs (RQ1) ..................... 84

Participants' Perceptions of Their Teachers' Expectations (RQ1)................ 88

Participants' Perceptions of Their Teachers' Behaviors (RQ1) ................ 92

Participants' Perceptions of Their Teachers' Positive Beliefs, Expectations and

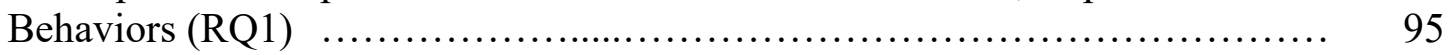

Participants' Perceptions of Their Teachers' Authentic Caring/ Auténtico

cariño, Required Caring/Cariño laboral \& Trust/Confianza (RQ2) ........... 99

Authentic Caring/ Auténtico cariño........................................ 99

Required Caring/ Cariño laboral …................................... 102

Trust/Confianza .................................................. 104

RQ2: Analysis of the Participants' Responses .............................. 106

RQ3: Teacher Relationships: Impact on Participants' Academic Motivation \&

Engagement F.................................................... 107

What Motivates and Engages Latino Male Students in Schools? ............... 111

Summary of Findings ................................................ 112

The Eight Teachers at EHS ............................................. 113

Conclusion ........................................................... 115

Chapter Five: Discussion, Recommendations, \& Conclusions.................... 118

Discussion ........................................................... 118

Recommendations ............................................... 126

Recommendation 1: Provide Leadership Training for Administrative Staff

Based on Student Identified Classroom Behaviors of Teachers and

Students.............................................................. 128

Recommendation 2: Teacher Training - Restorative Justice ..................... 130

Recommendation 3: Provide Teacher Training - Cultural Diversity of 


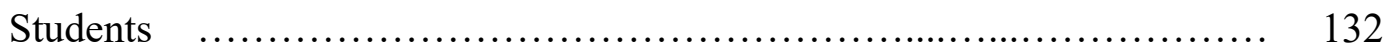

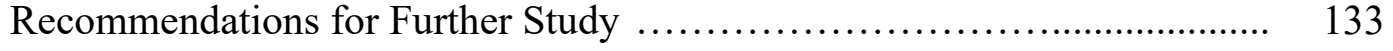

Conclusion $\quad$.................................................... 135

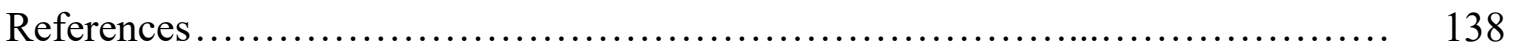

Appendices $\quad$........................................................... 147

Appendix A: Background Survey/ Encuesta

Appendix B: Interview Questions 


\section{LIST OF TABLES}

Table 1. Contextual, external, and outcome factors..................... 58

Table 2. $\quad$ EHS and AHS Student Identified Ethnicity 2017-18 _............... 80

Table 3. EHS and AHS Newcomer Designation 2017-18................. 81

Table 4. Students in the Free and Reduced Lunch program 2017-18 ....... 81

Table 5. Students' English Proficiency Designations: 2017-18................... 82

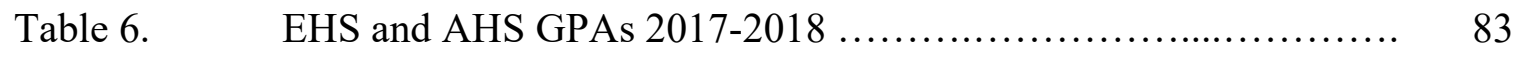

Table 7. Attendance and Truancy Rates While at EHS 2017-18.......... 83

Table 8. Student Participation Extracurricular Activities 2017-18........ 85

Table 9. EHS and AHS Favorite Classes 2017-18 ................... 85

Table 10. Student Perceptions of Teachers' Beliefs ...................... 88

Table 11. Student Perceptions of Teachers' Expectations .................. 92

Table 12. Student Perceptions of Teacher Behaviors in EHS Classrooms..... 95

Table 13. Student Perceptions of Their Teachers' Positive Beliefs............. 98

Table 14. Student Perceptions of Their Teachers' Positive Expectations ...... 99

Table 15. Student Perceptions of Teachers' Positive Behaviors............... 101

Table 16. Student Perceptions Authentic Caring / Auténtico cariño, Required Caring, \& Trust / Confianza

Table 17.

Table 18.

Teacher Behaviors: Authentic Caring / Auténtico cariño to Cause Full Student Trust/ Confianza 
Table 20. Participant Behaviors Triggered by Negative Student/ Teacher Relationships...............................................

Student Responses to Teachers Who They Believe Do Not

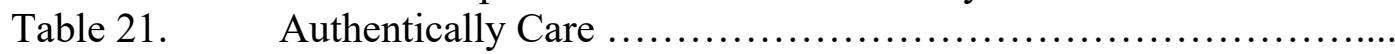

Motivating Teacher Behaviors 


\section{LIST OF FIGURES}

Figure 1. Conceptual framework ......................................... 130 


\section{Chapter One: Purpose of the Study}

\section{The Educational Equity Problem/Issue}

In 2006, Ladson-Billings challenged educational researchers to reconceptualize the "notion of the achievement gap and to begin to think about the incredible education (Ladson-Billings, 2007, p. 316). Ladson-Billings (2007) argues that instead of "telling people to "catch up," we, as society, need to think about what and how we can begin to pay down "this mountain of debt we have amassed at the expense of entire groups of people and their subsequent generations" (p. 316). Society and social policy have created an educational deficit for certain students as opposed to creating a "gap." She argues that we need to understand that there is an educational debt "that exists (and has always existed) in our nation's schools..." that is founded upon "historical, economic, sociopolitical, and moral decisions and policies that characterize our society" (p. 5). As many educators continue to see Latino high school students as "caught in the web" of needing "to catch up," they are blinded to the existence of the "education debt" that is in fact a complex set of issues that continue not to be adequately addressed in teacher training schools and public school professional development, so many Latino students continue to have their high school education disrupted and compromised.

California has the largest population of Latinos in the United States with more than 14 million under the age of 18. According to Becerra (2012), the Latino population in the United States increased 43\% from 2000 to 2010 . A majority are students in public schools. "Hispanic/Latinos already are the largest racial/ethnic group in the child population in California, accounting for $51 \%$ of children under 18 " (Kidsdata.org., 2016). 
The future of the state depends on the successful integration of Latino families and their children into the state's economy and society which in large part depends upon Latino students successfully progressing through California public schools.

Although the majority of enrolled students in California schools are Latino, many inadequate and often destructive approaches by teachers and staff whose jobs are to serve all students are pushing Latino students into the criminal justice system. According to the American Civil Liberties Union (n/d), some of the factors that support incarceration are overcrowded classrooms, lack of funding to support Latino students' emotionally, and teachers who are not supported or provided access to learning strategies that work with youth of color.

Sanchez, Colon, and Esparza (2005), share that sense of belonging predicts positive relationships, motivation, and academic performance. They also shared that Latino males are less likely to finish high school and have a lower grade point average than Latina females (Ladson-Billings, 1995; Sanchez et al., 2005). When Latino male youth sense from their teachers "low and negative expectations" due to the way teachers interact with them, their way of resisting to these treatments is by skipping classes (Cammarota, 2004). Students interpret teachers' actions as not caring about them, and often adopt the "I do not care attitude" as a way of survival (Katz, 1999; Sanchez et al., 2005). The students are forced into finding ways to maintain their sense of self when teachers send signals that they are "less than" in a classroom. Pizarro (2005) describes that Latino male youth become aware that the racial component becomes part of and shapes their identity. Some means of survival for youth include defending their identity in ways that cause them to 
pay a high price. In the classroom, they might challenge the teacher as a way to maintain their identity instead of focusing on the material being taught. Their identity gives them "strength and confidence" (Pizarro, 2005, p. 87); however, to connect their identity while finding their student role in schools is difficult (Pizarro, 2005).

The academic and behavior profiling experiences that most Latino male youth experience affects them psychologically. Being wrongfully accused by a teacher, accused for defiance for not understanding instructions (language), and pushed out to alternative settings makes Latino youth always running for survival and feeling hopelessness to think and believe they deserve a future, an opportunity to learn, to grow, and to have a family. Often Latino youth find on the streets, with gangs what schools couldn't, didn't want to offer: a sense of safety, and a sense of belonging and appreciation for who they are and how they look. Certain Latino youth see gangs as representing an offer, and its satisfies their needs as defined by Maslow's hierarchy of needs (Kunc, 1992), in terms of acceptance, feeling safe and of belonging.

\section{Why am I Focusing on Latino Males?}

Brown (2007) states that "Latino and especially African American students, particularly boys, are overrepresented among those students excluded from school” (Brown, 2007, p. 426). According to Brown (2007), school culture and school adults' beliefs and perceptions that low-income students exhibit more anti-social behavior. Fry (2003) shows that the Latino population increased from $11 \%$ of the 16 to 19 year-old population in 1990 to $16 \%$ in 2000 in the U.S. Fry's (2003) work shows an increase in the Latino high school dropout population as well. According to the California 
Longitudinal Pupil Achievement Data System (CALPADS), 8.5\% of Latino youth and 4.6\% of white youth in Santa Cruz County dropped out of high school in 2014-15 (CALPADS data, 2014-15).

There are a variety of identified reasons as to why Latino male students have such a high dropout rate. Historically, they have been overrepresented in school discipline referrals (Brown, 2007; Pizarro, 2005; Rios, 2011). Latino male youth are frequently suspended to the detriment of their academic progress (Weissman, 2015). Statistically, they are more likely to be arrested between the ages of 10 and 17 (Rios, 2011). Additionally, the zero-tolerance concept, when applied in high schools, has worked to push Latino male youth out of the education system and into the criminal justice system. Criminalization in schools is an every-day issue that Latino male youth face (Brown, 2007; Rios, 2011). These youth are often poor and from single parent homes and they have attended schools where they have experienced academic difficulties and alienation from school (Gordon, Della Piana, \& Keleher, 2001; Pizarro, 2005; Rios, 2011). Suspended Latino male youth are at a higher risk of using drugs, joining a gang, and ending up incarcerated.

Another issue that affects Latino male students is a discrepancy between the accountability that we demand of youth of color, in terms of self-regulation, and the accountability (or lack thereof) required from adults (Noguera, 2009). Many educators respond too quickly, without time for reflection, to their students' of color responses and engage in conversations that often escalate negatively that make Latino youth are seen as defiant. In addition, teachers sometimes do not provide their students an opportunity to 
explain the circumstances of their behavior (Weissman, 2015). Often, the attitudes of youth of color are assessed as 'sinister, intentional, fully conscious' (Weissman, 2015, p. 123).

According to Noguera (2003), "schools most frequently punish the students who have the greatest academic, social, economic, and emotional needs" (p. 342). Noguera (2003) states that "an examination of which students are most likely to be suspended, expelled, or removed from the classroom for punishment, reveals that minorities (especially Blacks and Latinos), males, and low achievers generally, are vastly overrepresented" (p. 342). Often, these Latino students are English language learners, newcomer students, students with learning disabilities, and students in foster care or who are homeless. Many of these students in California public schools are Latinos.

Erwin and Worrell (2012) state that often teachers' practices, expectations, and beliefs often keep Latino students out of accelerated programs despite evidence that they would benefit from more challenging work while they are continuously improving their English skills (p. 75). Teacher actions - or non-actions - often preclude talented Latino students from disadvantaged backgrounds from access to appropriate resources and attention that other students receive (p.79). A majority of these students are deprived of opportunities that are necessary to put them on the college track. Often, youth voices are silenced in schools without an opportunity to demand an advanced class and they get stuck in the low track classes (Auerbach, 2002; Ladson-Billings, 1995). Ladson-Billings and Tate (1995) argue that "race continues to be a significant factor in determining inequity in the United States" (p. 48). Youth of color, especially males, become victims 
of the color they represent and in schools, race is what determines students of color experiences in school.

\section{Overview of Existing Knowledge on the Issue}

According to Ford (2012), differences in values, beliefs, attitudes, customs, and traditions between white teachers and their racially, ethnically, and linguistically diverse students contribute "to low expectations and deficit thinking on the one hand and cultural misunderstandings on the other" (p. 392). Pizarro (2005) documents that excessive discipline actions and negative stereotyping make for highly negative public school experiences for Latino students. Consistent findings show that "Students who are less bonded to school may be more likely to turn to lawbreaking activities and become less likely to experience academic success" (Gregory, Skiba, \& Noguera, 2010, p. 60). Students that are suspended often become involved with older youth and/or other suspended students. Suspended students are at risk of delinquency, low grades, and antisocial behavior. According to Flannery (2015), "A suspension can be life altering. It is the number-one predictor - more than poverty — of whether children will drop out of school and walk down a road that includes greater likelihood of unemployment, reliance on social-welfare programs, and imprisonment" (Flannery, 2015, The School-to-Prison Pipeline: Time to Shut it Down, para. 5). Verdugo (2002) explains that the development and implementation of high school zero-tolerance policies have played a major role in the increased number of students of color who are suspended and/or expelled. The policy was created to address offenses such as the possession of firearms. In 1995, "the law changed its terminology from firearm to weapon" (Martinez, 2009, p. 154) and in 1999, 
some schools included truancy, disrespect, and dress-code violations. Gregory et al. (2010) argue that "Discipline sanctions resulting in exclusion from school damage the learning process."

Johnson, Boyden, and Pittz (2001) and Pizarro (2005) have identified that racial profiling operates and is accepted and then viewed as normal practice in our schools. In 2012, approximately $73 \%$ of the division's probation caseloads represented youth of color" (htpp://www.cdcr.ca.gov). The high number of Latino students that have contact with the law is an issue of concern. According to Johnson et al. (2001) racial profiling "works throughout the fabric of education" (p. 6). Gregory et al. (2010) stated that disciplinary practices at schools can affect the low academic performance among the group of students in greatest need of improvement.

De Velasco et al. (2008) explains that many Latino students are placed on a pathway to dropping out by being transferred from their comprehensive schools to continuation or alternative programs such as court and community schools. Many students who are placed in a continuation school suffer from low self-esteem, fall behind in their academic work, and do not continue their education and/or at risk of dropping out (Arcia, 2006).

De Velasco et al. (2008) shared that each year, more than $10 \%$ of California's public high school students are enrolled in some kind of alternative/continuation, court and community and community day school and these students are more likely to be Hispanic, African American, and English language learners (De Velasco et al., 2008). Hispanic students "comprise about $55 \%$ of all students in continuation schools... compared with the $42 \%$ of the total $11^{\text {th }}$ grade enrollment statewide" (De Velasco et al., 2008, p. 3). 
A majority of students who are placed in continuation schools are not given the encouragement and support they need to progress academically to earn a high school diploma (Weissman, 2015). They have limited access to pro-social activities such as access to sports' team participation, drama productions, and band participation that could prevent them from maladaptive behavior (Grana et al., 2010). Students often feel a great sense of helplessness. A student Weissman interviewed explains, "I feel like alternative school systems...set up kids like me to go to jail. You [are set] back [in] school so far that you just want to drop out of school" (Weissman, 2015, p. 2). Latino students who attend continuation schools have a higher risk of engaging in disruptive behavior. This behavior often results in a suspension, an expulsion, a request to transfer to another school, or a decision to leave school altogether if they are eighteen years old (Kelly, 1993). Students who are pushed out to a district's continuation school then find themselves pushed out of school altogether so they become dropouts. On the streets, they are invited/pursued to join gangs by relatives and friends, and/or become parents at an early age. Research by Fry (2003) identifies that the high number of Latino youth dropping out of school is an indicator of the education disadvantages that affect the lives of Latino youth. The outcomes of Latino students who leave school without a diploma often translate to low paying jobs with less employment opportunities. In addition, dropping out of school is associated with illegal activities, teen pregnancy, and idleness that could lead to substance abuse or depression. The National Center for Education Statistics presented evidence that "Regardless of how dropping out is defined, first, second, and third, and [even later] generations [of] Hispanic youth drop out of school at 
similar rates" (Fry, 2003, p. 3). Latino students' drop-out rate has a major impact not only on the students' lives and families, but on also on society at large. According to Orfield, Losen, Wald, and Swamson (2004), “Official dropout rates mask a widening 'graduation gap' between minority and white students. In America's 100 largest cities, $58 \%$ or more of ninth grade students in high minority schools do not graduate four years later" (Orfield et al., 2004, p. 3). Research shows that $41 \%$ of Hispanic adults 20 years of age or older and $23 \%$ of African American adults had not attained a high school diploma while $14 \%$ of white adults and $15 \%$ of adults of Asian origin were listed as dropouts (Fry, 2010; Orfield et al., 2004, p. 4). Becerra (2012) declared that dropouts are more likely to experience unemployment, to receive welfare, to have lower lifetime earning potential, to engage in delinquent or criminal behavior, and to suffer from mental health issues.

Addressing the educational needs of Latino male students is fundamental in educational settings. Latino students' population is increasing across the country. The research shows that pushing out Latino students in alternative school setting causes feelings of academic hopelessness, low self-esteem, and reduces their ability to become high functioning, self-sufficient members of their community. In addition, some students end their education after going to alternative high school and their needs of social services increase in the future as they would most likely need access to health care, housing, and other basic needs. With little education, Latino male students have more difficult time finding work that pays a living wage. Furthermore, Latino male youth are at a high risk of dropping out and become part of the criminal justice system. 


\section{Existing Knowledge Related to My Research Questions}

Although there is existing knowledge related to my research questions in regards to trust and authentic caring (see definition of trust and authentic caring in the Definition of Terms section), the main focus of my research is learning how confianza - or the lack of it - can affect Latino youths' academic success in school settings. How does trust/confianza develop daily in a classroom or on a school campus based upon such factors as teachers' ideologies and beliefs? How do these factors lead students to confiar so that they feel safe enough to take risks, learn, show mutual respect, feel that they too belong, feel acknowledged, ask openly for help and support? The gaps in existing knowledge show a need for research that shows how Latino students can be supported to gain a sense of confianza and auténtico cariño that leads to academic motivation and

engagement. As the students shared in the pilot study, they need to feel that teachers care and motivate them to listen, learn, and engage in the classrooms. Confianza has to be reciprocal. It means to find courage and commitment to allow the feelings of confianza and auténtico cariño to develop into a sense of belonging and a sense of worth and of feeling valued in their classrooms.

\section{Research Questions}

RQ1 How do Latino male students' perceptions of teacher beliefs, expectations, and behaviors toward Latino students, impact their relationships with these teachers?

RQ2 How do Latino male students' perceptions of teacher cariño and confianza impact their relationships with these teachers? 
RQ3 How do these Latino male students' perceptions and relationships impact their motivation and academic engagement?

\section{Explanation of Methods}

I employed a qualitative interview research study using the grounded theory approach. The students I interviewed were self-aware of their teachers' perspectives and adapted their behavior according to their social interactions and context with their teachers. These social interactions shape their experiences as students. Listening to the participants allowed me to understand the Latino male students' challenges with an approach that generates a "grounded" theory in their experiences (Merriam \& Tisdell, 2015, p. 32), the theory developed from the data itself. During the pilot study interviews, the grounded theory helped me begin to formulate and record tentative ideas about the challenges of Latino male youth in the classrooms.

My personal interviews with each student provided opportunities to build rapport with students and to gain their confianza. In addition, I had the opportunity to show the students that my aim is to identify and understand, from their point of view, the challenges that they face daily in their public school settings at Embarcadero High School (EHS) just to be able to gain an academic education. The purpose of my study was to learn what support and resources Latino students need to feel to believe in order to feel that they are wanted and valued as academic students with great potential at their specific high school site. The personal interviews with each student allowed me to add to and/or modify my questions on the spot to allow for reflections and depth of student responses. I integrated myself into the school community to gain and build trust and to facilitate my 
understanding of their perspectives in order to be able to promote objectivity and authenticity.

Latino male youth face daily negative interactions and experiences in their classrooms (Fernández, 2002). I identified some of the positive and negative experiences with my own field notes observations as a professional in the school. The research focused on identifying and describing positive and negative encounters students face and how these positive and negative experiences impact their motivation and engagement to learn. How do the negative experiences impact the lives of the Latino male students so they do not develop confianza to seek support from their teachers shutting down the desire to learn? The interview questions helped me learn and understand what confianza means for Latino male students and how confianza plays an important role in regards to their academic engagement.

\section{My Story}

My own experiences of discrimination as a woman, an English learner, an immigrant, a person of color, in my professional role, and an indigenous person, have made me focus my dissertation on the importance of developing and earning confianza with youth of color. My work with male Latino youth has shown me the deep meaning, hunger, and importance of la palabra, el respeto, la educación, la confianza, and el auténtico cariño, in the lives of youth of color. I keep working with youth because youth have often told me "tiene mi palabra" and "le di mi palabra" and they treated me with the word usted and shake my hand. These phrases and cultural practices are a sign of respect in the Latino community. Not everyone uses these phrases and not everyone has the 
opportunity to be on the receiving end of these phrases. Hearing these words, I am inspired and I know that, contrary to a common belief in the society we live in, Latino male youth are capable learners who can achieve the success they dream of in their lives if they are embraced with support and care. These youth have an untapped richness that is just waiting to be given the opportunity through auténtico cariño and confianza in order to emerge. It is Latino youth that made me pursue a doctorate degree. Their lives and experiences enrich my practices. Latino youth (mi gente) have historically been oppressed, humiliated, and pushed out of schools for speaking up- for being defiant. They give me strength at times when I find myself with people who do not see strengths in the culture I represent.

I emigrated from Oaxaca, México, when I was twenty-one years old. Although I did not attend K-12 public schools in the United States, I understand some of the complexities Latino male high school students encounter in the public school system. I have worked for the past nineteen years in public schools in a variety of positions. Starting in 1998, I worked for the Santa Clara County Office of Education as a migrant aid in Santa Cruz. Next, for eighteen years, I worked at both comprehensive and continuation high schools in Santa Cruz as a classroom aide, interpreter, school community liaison, and registrar.

In these positions, I have witnessed the daily discrimination and prejudice many Latino male students face. For example, on numerous occasions I have had to witness Latino male students being accused of acts without them ever having a chance to speak up for themselves. Expressions such as "the less the better" from some educators 
towards the already marginalized Latino students impacted my life as a Latina educator and person of color. Seeing students and hearing from the Latino male students of being suspended for misinterpretations or lack of communication (listening to students) empowered me to choose a doctoral degree in education. During my first year as school social worker, a special education Latino male student was wrongfully accused of vandalizing the school's restroom. The administrator became upset. He stated that I was accusing his school of criminalizing students. On another occasion, a counselor expressed poor judgement when he referred to a Latino male student as a poor kid that didn't care. One counselor wrote an email to six teachers and the administrators that said: "With a home environment that is not conducive to schoolwork, homework is just not being done."

Deficit thinking and negative judgements toward Latino youth continuously label and diminish their school lives and also increases the achievement gap due to the educational debt that many Latino male students face at their schools on a daily basis. Furthermore, I have seen the frustration and humiliation that some Latino male youth experience for not being able to advocate for themselves when they cannot communicate with school staff for being English language learners. For example, a teacher asked a student to go outside to get fresh air. The student understood ve afuera y agarra aire, which he did. He went outside, he followed the teacher's orders, walked outside and returned within 5 minutes. However, the teacher meant for him to go out by the door. And when she did not see the student, she reported him immediately to the office. The student was then accused of leaving the classroom and not following orders, and also was asked to see the principal. 
The EL Latino male student did not understand why he was asked to go to the principal's office. He was scared and did not want to be seen as a bad kid for seeing the principal. In addition, he did follow the teacher's orders so he was confused, upset, and ashamed of not understanding English well.

Currently, I primarily work with students of Mexican backgrounds, Mexicanos, and students from El Salvador, Salvadoreños. I am a member of the District Student Attendance Review Board. I work with youth in comprehensive and continuation schools. I work with students who have been sent to juvenile detention centers as well as those who have been reincorporated into the school system. I have worked with youth that are now serving life sentences and youth that have died because of drugs or gangs. Most of the students I work with are youth from single parent homes, youth in transition, homeless, youth in the foster educational systems, youth that work to support themselves, and youth that have experienced domestic violence. Most of my previous students are undocumented students. Currently, I am working with second or third generation students who are mostly of Mexican background.

Over the years, I have listened to many, many Latino male students as they describe negative experiences with K-12 institutions - experiences that shape Latino youth's view of schooling and school staff. I have observed, witnessed, and heard when people label and distrust youth of color. This deficit thinking - all too common in my experience in public schools - takes away possibilities and dreams from students of color. I have seen how people in power do not listen to youth's voices. 
Schools are the center in which children are getting their education and are responsible of preparing future citizens to be ready and participate positively in their community at large. The vulnerable Latino male student population at schools need the framework of confianza, auténtico cariño, and respeto to ensure that their education process is safe and effective - to ensure that they do not experience unsafe or negative learning environments that conduct to dropping out of school. Learning to develop mutual trust/confianza means listening, understanding, and building empathy, so we do not judge and think that our beliefs are correct about Latino youth not caring about school or that their parents do not value education is true.

As a school social worker, I work mostly with secondary school students. Some of the Latino male students I work with are seen and labeled as the "behavior" kids. The ones that "do not care about school." Although their reputation is that they generally do not care about school, they return to school every day and often their conversations with me are about school and graduation. To me, they do care and they like their schools. My identity, my work in schools, and work in the community are strengths that will support me to build rapport with the youth I meet and that participated in the study. I can reflect and easily identify with the Latino youth. I am confident I earned their trust/confianza so that my study is as strong as their voices for change.

\section{Potential Implication of the Dissertation Study}

The primary purpose of this dissertation was to capture the perspectives of Latino male youth in regards to their public school experiences to identify ways to improve them so that students feel welcomed and valued in their classrooms. What engages them in 
their academic life? What shuts them down and turns them away? Capturing their voices and giving them the opportunity to be heard through this study will create an avenue for their teachers, principals, counselors, and other staff members to have an opportunity to understand who the students are and why they exhibit certain behaviors - positive or negative. Providing a platform for student voices allows for a dialog as opposed to the too often top down approach that does not include students' voices or the perspective through which they perceive the events in their public school lives. Their voices will help guide us into better practices to appropriately serve them. Mills (2000), states that once people begin working on topics, people, such as teachers and school staff, will have the opportunity to become sensitive to its themes and how they relate to the real life effects of their behaviors on the students they are employed to serve (Duncan-Andrade, 2009). Listening would conduct to learning about students' struggles. Caring and confianza will support the Latino males to stay in school (Weissman, 2015). Noddings (2013) states of the need that secondary school teachers need to be "teachers of the whole child as well as teachers of their own subject" (p. 6). Through the research approach of this dissertation, public school staff will be able to read and hear how their actions and behaviors impact students of color. Therefore, students' expression of their personal experiences will become powerful catalysts for change (Senge, Cambron-McCabe, Lucas, Smith, \& Dutton, 2012). In addition, this research can have a powerful impact if utilized through professional development to inform and instruct school staff how to improve educational outcomes for Latino male students. 
The hope is that focused professional development will guide teachers to understand the impact they have on their students that can be either positive or negative. If teachers understand that some of their behaviors and practices actually damage some of their students' abilities to learn, they would, hopefully, be motivated to modify and change their beliefs and practices. If school staff are able to hear Latino student voices as they explain their public schools experiences - as they explain what makes them want to learn and be a contributing member of the school or what makes them turn away from their work and causes them to be angry and defiant - there is the possibility for authentic change that will result in the improvement in the public school lives of Latino students. If teachers have the opportunity to learn about their students' struggles directly from them, such knowledge could become a powerful catalyst for positive change.

\section{Definition of Terms}

Authentic caring: Valenzuela (1999) defines authentic caring as "sincerity and love" (p. 113); A moral ethic of caring that develop into a nurturing and valuable relationship. The students in the pilot study responded that un auténtico cariño was respect, relationship, and connection. To the students it meant que le importas that translates as "someone that cares for you."

Caring relationship: "Promotes prosocial and responsible behavior that helps students adapt to the school environment and school demands. Students receive fewer disciplinary referrals, have higher educational goals, and have increased levels of adaptive motivation and internalized interest in school when they perceive that their 
teachers and other school personnel care about them" (Lewis, Ream, Bocian, Cardullo, \& Hammond, 2012, p.8).

Cariño: The real academia española definition of cariño is: Inclination of love or good affection that one feels towards someone or something (www.rae.es). According to Bartolome, (2008), Daniels, (2013), Freire, (2000), and Valenzuela, (1999), authentic cariño and respect outweigh linguistic and cultural differences." The students in the pilot study stated that cariño is a reciprocal relationship. The students describe that to feel that a teacher had cariño for them, was to feel support during their personal and intellectual growth.

Confiar/Confianza: Confianza "means the leader has established trust based on his honesty, his personal relationships with people, and his demonstrated reliability" (Bordas, 2013, p. 62).

Required Caring/Cariño laboral: Described by the twenty participants as a feeling that their teachers cared about them in a limited way as opposed to authentic caring/auténtico cariño. A minimum caring that the teaching job requires.

Trust: Duncan-Andrade (2007) defines trust as an important teacher-student relationship. Trust is described as a commitment to the community, as a relationship that teachers build with their students, "between being liked and being loved by their students" (p. 634). Trust does not mean to coddle students. Trust requires additional investment of time, when "that help is from someone that loves you, in spite of your shortcomings, you learn to trust that person" (p. 635), by embracing realities and identities (Duncan-Andrade, 2007; Freire, 1993). 
Respeto/showing respect: A central cultural value. Everyone should be treated with dignity and courtesy, regardless of wealth or status; Respecting elders and adults is very important in the Latino culture. Latinos show respect through their body language, tone of voice, deference, and apologies and explanations. Latinos value real-life learning, hands-on experience, and self-mastery, the wise elder has a wealth of knowledge to share. Landsman and Lewis (2012) state that "respect permeates the tone that teachers use when responding to criticism from students" (p. 53). Respect is seeing all of the students. "Respecting who they are means they will respect you" (p. 53).

Palabra: Ser un hombre de palabra, to commit to something, to honor and value a commitment. Palabra is a promise, the youth learn to develop and maintain one's sense of palabra/credible word (Bordas, 2013, p. 62).

Educación: "It refers to the family's role of inculcating in children a sense of moral, social, and personal responsibility and serves as the foundation for all other learning" (Bordas, 2013, p. 23). It also refers to respect the "dignity and individuality of others" (p. 23). Bien educado or con educación means a respectful person that respects relationships. Mal educado is someone who "is deemed disrespectful and inadequately oriented toward others" (p.23). 


\section{Chapter Two: Literature Review}

The purpose of this literature review is to identify the disruptive trends and practices that public high schools as institutions of teaching and learning create and generate that are of great disservice to Latino male students. By identifying the many ways in which public schools push out Latino males from their comprehensive school learning environments will provide a path to understanding the reality of the problem at hand: Many Latino male youths are made to feel unwanted, unwelcome, and unteachable in their classrooms, so they disengage and lose motivation to learn. They disengage and lose motivation to go to school. They drop out.

\section{Teacher: Institutionalized Racism}

The impact of institutionalized racism manifests itself in relationships between teachers and students and can greatly affect Latino youths' academic achievement and performance with negative results. Institutionalized racism impacts not only the lives of Latino youth, but reverberates throughout the community they live in. Lea (2000) defines institutional racism as:

The collective failure of an organization to provide an appropriate and professional service to people because of their color, culture, or ethnic origin. It can be seen or detected in processes, attitudes and behavior which amount to discrimination through unwitting prejudice, ignorance, thoughtlessness and racist stereotyping which disadvantage minority ethnic people. (p. 220).

According to Bonilla-Silva (2017), "people of color still experience systematic discrimination and remain appreciably behind whites in many important areas of life; their chances of catching up with whites are very slim" (p. 26). The unwitting and unthinking prejudice of attitudes, thoughts, and actions such as using words that refer to 
Latino students as bad apples or the behavior problem kids exemplify institutional racism. Shirley Chisholm, a United States' first congresswoman, wrote that "racism is so universal in this country, so widespread and deep-seated, that is invisible because it is so normal” (Weissglass, 2001, p. 49). For many Latino students, institutional racism destroys their aspirations before they have the chance to dream about a successful future. According to Benner and Graham (2011) "Personal experiences with discrimination in combination with institutional mistrust can contribute to feelings of alienation and academic disengagement" (p. 509). Experiencing discrimination and feeling unwelcome becomes a major stress in Latino youth lives. Negative experiences in school can lead to lose confidence in themselves as learners and in their ability to be self-efficacious (Benner \& Graham, 2011). When students get oppressed and are humiliated due to their experiences, they are reduced to things (Freire, 2000, p. 68). Students become detached from reality and disconnect from the significance of learning (Freire, 2000, p. 71).

The greatest casualty to institutionalized racism is when students internalize it. Internalized racism causes many Latino students perceive and project themselves as incompetent and low academic achievers based on what their school environment is signaling to them. Their many failed academic experiences in school systems supports the idea that they are not college material. Weissglass (2001) describes racism as "the systematic mistreatment of certain groups of people [often referred to as people of color]" (p.49). The internalization and transfer of racism is described as the "the process in which people of color believe and act on the negative messages they receive about themselves and their group" (p. 52). Internalized racism impacts Latino male youth 
when they start to believe that they are in fact not as capable as their peers in terms of their academic work. They begin to give themselves the same negative messages as their teachers and the institutions themselves. Daily negative messages shapes students' identity and suggest "that a Chicana/o identity is incompatible with a positive school identity" (Pizarro, 2005, p. 97). Pizarro (2005) argues that "students' identities are fundamentally influenced by outside forces” (p. 96).

\section{Teacher: Power and Privilege}

Anyon (1980) explains that the consequences of hidden curriculum impacts teachers' daily activities, behavior, and interactions in classrooms. Anyon (1980) explains that the hidden curriculum in schools often mold students' perspectives of how to see the world. Issues such as gender, social class, stereotypes, privilege, cultural expectations, and language learned in schools sends messages to all students of their role in society. Race

and privilege impacts the students' school work daily. In a classroom, the cost of having more is "at the cost of the oppressed having less or having nothing" (Freire, 2000, p. 58). Freire (2000) shares that "the educator's role is to regulate the way the [dominant world] 'enters into' the students [world]" (p.76). Education for Latino male youth is to teacher them how to better 'fit' into the dominant culture. Education then is part of the oppression when Latino male youth become deprived of their own culture and are forced to adapt to and adopt the purposes of the dominant majority (Freire, 2000).

Anyon (1980) describes power in the classrooms as teaching procedures that are usually mechanical and with very little decision or choice given to students, where teachers tell students to copy the steps as notes. Significance and coherence between 
assignments are rarely explained while students are expected to follow the correct steps. Teachers control their students and their classrooms but do not engage their students in learning. Marginalized students sit in classrooms where they are educated to obey and adjust to fit the school's expectations.

Darder (2016) states that there is a need to critically think of social justice by disrupting inequality by acknowledging the daily privileges and position of power that white people have. When working authentically towards social justice in schools, classrooms and communities, there needs to be a commitment to the people and to the students, and one must re-examine themselves constantly (Freire, 2000). When disadvantaged children become silent to preserve the historical and institutional conditions of privilege in schools, they are deprived of speaking up; they become trained and immersed into a culture of silence - of the people who are forgotten. In his speech, Baldwin (1963) states that white people see invisible and silent people every day in their lives. He explains that "...one of the paradoxes of education was that precisely at the point when you begin to develop a conscience, you must find yourself at war with your society. It is your responsibility to change society if you think of yourself as an educated person" (p. 19).

Every day teachers see silent kids in their classrooms. Children of color find it "less painful to be thought of as stupid than to be defiant" so many of them keep quiet (Gross \& Gross, 1969, p. 334). In addition, Gross and Gross (1969) state that "disadvantaged children will not speak in class because they cannot trust their audience" (p. 336) and they "will not write if they are afraid to talk" (p. 333). 
White privilege and its representation in school curriculum, materials and positions of authority makes the "peasant feel inferior to the boss because the boss seems to be the only one who knows things and is able to run things" (Freire, 2000, p.63). Freire describes oppression as domestication. People in schools that daily oppress their students by controlling them and keeping them silent become people that perpetuate the oppression:

Hay que hacer la opresión real todavía más opresiva añadiendo a aquella la conciencia de la opresión haciendo la infamia todavía más infame, al pregonarla [to make the real oppression even more oppressive by adding to that the consciousness of oppression making the infamy even more infamous, by proclaiming it] (Freire, 2000, p. 51).

Exploring white privilege and making it visible hopefully has teachers interrogate themselves of their bias, beliefs, and practices with the hope that they will help to deconstruct some of the disadvantages that their students encounter in the classrooms. The intention is not to resent their white privilege, but to build critical consciousness and challenge their white privilege by becoming aware of the power, control, and dominance they have (Salomona, et al., 2005).

\section{Teacher: Disconnect}

One of the major results of institutionalized racism is teacher/student disconnection. There is a majority of teachers who are not comfortable interacting with students who are not of the same ethnicity (Bradley \& Renzulli, 2011). Stereotypes often apply to the concepts of being capable or being smart. When teachers do not believe in their students they are teaching, they close the doors of opportunities to them. More often than not, 
teachers are white and privileged whereas the students they teach come from worlds of poverty, violence, and scarce resources (Bradley \& Renzulli, 2011).

Some examples of teacher disconnections include when teachers greet and interact with white students while noticeably ignoring Latino students. Landsman and Lewis (2012) argues that respect is acknowledging students humanity; respect is seeing all of the students' races, culture, characteristics, gender, language, native language, age, and sexual preference. According to Vygotsky's (1978) sociocultural theory, learning occurs through social interactions. Thus, practices that rely on a classroom culture in which students feel safe to voice their opinions will create a trusting teacher-student relationship.

Valenzuela (1999) states, "Teachers occupy an uncomfortable middle ground. They are both victims of and collaborators with a system that structurally neglects Latino youth” (p. 70, 1999). Often, students who express and “...maintain that they don't care about school may often really mean something else" (p. 70). The absence of authentic relations with teachers reduces opportunities for youth to develop a feeling of competency and mastery of the curriculum in the classrooms (p. 71). Without feelings of academic competency, they feel disconnected from their teachers. Valenzuela shares that teachers need to "...get to the bottom of the problem of mentally absent students" (p. 71). They need to support and provide authentic caring to children whose limited opportunities severely damage their ability to think that they deserve opportunities to function effectively in the global community (Duncan-Andrade, 2007, p.41). We have a moral debt to the children that historically have been taken away the opportunity to 
receive an equitable education and encourage students "to embrace the socio cultural richness of the community as a resource, rather than as a barrier to be overcome" (Duncan-Andrade, 2007, p. 41). Kohl (1969) states that students that are labeled as "ignorant of the language of the schools" (p. 332) and with limited vocabulary, are mostly the ones that have been traditionally oppressed and are hungry for support and learning.

Teacher disconnections create barriers to students' learning (Freire, 2000, p. 74). One of the disconnections is to ignore that Latinos have been historically marginalized creating an academic debt (Ladson-Billings, 2006). Historically marginalized means to be forgotten in the curriculum, not allowed to have a voice, identity, or valued in schools (Valenzuela, 1999). Another is to ignore that demographic changes in many schools are such that teachers' cultures do not often mirror the cultures or experiences of their students. Teachers with a different background, "are often unable to build bridges between students and curriculum, but then attribute students' lack of engagement as disinterest in learning or their academic problems as inability to learn. Teachers from different cultures than their students' own often disconnect from Latino students (Solomona, Portelli, Daniel, \& Campbell, 2005). Effective teaching creates painful knowledge and awareness to the change of the demographics in American public schools. The more leaders focus their relationships, their work, and their learning on the core business of teaching and learning, the greater will be their influence on student outcomes (Robinson, 2011, p.15). For classroom teachers to learn about their Latino students' 
cultural backgrounds will be an ongoing process that will work to create and develop positive teacher-student connections (Noddings, 2013).

\section{Teacher: Lack of Understanding}

Teachers' lack of understanding the Latino students' needs and challenges forms a barrier to student learning (Valenzuela, 1999). However, teachers' lack of understanding the needs and challenges Latino students experience as people of color is often not intentional. Often, teachers and staff lack key information that would cause them to know who their students are, and what has happened to them and what is happening currently in their lives. A majority of Latino students suffer from frightening memories that include terrifying border crossings, leaving or being abandoned by their parents at an early age, living in poor neighborhoods, having undocumented parents or relatives at risk of deportation, unsafe neighborhoods, and/or feeling academically inferior at public schools in the United States.

\section{Teacher: Deficit Thinking}

Bernal (2002) states that "teachers'... [feelings of]... responsibility for student learning is connected with their beliefs about students' academic abilities through a deficit thinking lenses when students are from impoverished and disenfranchised communities of color (Bernal, 2002). In many low-income schools, teachers emphasize students' deficits and their sense of responsibility for [their] students' learning diminishes (Bernal, 2002). In addition, Latino are often enrolled in schools where classes are large and often underfunded; when feeling alone, students are at risk of not engaging and becoming alienated. 
Deficit thinking does not allow teachers to recognize abilities and strengths in students that are not like them, that they do not look like (Ladson-Billings, 2006; Weiner, 2006). When teachers believe that their students' background, socioeconomically status, or parents education are a barrier to learn, their teaching practices create impediments between their teaching skills and their students ability to learn; they do not take risks to approach their students and learn how to teach them (Senge et al., 2012). Deficit thinking makes the teaching of Latino youth very difficult because is based on teacher perceptions of their students' weaknesses rather than their strengths (Delpit, 2006; Delpit, 2012; Delpit, 1992; Ladson-Billings, 2006; Weiner, 2006). Students need to feel that they are treated just like everybody else. They need to feel and be treated the same as their white peers. They need to feel that their teachers see them as capable and smart. Listening and understanding Latino youth will make them feel safe and connect to school (Benner \& Graham, 2011).

\section{Teacher: Low Academic Expectations}

According to Diamond et al. (2004) teachers' academic expectations of youth of color are much lower than their expectations of white students. Often, students are "located in the regular, non-college-bound track" (Valenzuela, 1999, p. 13). Diamond et al. (2004) explains, "[that the outcome of ] teachers' low expectations reduce students' academic self-image, cause students to exert less effort in school, and lead teachers to give certain students less challenging coursework" (p. 75). Teacher determinations such as, "this poor child is reading below grade level, so I'll need a third-or fourth-grade book' (Rose, 1995, p. 415) do not support the student's learning. 
Teachers' perceptions that students of color do not care about their academic work are easily telegraphed to students (Diamond et al., 2004; Tinkler, 2002; Valenzuela, 1999). Valenzuela (1999) shares that teachers' repeated actions such as ignoring when Latino youth raise their hands to participate show and tell students that what they have to contribute could not possibly be relevant or meaningful. These highly visible actions affect students' academic self-concept (p. 72). This behavior makes the students lower their own expectations of their [academic abilities] and decreases the "likelihood of forming productive relationships with teachers" (p. 72). These negative experiences make Latino youth stop raising their hands and asking questions, while building distrust and anger. Freire (2000) explains, "Self-depreciation is another characteristic of the oppressed, which derives from the internalization of the oppressors' hold of them" (p. 63). When children hear that they are "good for nothing, know nothing, and are incapable of learning anything - that they are sick, lazy, and unproductive -... in the end, they become convinced of their own unfitness" (p. 63). When Latino youth witness their teachers treating them and other students of color as academically inferior, they lose confidence in their own ability to learn and believe that they are incapable of academic achievement (p. 63). Some Latino students are even told that they will not graduate from high school. Some students identify that their teachers' low expectations were often one of their challenges to achieve academically (Pizarro, 2005; Sosa \& Gomez, 2012; Solomona et al., 2005; Valenzuela, 1999). 


\section{Student: Cultural Identity and School}

Mallet et al. (2011) declares that not feeling part of the school community is a threat for Latino students. Mallet et al. (2011) states that "For students of color, one potential trigger of belonging creates uncertainty in an academic context as racial or ethnic identification. Unlike White students, students of color must contend with the knowledge that their group is taxed with a stereotype that calls into question their academic abilities" (p. 432). Feeling and becoming aware that stereotypes exist ingrain true emotional damage for Latino students. The threat of being seen as a socially devalued group impacts the level of participation in the classrooms and in school activities overall. Mallet et al., explains that "simply considering one's racial or ethnic identification can contribute to a sense of belonging uncertainty or a doubt about whether one will be accepted in an academic environment" (p. 432).

Latino's identity is molded by their culture, and culture is an essential component of an individual and social identity (Reagan, 2005). Latinos identify who they are based on their life experiences. A study by Schwartz, Zamboanga, and Jarvis (2007) found that "the relationships of cultural identity and adaptation to psychosocial adjustment may operate through self-perceptions. Ethnic identity appears to relate to academic grades and externalizing behaviors through self-esteem” (p. 371). Latino students' selfperceptions play a role in their learning. If students find that they are perceived as unwanted in academic settings, this impacts their self-perception negatively, and causes some to turn away from their home culture. According to Bordas (2013), cultural domination is a factor that disrupts Latino students from integrating into their own 
culture. Instead, it makes them often reject their culture, "becoming whitewashed, and distancing themselves from their own group" (p. 70).

When youth are distanced from their culture, they quickly assimilate to the dominant society. Assimilation hides/shames/erases one's cultural identity (Anzaldua, 1987). For example, assimilation creates and develops feelings of "inferiority that function at an unconscious level" (p. 71). Freire (2000) terms the psychological pain of rejecting one's own culture and group as psychology of oppression (Bordas, 2013). The "psychology of oppression is the process by which Latinos and other minorities internalize the negative messages and beliefs about their own people to come to believe that they are true" (p. 71). The constant negative messages that Latino youth receive can cause them to lose their native language because of shame (Anzaldua, 1987; Bordas, 2013). Pizarro's work (2005) shows that many students learn English and assimilate faster "to avoid being teased"). Pizarro's work (2005) states that students learn English and assimilate faster "to avoid being teased" (p. 142) for their use of Spanish. Students choose to assimilate to white culture. The loss of language makes them less vulnerable to the presumption of being less than others (Pizarro, 2005).

Often in schools, youth are labeled vulgar, deslenguados, and bad due to the Spanish they speak. Anzaldua (1987) names this treatment of students' native language use in the classroom as Linguistic Terrorism. Because of our "tongues of fire we are culturally crucified. Racially, culturally, and linguistically somos huerfanos - we speak an orphan tongue" (Anzaldua, 1987, p. 44). Language usage often negatively identifies Latino youth (Cameron, 1998). Anzaldua (1987) explains that Latino youth are deeply 
distressed when they hear people talk negatively about them and their language, as, for example, when in classrooms they are harshly told not to speak Spanish in front of other students, or when their teachers do not understand that their students' often struggle needing time to think - when they are asked to recall English vocabulary. Many English Learners suffer teacher misperceptions of being viewed as being defiant and unwilling to learn English.

Negative stereotyping and years of oppression shape negative beliefs of Latino male youth about their abilities to achieve their hopes and dreams to have future opportunities (Brown, 2007; Pizarro, 2005; Weissman, 2015). Discrimination is delivered into Latino youth at an early age. This practice is found in academic tracking, grade retention, and low teacher expectations (Benner \& Graham, 2011). Latino students recognize signs of not being accepted. They see and feel that they are treated differently than their white peers, so they often become discouraged from taking advanced academic courses, requesting assistance, and raising their hands to ask questions.

\section{Student: Cultural Identity in Other Communities}

Latino students are from a multiethnic and multilingual cultures with rich and unique mixed identities. They have developed unique skills to navigate in many subcultures (Carter, 2006). However, their attributes and richness are often perceived negatively (Carter, 2006; Gandara \& Contreras, 2009).

At home, they have to navigate between their Latino culture with their parents and the English language while doing their homework or talking with their friends or sibling. In their community, Latinos have to protect themselves on the streets from gangs. At 
school, they know that many people have low expectations of their academic abilities. In the workplace, they often suffer from injustice, discrimination, and disrespect. Latino students are constantly fighting for a place for themselves in society - a place where they are invited and welcomed. Instead, everyday many are victims of discrimination due their ethnic background (Baumeister \& Leary, 1995).

\section{Student: Language Identity at School}

Anzaldua (1987) shares that the belief that Chicano/a/Latino/a "speak poor Spanish" (p. 1017) is a direct attack that diminishes Chicano/a/Latino/a sense of self. Years of being "told that our language is wrong" (p.1017) impacts the low estimation of the language and of the individual. Latino's needs, interests, desires, and identities, are different than those of other minorities. In schools, students need to learn English and at home most need to speak Spanish (Valenzuela, 1999). However, history has taken away the value of their language; first with the conquistadores, who mutilated the indigenous languages and imposed their Spanish language. Now, native Spanish speaking Latino youth must learn English since it is the official language in schools.

Valenzuela (1999) argues that classes such as English as a Second Language send a message to Latino youth that "Spanish is a second-rate language" (p. 162). CavazosRehg, \& DeLucia-Waack, (2009) shares that language is a vital instrument that supports social, emotional, behavior, and cognitive self-regulation. When children are repeatedly told that the language their parents speak, and the language they use at home is seen as a failure and a "second-rate idiom (Cavazos-Rehg \& DeLucia-Waack, 2009, p. 48), their culture and identity is denigrated. Often Latino youth disengage from their culture 
values, traditions, beliefs, and behaviors because of their self-concept. The disinterest to identify with their culture is often a disadvantage to Latino male youth since it takes years to unlearn the belief that "white is better than brown" (Anzaldua, 2009, p. 43). If white is better than brown, then the thinking that English is better than Spanish is a belief that many people of color never unlearn.

Valenzuela (1999) explains that youth that were born in the United States often do not want to speak Spanish because of the fear of being discriminated against. Valenzuela shares the following statement from Trueba (1993):

Language is one of the most powerful human resources needed to maintain a sense of self-identity and self-fulfillment. Without a full command of one's own language, ethnic identity, the sharing of fundamental cultural values and norms, the social context of interpersonal communication that guides interactional understandings and the feeling of belonging within a group are not possible (Valenzuela, 1999, p. 169).

\section{Student: Opportunities to Talk}

Latino students often have at least two types of stories that need to be shared. One type is connected to their cultural heritage. Rose (1995) explains that in schools, Latino children are often identified as having something wrong when they want and try to share their cultural stories in school. Often, these stories are told to them by their parents and/or grandparents. They learn from their teachers that their "languages and traditions could limit and oppress" their progress at school, so they stop sharing them (p. 378). Rose (1995) states that celebrating 'the improvement of the mind and the collision of mind with mind' (p.417) and 'the general diffusion of knowledge has been restricted in this country and many voices remain silent (p. 417). 
The other type of story that Latino youth want to share are about their struggles at school, work, and at home. They often lack opportunities to tell and share their stories about what is happening to them at school and in the community. Often, their parents (if they live with one) are working from two to three jobs daily. At school, people are busy. No one seems to ask about or make the time needed to listen to their stories and struggles. Pizarro (2005) stated that “...interviews were, for many students, their only opportunity to have their voices heard" (p. 160).

Many Latino youth do not have people to share with how they feel or how they are perceived by society - what others' eyes do not see, but the students' bodies feel - feeling uncomfortable because they know and feel they are watched and being looked at every day.

Latino male youth often do not have opportunities to tell their stories without the fear of being judged or laughed at which often puts their socioemotional development at risk if they feel ignored or unheard (Rowe, 1986). They need opportunities to share their stories and to relate to people and understand them- to share that racial profiling is part of their daily lives (Pizarro, 2005). Many do not have a place to share their feelings of being viewed as different by their peers and adults which causes many of them to have feelings of inferiority. That they believe that they are viewed as underachievers by their teachers and their peers affects their academic motivation to learn and study (Lopez, 2016; Rowe, 1986). 


\section{Student: A Need to Belong}

The need to belong is a fundamental human need. According to Baumeister and Leary (1995), to feel that one belongs promotes a sense of both psychological and physical well-being for individuals. Maslow's hierarchy of needs supports this point, as students must gain a sense of belonging before they progress academically - before they can achieve goals after their basic physiological and safety needs have been satisfied (Archambault, Janosz, Fallu, \& Pagani, 2009). Students need to feel that they belong in their schools before they can learn. Archambault et al. (2009) explain that feelings of belonging in school promotes students' own high academic expectations, values, performance, and persistence. Walton and Cohen (2007) argue that when students of color do not feel that they belong, or that their sense of school belonging is threatened, their academic motivation, engagement, and achievement declines while White students are not affected by this threat.

In schools, many Latino students often feel disliked and unwanted by staff. Many feel that they are treated differently, beginning in the fifth grade. This is the grade when they become aware that society has designed certain places where they are not welcome. Kids are smart, and they know how to read people's body language (Cushman, 2009). Many Latino male youths are aware when their teachers have negative perceptions of them. This awareness is what leads to academic disengagement and the low achievement of students of color as reflected in standardized testing. This low achievement is generally referred to as the achievement gap. But is the achievement gap a failure by students of color to achieve enough, or is it a failure of schools to welcome and include 
students of color? What in fact the achievement gap is labeling is the neglect of the education of students of color (Cushman, 2009; Ladson-Billings, 1995; Sealey-Ruiz \& Greene, 2011). It is not that students of color need to achieve more, it is that they need to have a sense of belonging to achieve at all.

An issue facing Latino students is a lack of teachers of color in their schools-teachers who they can identify with either through shared languages and/or traditions (Anzaldua, 2009). Students feel empowered seeing themselves mirrored in their teachers. And their teachers have and carry with them into the classrooms the social and emotional tools needed to engage their Latino students.

The lack of quality in their relationships with their teachers in school influence Latino students' disengagement in their education. Valenzuela (1999) states that Latino students “oppose not education, but schooling” (p. 5). According to Mallet et al. (2011), experiences of discrimination, awareness of negative stereotypes, and not seeing their culture represented affects a student's sense of belonging. These negative experiences affect Latino youths' motivation to attend and participate in school. When Latino male youth do not attend school, they are at a higher risk of dropping-out of school and many become vulnerable targets for the punitive criminal justice system (Weissman, 2015). Suspensions and dropping out are the perfect storm to end up in prison for Latino males.

\section{Dropout Rate}

Latino students' drop-out rate is high when compared to other groups. According to Wald and Losen (2003), "Official dropout rates mask a widening "graduation gap" between minority and white students. In our 100 largest cities, $58 \%$ or more of ninth 
grade students in high minority schools don't graduate four years later" (Wald \& Losen 2003, p. 3). Fry (2010) explains that "In comparison with the $41 \%$ of Hispanics adults ages 20 and older who were high school dropouts, $23 \%$ of black adults had not attained at least a high school diploma. White adults (14\%) and adults of Asian origin (15\%) were less likely to be high school dropouts" (Fry, 2010, p. 6).

Brewster and Bowen (2004) declared that dropouts are more likely to experience unemployment, to receive welfare, to have lower lifetime earning potential, to engage in delinquent or criminal behavior, and to suffer mental health problems. Fry (2010) stated that the dropout outcome reflects the historical and contemporaneous performance of the education system. Research by Fry (2003) shares that the high number of Latino youth dropping out of school is an indicator of the education disadvantages that affect the lives of Latino youth. The outcomes of Latino students who leave school without a diploma often translates to low paying jobs with less employment opportunities. In addition, dropping out of school is associated with illegal activities, teen pregnancy, and idleness that could lead to substance abuse or depression. In 2000, "[the] Latino youth dropout rate, $21 \%$, was more than three times greater than the 2000 non-hispanic 'white alone' dropout rate of 6.9 percent" (p.2).

The National Center for Education Statistics presented evidence that "Regardless of how dropping out is defined, first, second, and third, and [even later] generations [of] Hispanic youth drop out of school at similar rates" (Fry, 2003, p. 3). Students of color suffer more adversely than their white peers on nearly every measure of well-beingeducational, social, financial, emotional, psychological, and physical—which impacts 
them in the long run. Latino students' disengagement is considered one of the most critical problems exhibited by students and puts them in grave danger of leaving school altogether (Daly, Shin, Thakral, Selders, \& Vera, 2009; Valenzuela, 1999). Reducing school dropout rates continues to be a national priority that presents significant challenges for schools and professionals in schools with rates that continue to climb.

\section{Teacher: Authentic Caring Relationship}

Howard (2007) states that "As diversity grows, so must we." Duncan-Andrade (2009), states that although the knowledge of the importance of trust in a teacher-student relationship should not be a surprise to anyone, there is more that teachers can do to build trust with their students of color. Landsman and Lewis (2012) believe that real changes in schools and classrooms begin when educators go through the process of deep reflection, re-evaluation, and continual re-visitation of actions and responses to students and their families" (p. 2). According to Solomona et al. (2005), "The failure to examine notions of whiteness facilitates the maintenance of its incorporeal nature thereby reinscribing its dominating power." Reflecting in their own practices, recognizing their beliefs, and how these shape their daily practices continuously, will renew teachers' commitment to learning and teaching (Senge, et al., p. 87). Teachers who believe that their students of color are "from the "wrong side of the tracks," "don't care about school," or "their parents don't care about them" increase the educational debt to their students ( $\mathrm{p}$. 100). The erroneous belief and assumptions or "equity traps" that Latino students do not care about education automatically dismisses their students from the possibility of pursuing opportunities to see themselves as capable learners (Green, 2017, p. 5). Years 
of teaching should cause teachers to acknowledge their own abilities, bias, assumptions, beliefs and as, they have a lot of power in their classrooms that can be have positive or negative impacts on their students' educational growth (Howard, 2007; Rose, 1995, p.7). They can create a communal relationship in their classrooms and highlight their role as “culture broker, boundary mediator, the provider of hope and change (Rose, p. 9). In addition, teachers have the, ability to foster growth and learning.

Rose (1995) explains that teachers who develop an authentic caring relationship, learning from their students, will "challenge the ways our schools tend to define ability and achievement" (p. 13). Rose also explains that teachers need to include a human dimension in their classrooms that works to get to know students personally ( p. 213). The culture of learning involves a culture of caring: developing the capacity to "respond to...students as whole human beings" (Valenzuela, 1999, p. 74). Furthermore, Rose (1995, p. 213). This is to say that to fully teach all students, teachers must develop human relationships with the primary interest of providing what will engage and motivate each student.

Rose (1995) shares that caring is the act of being with the students, walking with them on their path as students, learning from them and their challenges, and allowing time to listen to them, and to know them. Valenzuela (1999) explains that working with Latino youth is to be in a teaching/learning relationship, in which each learns from the other. Pizarro (2005), expressed that "There is not a more effective way to understand the lives and identities of Chicana/o students than to ask them to discuss these things [their feelings and thoughts]" (p. 36). 


\section{Student: Confianza}

In order to feel part of their schools, students need to trust the school's staff. Trust in Spanish is confianza. Goddard, Salloum, \& Berebitsky (2009) state, "trust is a potent feature of informal social structure that serves to mitigate risk, enhance efficiency, and thereby support learning in schools" (p. 295). Trust was defined by Tschannen-Moran and Hoy (2000) as “Trust is one party's willingness to be vulnerable to another party based on the confidence that the latter party is benevolent, reliable, competent, honest, and open" (p. 555). Latino students in public schools have a need to trust someone in their school. They need an adult who they can open up to, a person who will listen to them, and who they can feel safe to talk to. Trust is dependable relationship that will remain constant. When a teacher has gained the trust of students, this trust becomes ingrained in the classroom environment so that all students feel safe to ask questions, to raise their hands, and to speak with their authentic voices.

Trust was described by a student as a bonding experience "because we all gave each other a chance to humanize and let us know each other's stories" (Tschannen-Moran \& Hoy, 2000). Once a relationship of trust is developed, students and teachers keep learning from each other (p. 58). Trust or confianza produces change by engaging people to work together positively through challenges.

Trust provides what students need to overcome their fears and advocate for themselves. They use their voices and empower themselves. In their school, they ask questions, participate, seek support with homework, seek support from their counselor, and question or request the classes they want to take. According to Gregory and Ripski 
(2008), "schools with higher relational trust were more likely to achieve successful organizational reform as measured through gains in math and reading achievement" (p. 340). Confidence builds up when confianza is developed and then in turn develops into student motivation and engagement in the classroom.

Latino students have great needs to feel that they belong, are accepted, and viewed as competent (Battistich, Solomon, Watson, \& Schaps, 1997). Cariño and confianza in classrooms are key components to satisfying these student needs. Their level of engagement or disengagement with their school depends on the level of degree they feel these needs are met. When participating in school activities, feeling welcome, and accepted, students feel that they belong to a community where they are treated with respect and a community where they feel trusted as capable. Feeling safe in a community engages youth in learning and allows all to learn (Battistich et al. 1997). Classrooms that provide a sense of community include aspects of Latino students' culture. Thus, students become effectively bonded with, committed to, and identified with their school (Flanagan \& Stout, 2010). Feeling part of a safe community helps students learn about empathy, develop self-esteem, and an intrinsic motivation for learning that evolves into academic engagement.

Students who feel auténtico cariño and confianza from their teachers become sensitive and responsible and want to collaborate and see their school as their second home or their primary home since they find stability, consistency, and feelings that people trust and care for them (Senge, et al., 2012). According to Valenzuela (1999) relationships with peers are also very important for Latino youth. Latino youth 
experiences (making friends) also generates social capital, "and how that capital, in turn positively shapes individual and group perceptions of, and experiences with, schooling" (p. 118). The sense of connectedness with teachers, school staff, and peers associates with positive affective reaction to schools (Erath, Flanagan, \& Bierman, 2008; Furrer \& Skinner, 2003; Skinner \& Belmont, 1993).

Feeling of confianza is powerful. Confianza in schools promotes student engagement and learning. A good school is described by students of all ages and grades as classrooms that are "places that felt good to be in, places that honored their best interests" (Rose, 1995, p. 416). They are classrooms where students felt cared for, and where they felt like a family. Students added that it is a place where they have good teachers, people that believe in them, and teachers that teach them what they could not do before. Rose (1995) states that good schools include "nurturance, social cohesion, the fostering of competence, a sense of growth, a feeling of opportunity, futurity" and among the students "common recognition of concern and benefit" (p. 416).

Rose (1995) argues that schools would raise attendance and student engagement by having better schools; "a place where there's education going on, where [all] kids are engaged and motivated and want to come to school" (p. 214). Rose asks the following question "How do we set up schooling so that it instills hope? (p. 214).

\section{Student Centered Teaching}

Robinson (2011) describes student centered learning as visible teaching where the feelings of welcoming, accepting, belonging, and appreciating give pathways for all students to feel wanted and accepted at school; these feelings promote learning and 
opportunities to thrive in public school environments. A combination of factors can affect student- centered learning. Robinson describes that student-centered approaches "disrupt the assumption that what is good for the adults is good for the students" (p.6) and encourages a reflection of relationships between the teacher and students. Robinson (2011) divides student-centered practices into five broad categories: a) Establishing goals and expectations, b) Resourcing strategically, c) Ensuring quality teaching, d) Leading teacher learning and development, and e) Ensuring an orderly and safe environment (Robinson, 2011, p. 9). Robinson (2011) argues that when teachers discover what they need to learn to teach their students, the practices of student-centered approaches are achieved.

Student-centered teacher knowledge focuses on teachers learning about their students to find out what skills they bring with them into the classrooms [to discover] their needs and challenges to focus on motivating them to engage in learning (Nave, 2015). Enquiring about to understand students' prior skills and knowledge welcomes them and creates a space in which diversity, participation, and cooperation are values that connect to build a learning community. Student-centered learning teaches [us] that we all are constant learners and to praise students for their knowledge (Nave, 2015). For example, in classrooms we can learn from students [by asking them how they arrived at their responses]; they will be happy to [do so] especially because no one before ever asked them to show what they know (Nave, 2015).

Students need to be recognized for what they know - for their previous knowledge. Learning about students' previous knowledge meets students where they are, so teachers' 
expectations are connected to their students' starting points. This approach recognizes that Latino students have prior knowledge - a knowledge that gives them vital understandings and shows their capacity as learners. According to Reagan (2005), knowledge "is not something that is 'out there' that we need to grasp or obtain" (p. 8). Knowledge is something we build based on experiences, prior understanding, and each individual has its own knowledge (Reagan, 2005). Knowledge is the education that Latino students bring with them to schools. Latino knowledge and education has been historically mutilated over the years, greatly affected by conquest.

Currently, many schools are incorporating social-emotional learning into teaching (Durlak, Weissberg, Dymnicki, Taylor, \& Schellinger, 2011; Elias, Zins, Graczyk, \& Weissberg, 2003; Greenberg, Weissberg, O'brien, Zins, Fredericks, Resnik, \& Elias, 2003). However, it will not be enough without also changing teaching behaviors, practices, curricula, and school policies that can be assaultive to our students particularly students of color.

Communities become richer when they are open to changes and modifications to their systems to work toward improvements (Senge et al., 2012). Rose explains that it is "essential to note how the formation of intellectually safe and respectful space, the distribution of authority and responsibility, the maintenance of high expectations and the means to attain them - how all of this is essential to the development of the intelligence of a people (Rose, 1995, p. 417). 


\section{Building Community}

Rose (1995) explains that it takes more than a telephone call, sending a postcard, or giving attendance awards to engage kids and to make them feel that they are important and that their presence is a positive contribution to the school campus. He argues that a “teacher's 'presence' counts for a lot in school” (p. 215). Students need adults not with a disciplinary role or with a supervision presence, but adults being around and contributing, just as another human being on campus. Building a community where everyone cares for each other; setting examples that the school is a place where individuals build connections and a place where they are all learners and achievers. He argues that adults at school need to make it work every day. Complimenting "little things" such as picking up trash, who is at the school (seeing the students) and getting to know them. "These little things are big things" (p. 215). Students who feel proud of their school/proud of being a student at their school.

\section{Conclusion}

Studies cited in the Literature Review show the mechanisms through which the education debt (Ladson-Billings, 2006) is continually growing for students of color. Several studies show that institutionalized racism contributes to the blockage and then the derailment in the classroom of a high school education for many students. The studies explain several examples, but one that stands out is the often unconscious teacher behavior of feeling comfortable and friendly with students from his or her culture while in contrast treating students of color with negative responses such as not welcoming them into the classroom, or when they speak in their native language teachers signal that this 
behavior is unwanted and unwelcome in the classroom. This behavior is a form of institutionalized racism that is often not visible to the teacher, but it is very visible to students of color, as they see through teacher behavior that one group of students is wanted and supported while another is not.

The review also provides evidence that some teachers enter their classrooms with deficit thinking about their students of color. Studies show that students are deeply troubled by their teachers stereotyping of their interest and ability to learn. Research shows that when teachers already believe that students of color and their parents do not respect education, then it is going to be nearly impossible for students of color to feel emotionally safe enough to become motivated in the classroom to engage with and complete academic work. The concept of emotional safety is a key issue in terms of students' ability to learn. Without a warm and welcoming teacher, students of color turn off, tune out, and often drop out. They cannot get to the next stage of human development according to Maslow's hierarchy of needs. They become stuck on a lower level until their very real need to feel emotionally safe is satisfied.

Studies in the review also identify that students are at a far greater risk of dropping out than their white peers. When students of color feel unwanted and unwelcome, many often drop out, whereas their white peers, when treated in the same negative way are not affected to the point of dropping out. This insight provides a powerful way in which teachers can learn about how negative behaviors of rejection have a tremendously higher impact on students of color. Already marginalized in society, when they are at school, they are in a place where they can choose to stay or leave. Many choose to leave because 
it is so painful to feel neglected, belittled, and unimportant. But when they leave school altogether, they then are in the precarious position of needing an education, so that they can work toward having a career that gives them pride. In the workforce, they will find racism too, so it is very important they choose an occupation that leads to self-esteem. If students of color are going to have opportunities in life, they need to have an education through high school and beyond. The demarcation line of the education debt is hinges on this point.

The review also shows studies that support positive behaviors of teachers. Teachers who provide authentic caring allow students to build complete trust in them (Noddings, 2013 \& Valenzuela, 1999). Once students feel this deep caring and deep trust, they then can learn and see themselves as students. It is here at this junction that the educational debt starts to be paid down. In classrooms where teachers are welcoming and have authentic care for their students, students learn and thrive in public classrooms with great engagement and motivation.

The key to the issue of change for students of color is how to make visible the pain and suffering that so many of them endure in classrooms today. How can institutionalized racism be made visible to school staff such that it can be rooted out? These are challenges that can be addressed as soon as student voices are given a venue through which to be heard. 


\section{Chapter Three: Proposed Methods}

\section{Introduction of the Project}

Through students' voices, this grounded theory study aims to learn, acknowledge, and acquire insights from Latino male youth. The focus of this grounded theory study is the Latino male perspectives about teachers' beliefs, expectations, and behaviors that relate and impact their motivation and academic engagement. I want to try to understand how to build and develop mutual trust/confianza between teachers and Latino male students to motivate and engage them in learning and believing that staying in school can bring opportunities to a brighter future.

Participants in my project - students from two different highs schools and youth that have dropped out of schools - will help me identify the factors that affect Latino male students' academic motivation and lack of engagement at EHS that often result in Latino male students being transferred to the district's continuation school.

The following are the three research questions for my grounded theory qualitative study.

RQ1 How do Latino male students' perceptions of teacher beliefs, expectations, and behaviors toward Latino students, impact their relationships with these teachers?

RQ2 How do Latino male students' perceptions of teacher auténtico cariño and confianza impact their relationships with these teachers?

RQ3 How do these Latino male students' perceptions and relationships with their teachers impact their academic motivation and academic engagement? 


\section{Specific Variables That Are Being Analyzed for Relationships}

The following are the specific variables that will be analyzed for possible relationships between teachers and students. These relationships will be analyzed to understand the students' perceptions of teacher beliefs, expectations, and behavior in schools and the effects on Latino male students' academic motivation and engagement. The measurement variables in this study are contextual factors, external factors, and outcome variables. Measuring students' perceptions will be a combination of students' interviews and interpretation of their perceptions of their teachers' expectations.

Contextual factors are obtained from the knowledge of the out of school factors that the Latino male students experience in their daily lives. External factors are experiences lived by students that one would not necessarily connect to their academic well-being, but in fact have a tremendous influence on students' learning. External factors are composed of both in school and out of school factors. The outcome factors (academic motivation and academic engagement) are continuously changing due to the interrelationships of the contextual and external factors. A summary along with examples of these factors are found in Table 1.

A major external factor is unsafe neighbors. The majority of the Latino male youth live in areas in which drugs, gangs, prostitution, and police are visible at all times. They live in neighborhoods were drive by shootings are most likely to happen and neighborhoods where youth are easier prey for gangs and drugs. Poverty has an impact on where these youth's parents can afford to live. Immigration status, poverty, and discrimination due to ethnicity make their families unable to move to safer 
neighborhoods. The next external factor is being labeled at school. Often, one erroneous decision affects the future of Latino male youth in schools. Latino youth who are labeled at schools as troubled kids, troublemakers, kids that don't care, or kids whose families/parents do not care about education, often develop a negative relationship with school (Weissman, 2015). A final external factor is Latino youth challenging homes: experiences of living in single parent homes, being victims of child abuse and neglect, not having an immediate family to take care of them or having relatives or parents that are incarcerated and coming in and out of prison (Rios, 2011) are all challenges that students bring with them to school. Exposure to verbal abuse, physical abuse, bullying, sexual abuse, domestic violence (witnesses or victims) and emotional abuse are all factors that affect student learning. Motivation, and ultimately engagement in learning in schools influence their ability to succeed in school. Furthermore, the negative peer pressure of smoking weed and/or joining a gang are factors that impact the lives of youth of color in their neighborhoods, their homes, and their school (Brown, 2007; Pizarro, 2005; Rios 2011). The positive interactions with teachers who are able to support the students and have them engaged in their classrooms, the teachers that are helping their students dealing with their daily problems by listening and giving them hope. Teachers that give them hope and have showed them and shaped their behavior to believe that being in school is a safe space and a place to learn to overcome some of their lives adversities. The external factors are multiple, they are most significant since they exist outside schools. Some of these external factors are family and neighborhood. The goal of these methods is to control these external factors; controlling them provided 
opportunities to the youth of color. To believe that despite the many challenges that Latino youth experience at schools, their relationships and experiences at their schools can make positive changes in their lives as students.

\section{External Factors: Teachers Beliefs, Expectations, and Behaviors}

In my study, one primary external factor is teacher beliefs. Often teachers believe that their Latino students come from a culture that do not value education. The next external factor is teacher behavior. Teacher behavior impacts Latino students. Some students feel their teachers do not really care about them (Valenzuela, 1999). The third external factor that affects Latino students is teachers' expectations for Latino students. Some teachers do not see their Latino students with capabilities to do well in school. Students notice when they are not treated equally. They know and feel when adults think that they do not care about school or that they are not college material (Becerra, 2012; Pizarro, 2005; Senge et al., 2012; Valenzuela, 1999). One example is that they are placed in classes that do not challenge them. The external factor reflects teachers' mindsets about their Latino male students (Valenzuela, 1999).

\section{Outcome Factors: Academic Motivation and Academic Engagement}

The primary outcome factor is academic motivation. If students do not feel welcome at school or in the classrooms, they do not get motivated to participate. When teachers recognized that their students bring and or contribute to the classroom culture, students feel valued and motivated to be in the classroom and participate to their abilities and strengths students become committed to be successful, develop enthusiasm for the class, volunteers for activities in the classroom, becomes eager to improve his grade, studies for 
exams, participates in the classroom, and attends diligently his classes. When students feel accepted for who they are and where they are academically they develop confianza in themselves and confianza to ask for help to their teachers (Landsman \& Lewis, 2012). The positive and negative interactions impact the students' motivation to engage in classrooms activities (Landsman \& Lewis, 2012; Valenzuela, 1999). The next outcome factor is academic engagement. When students do not attend school, skip classes, do not receive positive messages and the interactions are not good in their classrooms, students do not engage in learning. Motivation induces to engagement. Motivations induces students to internally challenge themselves to improve academically because believe in their teachers. They develop cariño and respect for their teachers that they want them feel proud of their accomplishments. Teachers' beliefs, expectations, and behavior impact the motivation and the engagement in students.

Loera, Rueda, \& Oh (2015) describes motivation as '...the process whereby goaldirected activity is instigated and sustained' (p.5). Motivation is the relationship between the internal processes of beliefs, values, and goals with the external expression of action, such as choice, persistence, and effort Loera et al. (2015). The academic motivational variable has a link to academic engagement and academic success.

According to Loera et al. (2015) academic engagement is interrelated to behavior. Behavior can be negative or positive. Behavior also happens outside the classroom and the self-regulation and academic engagement motivates a student not to leave school, skip classes, to follow the school rules, pay attention in classes, ask for help, to feel encouraged and motivated to participate, to feel safe in classrooms and at school, to feel 
safe to ask questions, and to feel eager to engage in learning. Authentic engagement includes feelings, beliefs, and attitudes about school, and includes constructs such as belongingness and engage in learning (Brown, 2016; Sosa \& Gomez, 2012; Valenzuela, 1999). 
Table 1

Contextual, External, and Outcome Factors

\begin{tabular}{|c|c|c|}
\hline \multicolumn{3}{|c|}{ Factors } \\
\hline Contextual & External & Outcome \\
\hline $\begin{array}{l}\text { Teachers beliefs (TBEL) } \\
\text { - } \quad \text { They are loud and } \\
\text { they don't care } \\
\text { - } \text { The poor kids } \\
\text { - } \text { The behavior kids } \\
\text { - } \quad \text { Their parents don't } \\
\text { care } \\
\text { - } \quad \text { They are not college } \\
\text { material } \\
\text { - Assumptions about of } \\
\text { culture/historical } \\
\text { knowledge } \\
\text { - That's her/his second } \\
\text { language } \\
\text { Teacher expectations (TE) } \\
\text { - Deficit thinking in } \\
\text { relates to intellectual } \\
\text { capacity } \\
\text { - Not treating kids } \\
\text { Teachally } \\
\text { (TBEH) } \\
\text { - They are not college } \\
\text { - } \text { material } \\
\text { Treating them as bad } \\
\text { boys } \\
\text { S/T relationships } \\
\text { (could also be a D.V.) }\end{array}$ & 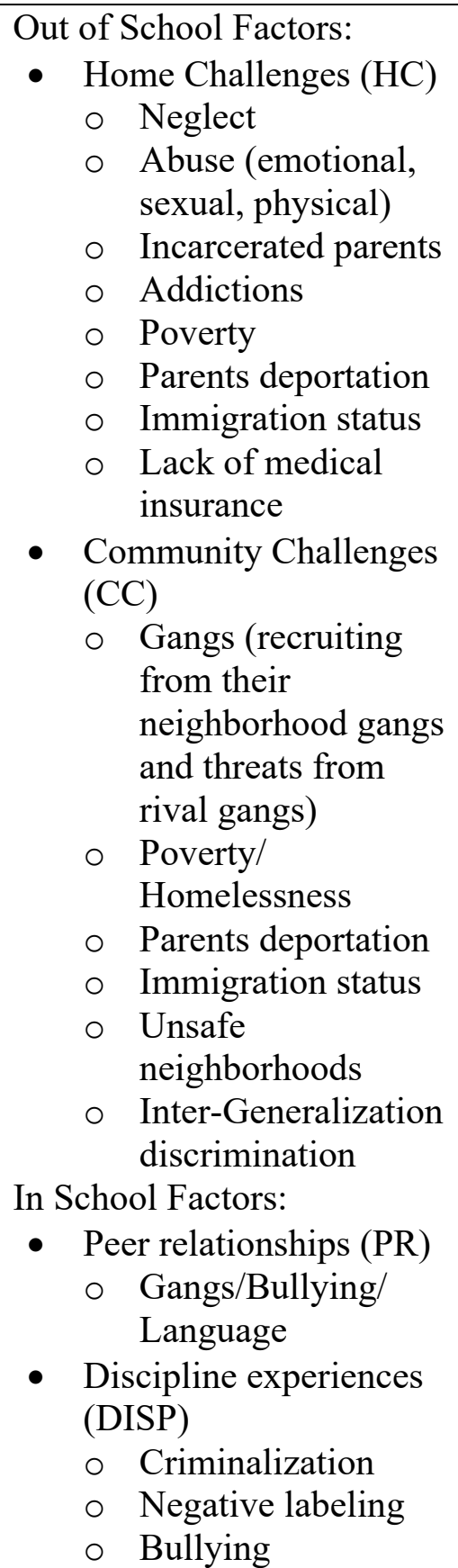 & $\begin{array}{l}\text { Academic Motivation (AM) } \\
\text { - Commitment to being } \\
\text { - } \text { successful } \\
\text { class } \\
\text { - Volunteers for } \\
\text { activities in the } \\
\text { classroom } \\
\text { - Eager to improve his } \\
\text { grade, studies for } \\
\text { exams participates in } \\
\text { the classroom, attends } \\
\text { diligently his classes } \\
\text { - Respect his teachers } \\
\text { and peers } \\
\text { - Ask for help to their } \\
\text { teachers } \\
\text { Academic Engagement } \\
\text { (AE) } \\
\text { - Positive and negative } \\
\text { interactions } \\
\text { - Attending class } \\
\text { - Recognition for their } \\
\text { strengths } \\
\text { Prior knowledge } \\
\text { Value them as } \\
\text { capable/good - } \\
\text { students/students that } \\
\text { are an asset in } \\
\text { classrooms } \\
\text { Completing homework }\end{array}$ \\
\hline
\end{tabular}


This particular research did not include a control variable because it is not an experimental study or one with non-Latino students. This grounded theory approach is a study focus on students' experiences, and its conclusions are based on the association between the students' interviews and analyses of the themes that the students shared with me, a Latina woman working with Latino male boys.

\section{Pilot Sample}

The informal pilot study that I conducted in July 2017 with Latino male high school students allowed me to select key terms that were the foundation of my study. During the interviews, the students centered the concepts of confianza, auténtico cariño, and respeto that was described like: reciprocal feeling that helped create a healthy and positive relationship, helping all the way through, acceptance, and encouragement to improve academically. These terms are defined on page number 16 at the end of Chapter One. The terms I selected for this grounded theory study are authentic caring/auténtico cariño, caring relationship, confiar/confianza, trust, respeto/showing respect, palabra/ser un hombre de palabra, and educación.

I invited three male Latino high school students from a local dance group to participate in the informal pilot study. I informally asked the students' parents permission to participate in the pilot sample. The students were informed that they were part of a pilot sample. The interviews were approximately forty minutes long. The informal pilot study tested the instruments that I used to collect data for the research study. It helped to improve the instruments before being used in the final data collection. 
The questions I asked the students were: a) What makes you feel comfortable around your teachers? b) How often do you ask questions in your classes? Do you feel safe to ask questions? What class is your favorite class? Do you have a class where you do not participate or participate less? The students mentioned confianza and they also mentioned auténtico cariño. I also noticed that I started asking them the questions in English and we finished our conversations in Spanish. I then decided that my questions needed to be in both languages, Spanish and English. In addition, they described cariño as holding our hands/agarrarnos de la mano y ayudarnos. By listening to the students' answers, I learned of the ingrained perceptions that Latino male students have of their teachers' practices, beliefs, behaviors, and expectations. And how these perceptions do not support the development of respeto which leads to confianza and allows for the teacher and the student to have a reciprocal behavior of auténtico cariño.

\section{Contextual Analysis -Study Sites (EHS and AHS)}

I conducted this grounded theory study at two high schools, Embarcadero High School (EHS) and Amanecer Continuation High School (AHS) in Santa Cruz County. One school is a comprehensive High School and the second is a continuation school. Although I collected data from students at these two sites, data for this grounded study research project (students' interviews and testimonies) was collected at EHS, the comprehensive school. The participants at AHS were students that previously attended EHS. The interview questions for AHS students were regarding their experiences at EHS. These students were enrolled at the continuation school; therefore, my 
observations at the continuation school were minimal. In addition, I interviewed youth that attended EHS and were at risk of dropping out of school.

\section{Why I Chose EHS}

EHS is one of the three high schools in the school district. Of the three schools, EHS has the largest Latino population (51.6\%). Many EHS Latino students were not performing well in their classes. In $2014,51 \%$ of the Latino youth were not proficient in English- Language Arts and 51\% were not proficient in mathematics (School Accountability Report Card). I gathered data directly from Latino students' through their voices about their daily experiences in relationship to their academic progress at EHS. The students' stories of what it means to be a Latino at school were important in identifying the issues confronting them to understand the triggers that lead to academic disengagement. In addition, the dropout rate for Latinos in 2014 was 1.7\% ((School Accountability Report Card).

Since 1967, EHS has continuously provided a "comprehensive academic program focused on high expectations, caring relationships, and opportunities for all students to participate and contribute" (2015-2016 School Accountability Report Card). EHS classes are block classes that meet for one and a half hours every other day. Approximately 1,032 students are enrolled in grades 9-12. There are sixty-five faculty members, three full time counselors (two female, and one Latino male). Two of the counselors are bilingual, three monolingual administrators (two female and one male), one school community coordinator (Latina and bilingual), a psychologist, two campus supervisors, and approximately twenty additional school personnel. Four out of six office staff 
members (the attendance clerk, counselor's secretary, registrar, and the administrative assistant) are bilingual and are all female and Latino. EHS hosts the Newcomer Program (NCP) that was developed in 2010. EHS offers credit recovery classes to all students who have failed a class and are in need of credits to graduate. The school's demographics are as follows: 53.6\% Latino/Hispanic, 4\% Asian, 1\% Black, and 41.4\% White. The total minority enrollment is $61 \%$ of which $57 \%$ are economically disadvantaged.

\section{Brief Description of the Continuation School}

AHS, the continuation school, receives students from the district's comprehensive schools. These students were transferred from EHS. AHS has a student population of 92 students, a teacher population of six (five full-time teachers and one part-time teacher; one of the teachers is bilingual and Latina), a librarian, school community coordinator (bilingual and Latina), a school registrar, attendance person (bilingual and Latino), a secretary, and a counselor (bilingual Latina who shares her role with the independent studies program), and an administrative staff of two (both administrators are bilingual). AHS students are offered one on one support most of the time. Most of the students at AHS are juniors, seniors, and the super seniors (student who couldn't meet the requirements to receive a high school diploma with their cohort). AHS does not provide students with homework. Students only attend school for four hours and thirty-five minutes. Most of the students' main goal is to return to their home schools and graduate with their cohort, it is rare but not impossible for this desire to happen. Among the Latino students AHS is also called the paisa school. Paisa is short for paisano a term 
that is used to refer to people who are from the same region or town. However, it can have a derogatory meaning. Some Mexicans use it to refer to Mexicans who they believe are beneath them. Generally it is used to refer to Mexicans from rural areas of Mexico or who are indigenous. In short, when used as an insult, paisa means stupid. Therefore, calling AHS a paisa school is derogatory. It shows that Latino students view the school as a school for the unintelligent, a school that is beneath them, a school that they do not want to end up attending.

\section{Sample \& Demographic of Participants}

This study was based on a sample of twenty participants. All of the participants were Latino male sophomores who attended and/or were enrolled at EHS during their freshman year. Twelve participants were recruited from EHS, four participants from AHS who were previously enrolled at EHS, and four participants were at risk of dropping out from EHS or from AHS for those who had previously attended EHS. At EHS and AHS, students were selected to participate in the study by their school academic counselor. At EHS three groups of four participants were chosen from a group of sophomores who failed two classes during their freshman year, four participants who had two or less D's as Freshmen, and four participants who had all A's and B's as Freshman. My research aimed to determine what factors contributed to student motivation and which ones contributed to student academic engagement. The age of participants ranged from fourteen to seventeen years old. At AHS, the continuation school counselor invited the students to participate. The counselor also helped me recruit students who dropped out altogether. To minimize the role of external factors, I selected from the list given by 
the counselors, students who attended the school's feeder middle school. These students had similar neighborhoods and were students who attended Santa Cruz Schools since kindergarten.

At both the continuation and comprehensive high schools, the participants were recruited by their counselors. The counselors provided me with the prospective participants' names. These students were invited to participate in the qualitative interview study. The study was explained to the students. The parents' consent form included an explanation of the study and also invited them to contact me for additional information. Students and their parents were informed that the students did not have to answer all of the interview questions, and that the students would have been free to leave the study at any time.

\section{Insights from Stakeholders}

I gained insights from stakeholders by talking to them about my research study. I developed the three research questions for this project after speaking with two high school teachers, high school students during the pilot study, and a continuation school academic counselor. I spoke to four high school students (attending another high school in the same district). They explained how confianza developed from their perspectives of their daily experiences. The students talked about the impact of having confianza with an adult at school gave them confidence to ask questions, participate in school activities, and community events. The youth translated trust into confianza. Each one of them mentioned the importance of feeling confianza with their teachers and how confianza allowed them to seek help with assignments, participate in the classroom, and raise their 
hand to ask questions. In addition, they mentioned the importance of developing auténtico cariño with their teachers.

Two Latino academic counselors were interviewed separately. One female counselor from a continuation school and one male counselor from a comprehensive high school. Both stakeholders shared their worries of how the lack of empathy from some school staff impacted and affected Latino male students at their schools. The impact of deficit thinking and the absence of a transcultural perspective build negative relationships with the male Latino youth at their schools. The lack of being aware of white privilege did not allow teachers to listen and pay attention to their Latino students' struggles. They shared that some of these struggles were: the struggle with their identity by being part of two cultures, being labeled as people that do not care about education, not having access/or not moving towards advanced courses to attend college, giving up in school work, being singled out, kids not trusting adults, adults thinking of their students as loud and vulgar, students being labeled as bad kids or talking about them with other teachers (spreading their thoughts to others), and breaking their students' confidentiality. The lack of confianza and auténtico cariño from adults that do not trust them harm Latino students. The EHS counselor mentioned that with the change in demographics in the school district, some type of training was needed to build awareness for teachers of the importance of getting to know their students.

The school principal shared that she wants to learn about students' perspectives about school. The 2016-2017 school year was her first year as principal at EHS. Previously, she was in the role as assistant principal at EHS school. The meeting with the assistant 
superintendent of curriculum (first year at this position) and superintendent of the schools' district and their insights of learning about the Latino community reflected that there is a great need for research to address deficit thinking that increases educational debt and makes profound the achievement gap; the urge to learn by listening to Latino male students so they feel connected in school, to feel safe to ask questions, and to be seen as achievers.

\section{Why this Sample was Most Appropriate for Answering my Research Questions at These Sites}

I wanted to identify, from students' perspectives, the factors that influenced their high or low grades at EHS. Did the students feel supported? Did they feel confianza to ask their teachers for support? Did they feel listened to and heard? Youth experiences in these three different areas have enriched my grounded theory study since their school experiences were different and shaped their beliefs about schooling in American public schools.

\section{The Specific Methods I Employed}

The rationale for choosing a qualitative interview study and a grounded theory approach directly connects to the nature of the project's participants - male Latino students with low to high academic performance - to foster an understanding of their perceptions and beliefs about their public school experiences and to understand them from their perspectives (Merriam \& Tisdell, 2015, p. 6,). The primary data collection were informal and unstructured interviews and my professional notes as a professional in schools. Informal and unstructured interviews elicited information and generated detailed data and enabled in-depth understanding of the students' perceptions and beliefs 
(Merriam \& Tisdell, p. 112). Students' consent forms were sent home in English and Spanish for parents to authorize their child/ward to participate in the study. I completed the initial background information for the students to acquire the following information: age, primary language, ethnic identity, prior schooling in country of birth, the year the participant moved to the US, the number of years the participant was enrolled in American schools, and if the participant is designated as an ELL student. This information was collected during my initial meeting with each student. I worked to build trust from the beginning, so as I collected this personal data, I began to develop personal relationships based on respect. The ono-on-one interviews allowed participants' authentic voices and points of view to be heard and recorded (p. 7). Recording students' perspectives allowed me to find descriptive relevant details that became themes as I analyzed the data (Miles et al., 1994).

My reputation at the school, in the school district, in the community, and my experience and commitment to the support of students ensures trustworthiness, reliability, and credibility. Grounded theory approach was one of the most appropriate methods for answering the research questions because the participants' stories provided me an insight of how their points of views and experiences shaped their world as Latino adolescents in school. The research was richly descriptive by capturing the real-life context with indepth descriptions from interviews, my observations, and students' testimonies.

Students' data also included their attendance, grades, and discipline issues. These three categories of student information gave me valuable information about the participants. The data allowed me to know in advance that their grades were affected by 
their attendance. I analyzed the qualitative data based on themes identified from the student interviews. Content analysis was conducted after identifying specific themes. Once the themes were analyzed, a coding sheet was being created that lists themes identified through participants' descriptions. The students' responses were organized under the following themes: Trust, Student Engagement and Support, Caring and Sense of Belonging, and Teachers' beliefs and practice. Descriptive coding worked to help me to identify what was affecting students' academic progress both negatively and positively (Miles, Huberman, Huberman, \& Huberman, 1994, p. 74).

Multiple informal conversations/pláticas with the students helped in gathering data. The more the students became comfortable with me, the more they provide me with data related to the research questions. Students were interviewed two times individually in a private office. The duration of the oral interviews was approximately forty-five minutes in length.

\section{The Specific Components of the Data Collection Tools and How They Answered the RQs}

Instruments for the study: Background Survey (Appendix A) and Research Questions (Appendix B)

\section{Analyzing the Data}

To analyze the qualitative data, I reviewed the themes generated from the interviews and from the literature review. The grounded theory is an inductive methodology approach that gathers, synthesizes, and conceptualized qualitative data (Merriam \& Tisdell, 2015, p.31). This study will analyze cultural systems, processes, meanings, and perspectives based on grounded theory. Having data regarding grades, attendance, and 
discipline helped me find students' behavior patterns that showed me why a student acts in certain way in some of his classes and not in others. Listening to their testimonies gave me a sense of how they felt when they experienced certain teachers' behaviors.

The following critical codes cariño, entendimiento, respeto, mi maestro/a escucha $y$ le importa, hace algo por mi, and es alguien con quien puedes hablar were identified and extracted from the entire coded data. These critical extracted codes were featured in the study analysis. The transcription of the verbal data obtained from the students helped me to familiarize myself with the data; the data then led to a thematic interpretive analysis (Miles et al., 1994).

Triangulation is a method that was be used to "ensure consistency and dependability or reliability" (Merriam \& Tisdell, 2016, p. 252). Triangulation is "The use of multiple methods of collecting data" (p. 252). The students' interviews and data from their attendance and grade records will support the data. The existing data from the interviews helped me cycle back and forth between thinking about the existing data and helped me to generate strategies to collect new, better data. It was a healthy corrective for built-in blind spots (Miles et al., 1994, p. 70). Recordings of the interview were transcribed into text to analyze. These interviews were coded and analyzed (p.71); my notes of the interviews assisted me to remember things that happened at the time that the participants were interviewed.

\section{Limitations of the Data Collection}

As a Latina, indigenous immigrant I realize that I am challenged when working with youth of color. I am aware of my feelings, emotions, and bias. Interviewing the first 
students was difficult, however I reminded myself to take a step back and evaluate my thoughts before becoming emotional when I hear from the students what students of color historically face in public schools. I also constantly need to avoid becoming judgmental, so as not to stereotype school employees. If I had not, these thoughts and feelings could have caused a conflict of interest in the grounded theory study by causing me to make subjective conclusions. I needed to remain an objective observer. I needed to be vigilant and professional in order to develop a valid study through in which facts speak for themselves and are not discounted by bitter feelings or resentment. Students' testimonies centered on students' voices and this drove the study's analysis.

While reading the literature, I reminded myself that I needed to remain objective. Objectivity helped me to analyze students' responses in a neutral and unbiased manner while providing a fair and truthful analysis. I wanted real answers because our students needed real answers to help address the realities that they are facing. I needed to seek real answers to address the too often defeating realities that so many Latino youth face in public schools. My research would have not of benefit to anyone if I had tried to push it in a certain direction. Being aware of my biases helped me to put them aside to be accurate and professional to the best of my capacity, and to generate a research project with valid findings. My responsibility to the research study was first and foremost to gather data. I built confianza with the students so the students would be truthful. I explained to the students that their answers have a benefit to future students at EHS. I explained that their answers will be valuable data for school staff when learning how the reciprocity of confianza and auténtico cariño impact students' motivation and academic 
engagement. I work closely with teachers, counselors, and administrators on a daily basis. I am often part of their decisions. Data that was collected will help me to listen better to the students and at the same time share some of my insights and observations with school staff, so the voices of youth can be heard, affect change to current practices, and challenge deficit thinking by adults about youth of color.

Another limitation was time. I only had two months to build rapport with the participants. I needed to immediately work to build trusting relationships with the students, so they did not see me as an outsider. An additional limitation is that this study was limited to sophomore students at EHS and only their perspective became part of the study. I addressed the time limitation by introducing myself to the bilingual school community liaison at school, one who was instrumental to reserve the classroom where I had two initial meetings with the students when I originally invited them to participate in the study.

\section{Confidentiality}

Students participants were given a parent consent form, written in English and Spanish, to take home to explain the project to their parents/guardians. Participants were given an assent form. Their legal guardians or parents were required to sign the informed consent form in order to participate in the study. The consent forms were written in English and Spanish.

At the beginning of the study, each student was assigned a numeric identification code to protect and ensure the confidentiality and anonymity of participants. No personal data, such as names or school identification numbers, appeared on any documentation. I 
was the only person that knew the identity of each participant. The list of the identities of the participants with their assigned numbers was placed in a locked cabinet in my office. I was the only one with access to it. The project's data was contained on a laptop computer. In addition, I created pseudonyms for the students and teachers so that the identities of those in my notes were not be identifiable.

Before participating in the project, participants were informed that they could opt out of the project if they in any way felt uncomfortable, unsafe, and/or vulnerable. If participants experienced anxiety or/and embarrassment at any time during the study, they were informed that they were free to leave the room at their request. In addition, I completed the study with extensive training and experience working with students in crisis or with anxiety.

Although confidentiality played a major role in the research study, there could have been some ethical complexities that impacted some students. I explained to participants their rights concerning privacy and confidentiality. Some examples of these complexities were: students who could have been experiencing neglect or domestic violence at home and/or being sexually abused; or being bullied by others or wanting to harm themselves. Some outcomes of interviews and/or testimonies from informal conversations could have affected the participants if a question made them feel uncomfortable. I asked for the help of a school's counselor to support students if they needed emotional assistance.

\section{Role of my Positionality}

I was not raised in the United States and did not attend a public school in America. I cannot feel their challenges growing up as a person of color. I consciously and honestly 
contributed in the narrative of the often unexpected and uncomfortable feeling and difficulties of interviewing the participants while they allow me to "enter into" their perspective of schooling (Merriam \& Tisdell, 2015, p. 108). DeLuca and Maddox (2015) address and explore questions of "reflexivity, positionality, identity, and emotion within the process of research" (p. 284). They state the importance of reflecting on the feelings of privilege, guilt, and the struggle with racism while conducting the study and listening the participants' perspectives on this grounded theory fieldwork (p. 284). They also discuss how these experiences "encouraged reflexive thinking and a crucial interrogation of the place of the self in the research process" (p.284). They argued that researcher's experiences "are important in the production of knowledge, during the research, work, and live.

My positionality as a woman of color shaped the way I see what happens in the field of work. I often get students referred to my caseload because of not attending school or because they skip their classes. Listening to the students I interviewed and reflecting on their experiences helped me to modify some of my practices when speaking with them; when I asked them the reasons why they skip school or the many reasons why they can ask for teachers' support to improve a grade. My job as a school social worker (SSW) is to talk to students and support them to do well in school.

I speak the same language of the participants interviewed and I am Latina. These two attributes helped me to establish a quick rapport with the participants. As a SSW, the findings of the research may have an impact on the people I work with at the school and 
an impact on people's lives. Learning from the students' experiences, perspectives, and beliefs made me reflect on my daily approaches when working with youth of color.

\section{Conclusion}

Having the opportunity to do the study at the comprehensive school and the continuation school allowed me to understand the challenges that the youth face on a daily basis. The methodology on this study helped me to analyze why it is some students become engaged in schools, why some students feel more connected than others in schools, why students' negative experiences make them feel not connected to their schools, the effect it has to be sent to an alternative setting; and most important, how do they feel as students when they are asked to leave their schools and sent away from their peers and friends. In addition, it allowed me to learn more of the students at risk of dropping out of school or that have dropped out of school, and to learn more about what affected them or made them take the decision to leave school, and how to go about reducing that chance from happening. Furthermore, if despite all of the challenges Latino male youth face outside schools, if they can find in schools the sense of belonging, they will in turn become motivated, and successfully engage in their learning. 


\section{Chapter Four: Findings}

In the study, through their own voices responding to the research questions, the participants described their high school classroom experiences. Their testimonies captured negative reactions and positive experiences in relationship to their perceptions of their teachers' beliefs about them as public high school students. The findings suggest that EHS was an overwhelming negative environment for a majority of the participants. The study identified key factors that clearly caused students to transfer to the continuation school or to remain in their comprehensive school. These included many negative students' perceptions of their teachers' beliefs, expectations, and behaviors towards them, students' understanding of their teachers' feeling authentic caring/auténtico cariño and trust/confianza and for them as students, and how students' perceptions of their feelings of their teachers' care and trust impacted their academic learning and motivation.

The findings suggest that a major cause of the negative space in classrooms at EHS was that many of the participants reported encountering teacher behaviors daily that made them believe that some of their teachers did not want them in their classrooms and/or believed that they as students were not interested in or capable of learning. Because the teacher behaviors were daily, the participants felt that they either had to figure out how to cope with them -they did not believe that the negative teacher beliefs and behaviors would change - or they stopped attending classes.

To provide context in relationship to the participants' lives as students, this chapter includes students' ethnicity, socioeconomic status (SES) as identified by their eligibility 
for free or reduced lunch, students employed to help families pay for basic necessities such as rent, utilities, and food, language preferences (LP) at school and at home, language proficiency as determined by school administered assessments, attendance rates, grade point averages (GPA), specific classes designed to promote the students' college readiness, favorite classes, and extracurricular activity participation.

\section{Background Related to Participants and Their School Placements}

Qualitative data collected through interviews showed that the transferred students had not felt connected to EHS. The reasons for the transfers included truancy, inappropriate behavior, and a lack of sufficient academic progress as exemplified by failing grades. They explained that their perceptions of negative teacher behaviors made them feel unwanted and unwelcome troublemakers who were not in fact capable of learning. These negative teacher behaviors included harsh verbal and facial expressions daily, not being invited to contribute to class discussions, and being ignored when they raised their hands.

At the start of the study, I met with all of the participants. These students were jovial and eager to participate. As a group they seemed really happy. They were loud. Once I had the opportunity to meet with them, one on one, I was able to learn about them and their struggles at school. The findings support that many classroom teachers are not nourishing all of their students - they are not listening to try to understand them and their classroom behaviors. Many do not see them as individuals or recognize their cultural strengths such as their use of their primary language at school with their peers. They were indeed loud; they were happy to see each other. Their teachers should have been pleased to have such happy students. I have to admit that I was stunned and became 
impotent as the data provided by the students described the daily negative reactions to them by many of their teachers. Their voices became one, all communicating the same thing, all supporting previous negative findings.

During the interview times, I noticed how quickly the EHS students were pushed to the continuation school; they were "forced" to move as one participant expressed. To hear the disappointment of participants as they told me that they would be leaving EHS was difficult. Having heard their perspectives about their teachers' negative behaviors, I felt their powerlessness. They were not recognized or valued in their classrooms to the point that they were asked to leave their school altogether. The participants were young teens who were finding their identities. As a Spanish speaking person, I identified completely with the students when they mentioned that they needed to switch to Spanish when they needed to ask help from each other to understand a subject in class. To have such severe consequences for behaviors that had no negative intentions, for trying to understand a class concept, made me realize just how tragic and damaging their high school classroom experiences were. They had no one who could advocate for them. This was very difficult for me to watch because as a SSW my first impulse was to help the participants, but because they were part of the study, I could not. I felt caught between my role as an advocate for students and my role as a graduate student investigating my research questions. As a result, I feel inspired by the participants to work to change teachers' negative classroom behaviors through identifying them and through advocating for Student-centered learning curriculum. I see the challenges on two fronts. The first is teacher classroom behaviors and the second is curriculum that through its own design can 
prevent the most hurtful of the study's participants' responses that explained that their teachers did not see them as capable students who could learn.

\section{Background: Description of Students}

Twenty male students participated in this study. At the beginning of the study, nineteen participants attended EHS, the comprehensive school, while one EHS student had already transferred from EHS to AHS, the continuation school. By the end of the interview process, twelve participants remained at EHS and eight had transferred to AHS, the continuation school, from EHS. No student returned to EHS. It was a one-way path: participants in the study transferred out of EHS and into AHS. Seventy-five percent of the students were interviewed at AHS to respect their privacy, while $25 \%$ were interviewed at EHS. In preparation for the interview process, I asked students for background information to determine which language they speak at home and which one they speak at school. Ninety percent of the students stated that they speak Spanish at home while $70 \%$ preferred to speak Spanish at school. Seventy percent said that although they speak Spanish at home, they speak English at school. In response to the study's interview questions about home and school language preferences, $58 \%$ of the EHS students chose to be interviewed in English, while $42 \%$ of them requested to be interviewed in Spanish. At AHS, 50\% chose to be interviewed in English and 50\% of them requested to be interviewed in Spanish. By asking students about their language preference, my aim was to make them as comfortable as possible, so that issues of language would not cause the students additional stress. 
Seventy-five percent of all students identified as of Mexican origin, while 15\% percent of the students identified as Salvadorian, $5 \%$ as Chicano, and 5\% as mixed. At EHS, $84 \%$ identified as Mexican, $0 \%$ as Salvadorian, $8 \%$ as Chicano, and $8 \%$ as mixed. At AHS, $63 \%$ identified as Mexican, $37 \%$ as Salvadorian, $0 \%$ as Chicano, and $0 \%$ as mixed. The students' ethnicity at EHS and AHS is shown in Table 2.

Table 2

EHS and AHS Student Identified Ethnicity

\begin{tabular}{lcccc}
\hline & \multicolumn{3}{c}{ Ethnicity } \\
\cline { 2 - 5 } School & Mexican & Salvadorian & Chicano & Mixed \\
\hline EHS (12 students) & $84 \%(10)$ & & $8 \%(1)$ & $8 \%(1)$ \\
AHS (8 students) & $63 \%(5)$ & $37 \%(3)$ & & \\
\hline
\end{tabular}

An additional factor connected to students' identities at EHS was their designation as a Newcomer (NC) student. A NC is defined as a student who arrives from another country during the school year who does not speak English and hence is placed in English Language Development (ELD) classes designed specifically for NC. EHS is the designated NC school for the district, so all NC students start at EHS. Students retain the NC label until they advance out of the NC ELD classes. Table 3 shows the ethnic identity and students designated as NCs. 
Table 3

EHS and AHS Newcomer Designation

Newcomers at Each School

\begin{tabular}{lcc}
\cline { 2 - 3 } Ethnicity & EHS (12 students $)$ & AHS (8 students) \\
\hline Mexican & $0 \%$ & $0 \%$ \\
Salvadorian & $0 \%$ & $25 \%(2)$ \\
Chicano & $0 \%$ & $0 \%$ \\
Mixed & $0 \%$ & $0 \%$ \\
\hline
\end{tabular}

Over $80 \%$ of participants have low socioeconomic status (SES), as identified by their eligibility for free or reduced lunch. Table 4 below shows that $84 \%$ of EHS participants qualified for the Free Reduced Lunch Program, while 87\% of AHS students qualified.

Table 4

Students in the Free and Reduced Lunch program

\begin{tabular}{lcc}
\hline & \multicolumn{2}{c}{ Qualify for Free \& Reduced Lunch } \\
\cline { 2 - 3 } School & Yes & No \\
\hline EHS (12 students) & $84 \%(10)$ & $16 \%(2)$ \\
AHS (8 students) & $87 \%(7)$ & $13 \%(1)$ \\
\hline
\end{tabular}

To help their families pay for basic needs, $8 \%$ of EHS students work two part-time jobs (16 hours per week). Of AHS students, 75\% work from four to six days per week, and of those, $50 \%$ do not have a work permit. The average number of hours AHS students work is five hours per day. Students without a work-permit work six to eight hours per shift; one of the students finishes his shift at 11:30 pm and gets home after midnight. 
Table 5 shows the language proficiency of students at each school as determined by the school administered assessment, the California English Language Development Test (CELDT). The following clarifies the assessment:

Students in kindergarten through grade twelve whose home language is not English are required by law to be assessed in English language proficiency (ELP). In California, the ELP assessment is the CELDT. The CELDT allows schools to identify students who need to improve their speaking, listening, reading, and writing skills. Schools also give the test each year to students who are still learning English (captured 4-3-18 from the California Department of Education website).

Table 5 shows that students at EHS had considerably higher English language skills than the students who transferred to AHS. Ten percent of EHS students were designated as English Language Learners (ELLs), 50\% were designated as Reclassified English Fluent Proficiency (RFEPs) students, and 40\% were classified as Fluent English Speakers. In contrast, $50 \%$ of AHS students were designated as ELLs, $25 \%$ were designated as RFEP students, and 25\% were classified as Fluent English Speaker. The data shows that a majority of AHS students were ELLs, 25\% less were RFEP students, and 25\% less were Fluent English Speakers.

Table 5

Students' English Proficiency Designations

\begin{tabular}{lccc}
\hline & \multicolumn{3}{c}{ Language Proficiency } \\
\cline { 2 - 4 } School & ELD & RFEP & $\begin{array}{c}\text { Fluent English } \\
\text { Speaker }\end{array}$ \\
\hline EHS (12 students) & $10 \%(1)$ & $50 \%(6)$ & $40 \%(5)$ \\
AHS (8 students) & $50 \%(4)$ & $25 \%(2)$ & $25 \%(2)$ \\
\hline
\end{tabular}


Grade point averages (GPA) differed markedly for students at each school. Table 6 shows that EHS students had no GPAs at 1.0 or below, 10\% had GPAs at 1.0 to $2.0,40 \%$ had GPAs of 2.0 to $3.0,40 \%$ had GPAs from 3.0 to 4.0 , and $10 \%$ had a GPA of 4.0 . In contrast, $10 \%$ of AHS students had a GPA of 1.0 or less, $70 \%$ had a GPA of 1.0 to 2.0 , $20 \%$ had a GPA of 2.0 to 3.0. No AHS students had a GPA higher than 3.0.

Table 6

EHS and AHS GPAS

$\%$ of Students in GPA Ranges

\begin{tabular}{lccccc}
\cline { 2 - 5 } School & $\begin{array}{c}\text { Less than } \\
1.0\end{array}$ & $1.0-2.0$ & $2.0-3.0$ & $3.0-4.0$ & 4.0 \\
\hline EHS (12 students) & $0 \%$ & $10 \%(1)$ & $40 \%(5)$ & $40 \%(5)$ & $10 \%(1)$ \\
AHS (8 students) & $10 \%(1)$ & $70 \%(5)$ & $20 \%(2)$ & $0 \%$ & $0 \%$ \\
\hline
\end{tabular}

Table 7 shows the attendance rates of all participants while attending EHS. The students' attendance rates show that $35 \%$ of students attended every class during the fall. In the spring, after the 12 students were transferred to AHS, the rate increased to $75 \%$. The truancy rate in the fall was significantly high. Sixty-five percent of all students received a truancy letter. 
Table 7

Attendance and Truancy Rates While at EHS

\begin{tabular}{lccccc}
\hline & \multicolumn{2}{c}{ Perfect Attendance } & & \multicolumn{2}{c}{ Truancy } \\
\cline { 2 - 3 } \cline { 5 - 6 } School & $\begin{array}{c}\text { Fall } 2017 \\
(20 \text { students })\end{array}$ & $\begin{array}{c}\text { Spring } 2018 \\
(12 \text { students })\end{array}$ & & $\begin{array}{c}\text { Fall } 2017 \\
(20 \text { students })\end{array}$ & $\begin{array}{c}\text { Spring 2018 } \\
(12 \text { students })\end{array}$ \\
\hline EHS (12 students $)$ & $35 \%(7)$ & $75 \%(9)$ & & $65 \%(13)$ & $25 \%(3)$ \\
AHS (8 students $)$ & At EHS & At AHS & & At EHS & At AHS \\
\hline
\end{tabular}

Eight Latino males participants were identified by EHS staff to enroll in EHS classes designed to provide extra support and resources to guide students to become college eligible upon graduation. Data from the interviews revealed that $40 \%$ of the participants from EHS were involved with programs designed to advance their academic progress. At the time of the interviews, $20 \%$ of the participants were enrolled in an Advancement Via Individual Determination (AVID) class. The AVID program prepares students to be college-ready and is designed to guide students to learn what is needed for them to apply and actually attend college. At EHS, AVID teachers support underrepresented students and help them to apply and get admitted to colleges. Fifteen percent of the participants were identified as gifted and participated in the Gifted and Talented Education (GATE) program. The GATE program provides students with opportunities to enhance their skills in their academic areas of strength, to interact with other GATE students, and to have access to differentiated teaching materials to support their needs. Five percent of participants were enrolled in Honors or Advanced Placement classes. 
The interview data revealed that $75 \%$ of the twelve EHS students do not participate in extracurricular activities, while $25 \%$ participate in activities that include soccer, wrestling, and baseball. EHS provides tutoring at its Learning Center in the library after school on Tuesdays, Wednesdays, and Thursdays. Table 8 shows that $67 \%$ of EHS students and $87 \%$ of AHS students did not participate in any after school programs while at EHS. It also shows that $33 \%$ of EHS students participated in one or more after school activity, while $13 \%$ of AHS students participated in one activity while at EHS.

Table 8

Student Participation Extracurricular Activities

Level of Participation

\begin{tabular}{lcc}
\cline { 2 - 3 } School & No activities & One or more activity \\
\hline EHS (12 students) & $67 \%(8)$ & $33 \%(4)$ \\
AHS (8 students) & $87 \%(7)$ & $13 \%(1)$ \\
\hline
\end{tabular}

Table 9 shows participants favorite classes at EHS. EHS students' results show that 25\% selected Spanish and PE as their favorites, while 18\% selected English. Seventyfive percent of AHS students selected math, ELD, Spanish, and no class as their favorites. Not one EHS or AHS student selected AVID, the college preparation class, as a favorite while at EHS. 
Table 9

EHS and AHS Favorite Classes

Favorite Class

\begin{tabular}{|c|c|c|c|c|c|c|c|c|c|}
\hline School & Math & English & ELD & $\begin{array}{l}\text { Graphic } \\
\text { Design }\end{array}$ & Spanish & $\begin{array}{c}\text { Social } \\
\text { Science }\end{array}$ & P.E. & AVID & None \\
\hline $\begin{array}{l}\text { EHS (12 } \\
\text { students) }\end{array}$ & $\begin{array}{l}8 \% \\
(1)\end{array}$ & $\begin{array}{c}18 \% \\
(2)\end{array}$ & $0 \%$ & $\begin{array}{l}8 \% \\
(1)\end{array}$ & $\begin{array}{c}25 \% \\
(3)\end{array}$ & $\begin{array}{l}8 \% \\
(1)\end{array}$ & $\begin{array}{c}25 \% \\
(3)\end{array}$ & $0 \%$ & $\begin{array}{l}8 \% \\
(1)\end{array}$ \\
\hline $\begin{array}{l}\text { AHS (8 } \\
\text { students) }\end{array}$ & $\begin{array}{l}25 \% \\
(2)\end{array}$ & $0 \%$ & $\begin{array}{c}25 \% \\
(2)\end{array}$ & $0 \%$ & $\begin{array}{l}12 \% \\
(1)\end{array}$ & $0 \%$ & $0 \%$ & $0 \%$ & $\begin{array}{c}38 \% \\
(3)\end{array}$ \\
\hline
\end{tabular}

\section{Research Questions}

The research questions for this qualitative study are designed to understand the participants' experiences in their public high school classrooms at EHS. The following is the study's first research question (RQ1): How do Latino male students' perceptions of [EHS] teacher beliefs, expectations, and behaviors toward Latino students impact their relationships with these teachers? RQ1 is designed to identify participants' perceptions of their teachers' views of them to understand how these impressions impact their relationships with their teachers.

The study's second research question (RQ2), focuses on the impact on participants' relationships with their teachers in their classrooms. RQ2 is as follows: How do Latino male students' perceptions of their teachers' authentic caring/auténtico cariño and trust/confianza impact their relationships with their teachers? RQ2 is designed to understand participants' views of authentic caring/auténtico cariño and trust/confianza from and in their teachers. What will be their reactions in classroom settings? Do they 
need to feel authentic caring/auténtico cariño caring and trust/confianza before they will engage in positive behaviors such as asking questions and/or seeking support from their teachers? Additionally, the question aims to find out if students who not do feel authentic caring/auténtico cariño and trust/confianza, initiate or participate in negative, disruptive behaviors.

The study's third research question (RQ3), is designed to elicit information from students to identify ways to direct change in student/teacher relationships, so that students feel welcomed and respected, so in turn they can focus on their learning and engage in positive classroom behaviors. RQ3 is as follows: How do Latino male students' perceptions and relationships with their teachers impact their motivation and academic engagement? The hope is that responses to the question will identify what is needed from teachers for Latino male students to feel that their teachers are people who they can feel safe with, so that they can ask questions and learn in their classrooms. The question is designed to find out what will promote Latino males' participation in class and their engagement in their academic achievement. It is also designed to shed light on how teachers can develop trusting and meaningful relationships with their Latino male students. What can classroom teachers do to convince their students that they authentically care about them to increase Latino male students' classroom engagement to participation to facilitate learning?

\section{Participants' Perceptions of Their Teachers' Beliefs (RQ1)}

Participants' responses to RQ1 identified their beliefs as to how their teachers viewed them as students. They believed that many of their teachers saw them as students who 
did not want to positively participate in class - they were only in their classes to "mess around." Table 10 shows that $42 \%$ of EHS and $62 \%$ of AHS students believed that their teachers viewed them as students who did not want to participate positively in class. Participants explained that they held this belief because their teachers would often abruptly stop them from talking to one another in Spanish. The teachers thought they were off topic, but the participants explained that more often than not, they were asking each other for help about the lesson. Participants also believed that their teachers perceived their greetings of one another as being disrespectful students who were not coming to class to learn. Participants explained that in fact they were saying, "Hello," in a way that was normal for them whereas their teachers saw their behavior as that of troublemakers and not as students. The word troublemakers was used by $90 \%$ of participants in reference to how many of their teachers perceived them. One participant explained:

We are loud. Latinos are loud. We enter a classroom laughing about each other, we are always talking about soccer and about our lives and our families. Our teachers think we are only messing around; that we are loud, noisy, and we are always talkative. What happens is that we are always greeting each other and always think how we support each other at school. We need to feel the connection among us. But teachers think we just don't care. We're just messing around.

The student quoted above describes his behavior as normal, whereas he believes that the teacher sees him as a troublemaker. The teacher's behavior is translated by the student into a belief that his behavior is not student behavior, so his teacher sees his actions as showing that he is deliberately choosing to not be a student in the classroom. 
Table 10

EHS and AHS Student Perceptions of Teachers' Beliefs

\begin{tabular}{lllll}
\hline & \multicolumn{4}{c}{ Student Perceptions of Teachers' Beliefs } \\
\cline { 2 - 5 } & $\begin{array}{l}\text { Students do not } \\
\text { want to } \\
\text { participate } \\
\text { positively in } \\
\text { class }\end{array}$ & $\begin{array}{l}\text { Students do not } \\
\text { want to learn } \\
\text { because they } \\
\text { speak Spanish }\end{array}$ & $\begin{array}{l}\text { Students are not } \\
\text { capable of } \\
\text { learning }\end{array}$ & $\begin{array}{l}\text { Students will } \\
\text { get into trouble } \\
\text { with authorities }\end{array}$ \\
\hline $\begin{array}{l}\text { ShS } \\
\text { (12 students) }\end{array}$ & $42 \%(5)$ & $50 \%(6)$ & $33 \%(4)$ & $33 \%(4)$ \\
AHS & & & & \\
$(8$ students $)$ & $62 \%(5)$ & $63 \%(5)$ & $75 \%(6)$ & $100 \%(8)$ \\
\hline
\end{tabular}

Participants also believed that their teachers saw them as students who did not want to learn because they spoke Spanish in the classroom. Participants made a connection between their teachers' negative responses when they spoke Spanish and their teachers' comments about them not acting as students. In the following, one participant explains this connection:

I was just very frustrated when the teacher over and over said to us, the Spanish speaking kids, that we were just messing around, that we were not really acting [as students]. The teachers show or say so sometimes many times over and over.

This connection takes the point of view that it is the participants who chose not to learn and the evidence for the teachers is that the participants are speaking in Spanish. A number of participants explained that one reason they came to this conclusion was their teachers would often say their names in a negative tone of voice, as if to make them stop talking in Spanish because they were doing something wrong. One of the participants 
supports this point in the following, "Some teachers think that we are saying something inappropriate when we speak in Spanish...that we are planning something, that because we are in a group, we are plotting some kind of scheme [that has nothing to do with learning]." Some participants explained that they felt less than others in the classroom just for speaking Spanish because they believed that their teachers had made it clear that students don't speak Spanish during class time. In the following, a participant articulated what it feels like to have to hide the fact that he needed to speak Spanish as a way to learn in his classroom:

The feeling that I have to watch what I say is not fun. We often whisper in Spanish to help each other with class work, but the teachers would tell us to be quiet 'you are supposed to do the work.' They [teachers] don't understand that we are working and we need to communicate in our language [to get help].

The participant was trying to learn in the classroom using his primary language, but he was reprimanded because his teacher believed that he had his motivation was not connected to his completing his class assignments.

In the above example, the participant believes that his teacher views him as someone who does not want to learn. The next shared perception revealed by participants was that they thought their teachers did not see them as capable learners. Whether they chose to learn or not is no longer the issue. Instead, participants revealed that they believed that their teachers believed that the participants were not capable of learning. Table 10 shows that $33 \%$ of EHS and $75 \%$ of AHS students held this belief. The following participant's explanation supports this view:

They tell us often that school is hard for us, and I don't think they should say that to us and I argue and I disagree with them [when they say I am just messing around] and then I get in trouble. 
This participant is trying to explain to his teacher that when he is told that school is hard it is not helpful to him as student in a classroom. He wants and needs to be heard and viewed by his teacher as a student who wants to and is trying to learn. In trying to make himself understood, he is further misunderstood to the point that his teacher believes that he is now being defiant and he gets into trouble. His perception that his teacher believes that he is a troublemaker and not a student is again confirmed.

This model of polarization of the student as either troublemaker or real student is further compounded by the belief of many participants that their teachers saw their behaviors as such that they would cause them to get into serious trouble with figures of authority. Table 10 shows that $33 \%$ of EHS and $100 \%$ of AHS participants believed that their teachers expected them to get into trouble with school authorities for issues that included arguing with the teacher during class, cutting classes, and not following the school's dress code. Twelve percent of EHS and 62\% of AHS participants believed that their teachers saw them as students who would engage in actual physical fights or verbal altercations. In the following, a participant explained this point, “...the majority of teachers see us as troublemakers...They see us like street fighters like criminals." Sixtytwo of EHS and $41 \%$ of AHS participants believed that their teachers thought that they would be transferred to alternative schools that included the continuation school, AHS, because they were troublemakers.

\section{Participants' Perceptions of Their Teachers' Expectations (RQ1)}

Participants believed that their teachers had low expectations of their academic abilities. When students tried to participate in class, they perceived exasperation on their 
teachers' faces when they asked for clarification of an assignment, as if it was a waste of the teacher's time to even answer their questions. Table 11 shows that $67 \%$ of EHS and $75 \%$ of AHS participants believed that their teachers expected little to no academic achievement from them.

Table 11

Student Perceptions of Teachers' Expectations

\begin{tabular}{lcll}
\hline & \multicolumn{3}{c}{ Teacher Expectations } \\
\cline { 2 - 4 } & $\begin{array}{l}\text { Low academic } \\
\text { expectations of } \\
\text { students }\end{array}$ & $\begin{array}{l}\text { Students not capable } \\
\text { to become college } \\
\text { ready because of } \\
\text { their ethnicity }\end{array}$ & $\begin{array}{l}\text { Students would not } \\
\text { continue their } \\
\text { education in college }\end{array}$ \\
\hline EHS (12 students) & $67 \%(8)$ & $75 \%(9)$ & $67 \%(8)$ \\
AHS (8 students & $75 \%(6)$ & $87 \%(7)$ & $87 \%(7)$ \\
\hline
\end{tabular}

Participants explained that this perception was a result of some teachers' reactions when they tried to participate in class. They felt that their teachers did not welcome their questions and often did not answer them because it was not worth their time. Participants described this treatment as being humiliated and rejected in front of the other students in the class. They explained how painful it was to try to include themselves, but to then be shut down by the teacher. The following participant explains:

I would ask a question, but the teacher would just talk and it was like I hadn't said anything - like I wasn't there. And I raised my hand and she would not look to me. One time, she approached me and asked somebody else, and I was... what happened? I am here. It happened to me like 3-4 times. I just do my own thing now. 
Because the participants believed that their teachers saw them as students with nothing to contribute, the participants believed that their teachers had very low academic expectations of them. Participants believed that if their teachers had high expectations of them, they would have been happy when they raised their hands and tried to ask questions.

Many participants believed that their teachers thought that they were not capable of becoming college ready because of their ethnicity. They explained that their teachers often did not give them feedback to improve their assignments while white students were given much more feedback. Participants perceived these students as the ones who the teachers talked to about their work and their college plans. Participants reported that many teachers chose white students to participate during class rather than the participants. A participant explained, "It makes me think that my participation is not important when I raise my hand. They [teachers] look at me and they ask the white kid next to me or behind me to participate." Participants saw this clear preference as teachers choosing who they thought would be worth spending their time to teach. This reinforced to them that because their teachers did not expect that they would go to college, it wasn't their job to take the time to guide them to improve their academic work. Table 11 shows that $75 \%$ of EHS and $87 \%$ of AHS participants believed that their teachers did not regard them as worth the effort to prepare for college. One participant shared that while meeting with his teacher to discuss his Individualized Education Program (IEP), the teacher said to him, "School is hard for you." The student said that teacher repeated the phrase over twenty times. He laughed and said, "For real." The teachers' behavior made him feel 
that he was not worth teaching because the work was too hard for him. Other teachers made equally hurtful comments to students, and these were in classrooms in front of other students. These included telling participants that they were irresponsible for not finishing their classwork on their own. Participants explained that teachers often made them feel verbally threatened in class by telling them that they would fail their classes and put their graduation at risk. In the following, a participant explains this experience, "When the teachers raise their voices, it means trouble...it is embarrassing to hear the teachers tell you over and over that you are going to fail." Whether the teacher is telling the student that the work is too hard for him, or that he is going to fail, the ultimate message is that the student is not a real student - that his teacher views him as not capable.

In addition to believing that their teachers did not think it worth their time to prepare them for college, participants believed that their teachers did not see them as continuing on to college. Many arrived at this belief because they often heard their teachers ask white students in class about college while never providing any advice to the participants. One student clarified this point, "Not one teacher, not one teacher ever even asked me if I was going to college, but they'd asked the other ones all the time." Table 11 shows that $67 \%$ of EHS and $87 \%$ of AHS participants believed that their teachers did not view them as continuing their education in college. Seventeen percent of EHS participants saw themselves becoming dropouts, while $62 \%$ of the AHS students explained that they saw themselves becoming dropouts to never receive a high school diploma. They did not see a college education as a normal part of their futures. 


\section{Participants' Perceptions of Their Teachers' Behaviors (RQ1)}

The different teacher behaviors that participants identified and shared with me were generated from their experiences when they described their personals ordeals in their classrooms. The teacher behaviors emerged from the participants descriptions during their interviews. The majority of the behaviors participants described were overwhelmingly negative. One of the most common behaviors that participants described was that of being ignored in the classroom. Table 12 shows that $66 \%$ of EHS and $87 \%$ of AHS participants believed that their teachers deliberately ignored them during class. Participants explained that when they raised their hands, their teachers would ignore them for the duration that their hands were raised. One participant said, "Feeling ignored when I raise my hand makes me feel not respected as a person and as a student." In addition to ignoring participants when they signaled that they wanted to participate, some teachers would cut off or speak over participants. Participants explained that often when they start to speak about what was being discussed, a teacher would right away make them feel that they should stay quiet by talking. Table 12 shows that $33 \%$ of EHS and $100 \%$ of AHS students experienced teachers either stopping them altogether or speaking over their verbal participation. 
Table 12

Student Perceptions of Teacher Behaviors in EHS Classrooms

\begin{tabular}{|c|c|c|c|c|c|}
\hline \multirow[b]{2}{*}{ School } & \multicolumn{5}{|c|}{ Teacher Behaviors } \\
\hline & $\begin{array}{l}\text { Not calling } \\
\text { on students }\end{array}$ & $\begin{array}{l}\text { Cut off } \\
\text { students } \\
\text { when they } \\
\text { speak or } \\
\text { speak over } \\
\text { them }\end{array}$ & $\begin{array}{l}\text { Help the } \\
\text { same group } \\
\text { of students } \\
\text { without } \\
\text { helping } \\
\text { them }\end{array}$ & $\begin{array}{l}\text { Negative } \\
\text { body } \\
\text { language }\end{array}$ & $\begin{array}{l}\text { Negative } \\
\text { facial } \\
\text { expressions }\end{array}$ \\
\hline $\begin{array}{l}\text { EHS } \\
\text { (12 students) }\end{array}$ & $67 \%(8)$ & $33 \%(4)$ & $33 \%(4)$ & $75 \%$ (9) & $50 \%(6)$ \\
\hline $\begin{array}{l}\text { AHS } \\
\text { (8 students) }\end{array}$ & $87 \%(7)$ & $100 \%(8)$ & $75 \%(6)$ & $75 \%(6)$ & $75 \%(6)$ \\
\hline
\end{tabular}

One participant shared: "I feel the discrimination when my teacher does not even listen to me and silences me when she puts her voice over mine." This student explains the humiliation he experienced when he had something that he wanted to contribute, but the teacher decided before he even spoke that what he was going to say was not of value in the classroom.

Participants identified another teacher behavior that they described as particularly hurtful to them. They described that many teachers would only help a select group of students. They explained that this group would be helped day after day in exclusion to the teacher helping them. One participant used the phrase, “... white students get the help." Thirty-three percent of EHS and $75 \%$ of AHS participants identified this teacher behavior as negatively impacting them. They explained that feeling that they were being 
treated differently than other students made them less motivated to do anything and made them just not care anymore. One participant explained that he stopped caring about anything. Ninety percent of EHS and $100 \%$ of AHS participants agreed that feelings of being treated differently from other students in the classroom often made them lose respect for their teachers.

Participants also identified negative teacher body language as a behavior that negatively impacted them. An equal percentage, $75 \%$ of EHS and $75 \%$ of AHS participants, reported that they experienced negative teacher body language daily. The following is an example: "I often feel my teacher does not care if I go to class. She sees me and says, "You are here" and other kids walk into the classroom and she greets them with smiles. These actions show me she doesn't want me in her classroom.” The student noticed that she did not smile at him when he entered. He also noticed that the teacher greeted other students with smiles. That teacher's lack of a smile told the participant that he was not welcome and did not belong, while telling other students through smiling that they were welcome and did belong. Negative teacher facial expressions were perceived by participants. Fifty percent of EHS and $75 \%$ of AHS participants witnessed them daily. They included frowns, furrowed eyebrows, squinting eyes, and jaw clenching. An example described by one participant, "When I ask my teacher about the lesson, she often rolls her eyeballs, which makes me feel a nuisance." The participant perceived that he is being told through the rolling of his teacher's eyes that he is not worth her time to teach. 


\section{Participants' Perceptions of Their Teachers' Positive Beliefs, Expectations and Behaviors (RQ1)}

EHS and AHS participants shared that when they perceived that their teachers saw them as real students it made them feel that they were positive and equal members of their classrooms. They felt like real students who belonged. Participants broke down these positive teacher beliefs into three areas: teacher expectations that students can do the work, will do the work, and will ask for help. For these three to be in play, participants explained that they needed to feel that their teachers thought that they were honest and that their teachers trusted them. These two very fundamental values of honesty and trust were very important to the participants in relationship to their perceptions of their teachers' positive belief in them. In Table 13, 58\% of EHS and 50\% of AHS participants believed that the teachers they trusted saw them as honest people. Table 13

Student Perceptions of Their Teachers' Positive Beliefs

\begin{tabular}{lrc}
\hline & \multicolumn{2}{c}{ Teacher Beliefs } \\
\cline { 2 - 3 } School & $\begin{array}{l}\text { Teachers believe that } \\
\text { participants are honest people }\end{array}$ & Teachers trusted participants \\
\hline EHS (12 students) & $58 \%(7)$ & $67 \%(8)$ \\
AHS (8 students) & $50 \%(4)$ & $50 \%(4)$ \\
\hline
\end{tabular}

AHS students expressed that the teachers who they felt believed in them made a difference in their lives by treating them as trustworthy individuals. For example, when their teachers asked them to get an item directly from the drawers, the students felt that they were treated as someone who is trustworthy. This was a key perception for them 
because they explained that they believed that the teachers who treated them negatively did not think they were honest and did not trust them. One participant explained, "That teacher makes me feel like I am going to steal something from her or the class. She looks at me weird like I am a criminal or something." Other students described how they would get this feeling that some teachers were almost afraid of them. Participants explained that the difference between feeling that one teacher thought that they were bad people while another would treat them like they were good people - was a difference like night and day. Participants described how in one class they might feel uneasy and angry while in another, they would feel safe and happy. Their classes were all nearby one another, yet their differing experiences provided them with very different beliefs about their teachers' perceptions of them.

Participants explained that it was the teachers who believed that they were honest people who they could trust and who had high expectations of them as learners. Participants were eager to explain what caused them to believe that their teachers had high expectations. When teachers provided help during class by reviewing the work together or working with participants individually, the participants felt not only that they were a part of the class, but that there was no difference between what the teacher felt for any student in the class. Table 14 shows that when teachers provided participants with help during class, $80 \%$ of EHS and $50 \%$ of AHS participants believed that their teachers saw them as learners and believed that they could do school work. Participants were most excited to talk about the teachers who actually invited them to participate in class by calling on them even when they didn't raise their hands. This made them feel that the 
teacher thought they had something valuable to contribute. One hundred percent of EHS and $80 \%$ of AHS students explained that they knew that their teachers believed in them as good students when they asked them to participate.

Table 14

Student Perceptions of Their Teachers' Positive Expectations

\begin{tabular}{lcll}
\hline & \multicolumn{3}{c}{ Teacher Expectations } \\
\cline { 2 - 4 } School & $\begin{array}{l}\text { Provides help during } \\
\text { class }\end{array}$ & $\begin{array}{l}\text { Invites participants to } \\
\text { participate }\end{array}$ & $\begin{array}{l}\text { Provides help with } \\
\text { homework }\end{array}$ \\
\hline $\begin{array}{l}\text { EHS } \\
(12 \text { students })\end{array}$ & $80 \%(10)$ & $100 \%(12)$ & $75 \%(9)$ \\
$\begin{array}{l}\text { AHS } \\
(8 \text { students })\end{array}$ & $50 \%(4)$ & $80 \%(7)$ & $25 \%(2)$ \\
\hline
\end{tabular}

Another indication that showed them that their teachers saw them as real students was when they would provide help with homework. The teachers that helped with homework, made the participants feel like they were students capable of learning.

Participants also identified positive teacher behaviors that made them feel motivated and engaged to learn. Students wanted to attend their classes. These behaviors included smiling when the students entered and left the classrooms. Also, participants explained that during class, the teachers who smiled and did not show negative body language were the ones they felt safe with. Some of these teachers, instead of rolling their eyes or pointing fingers at them would sit down next to them and go over the lesson. Table 15 shows that $84 \%$ of EHS and $75 \%$ of AHS participants explained that when they were treated in positive ways in the classroom they felt that they could learn. Another 
behavior of the positive teachers was that they would give participants responsibilities during class. These ranged from having students pass out materials to timing activities to being in charge as a leader of an activity. One participant explained, "She would ask me to get the timer and I would know just how to do it. It felt like I was part of it." Table 15 shows that $65 \%$ of EHS and $88 \%$ of AHS students described how being give responsibilities made them feel a part of their classrooms.

Table 15

Student Perceptions of Teachers' Positive Behaviors

\begin{tabular}{llll}
\hline & \multicolumn{3}{c}{ Teacher Behaviors } \\
\cline { 2 - 4 } & $\begin{array}{l}\text { Treating participants } \\
\text { in positive ways } \\
\text { classrooms }\end{array}$ & $\begin{array}{l}\text { Giving participants } \\
\text { responsibility as } \\
\text { learners }\end{array}$ & $\begin{array}{l}\text { Teaching participants } \\
\text { how to organize their } \\
\text { work for success }\end{array}$ \\
\hline $\begin{array}{l}\text { EHS } \\
(12 \text { students })\end{array}$ & $84 \%(10)$ & $65 \%(8)$ & $75 \%(9)$ \\
$\begin{array}{l}\text { AHS } \\
(8 \text { students })\end{array}$ & $75 \%(6)$ & $88 \%(7)$ & $75 \%(6)$ \\
\hline
\end{tabular}

Positive teacher behaviors also included teaching participants how to organize their work. Participants explained that this behavior during class time caused them to know that their teacher not only believed in them as learners and that they belonged, but that what they were learning was part of something larger. They weren't just turning in work and getting it back. They were learning how to "take care" of their work, so it would be stronger. The following provides support of this point, "She cared about how we did our work. It wasn't just papers in and out. The teachers showed me previous work and I 
could see improvement. To see improvement in my work makes me proud and believe that my teacher sees in me potential to learn." Table 15 shows that $75 \%$ of EHS and $75 \%$ of AHS participants viewed their teachers' behaviors as positive when they took that extra step to show them how to get and keep their work in order.

\section{Participants' Perceptions of Their Teachers' Authentic Caring/Auténtico Cariño, Required Caring/Cariño Laboral \& Trust/Confianza (RQ2)}

RQ2 focuses on the impact of students' perceptions of their teachers' authentic caring/ auténtico cariño relationships and trust/confianza and how they impact their relationships with their teachers. During the course of the study, students made a distinction between authentic caring/auténtico cariño and required caring/cariño laboral. The study has included the distinction to better understand the experiences of the participants with their teachers in their classrooms.

\section{Authentic Caring/Auténtico Cariño}

Authentic caring/ auténtico cariño cariño is a complex feeling that students were able to describe based on their perspectives and experiences. When the participants described teachers who they perceived as authentically caring for them, they shared stories of their teachers helping their peers, teachers calling their homes about what happened at school, and positive experiences like feeling like a family in their classrooms. One expression a student shared: "If the teacher supports me, nothing wrong will happen." Another similar phrase was, "She cares for me, she believes in me and has trust in me." Another participant describes authentic caring/ auténtico cariño as follows:

Auténtico Cariño is when the teachers likes you and cares about you. When you are talking she gives you her attention and wants to help you. When they 
[teachers] are hard [strict] but they care. They are like family, you feel like family, you can talk to them about anything. With them you are safe.

Participants did have teachers at EHS who did provide them with authentic caring/ auténtico cariño. It was through describing these teachers that participants came to their definitions and descriptions. Table 16 shows that $20 \%$ of EHS and $12 \%$ of AHS participants believed that one teacher showed authentic caring/ auténtico cariño with complete trust of the student.

Table 16

Student Perceptions Authentic Caring/Auténtico cariño, Required Caring, \& Trust/Confianza

\begin{tabular}{llll}
\hline & \multicolumn{2}{c}{ Level of Authentic Caring/auténtico cariño and Trust/Confianza Experienced } \\
\cline { 2 - 4 } & $\begin{array}{l}\text { At least one teacher } \\
\text { shows authentic } \\
\text { caring/auténtico cariño } \\
\text { with complete trust of } \\
\text { student }\end{array}$ & $\begin{array}{l}\text { Teachers show required } \\
\text { caring without complete } \\
\text { trust in students }\end{array}$ & $\begin{array}{l}\text { Teachers show trust/ } \\
\text { confianza in students }\end{array}$ \\
School & $20 \%(2)$ & $50 \%(6)$ & $30 \%(4)$ \\
EHS & $12 \%(1)$ & $76 \%(6)$ & $12 \%(1)$ \\
AHS & & & \\
\hline
\end{tabular}

Students responded that when their teachers made positive comments about them or their work in the classroom such as, "Good job!" or "Great work!" students felt not only recognized as learners, but also that they belonged in the classroom and these feelings caused them to believe that such teachers authentically cared/auténtico cariño for them. They explained that when teachers approached them and asked, “Are things okay?” or "What can you do to improve the quality of your work?" participants felt that they were 
cared for. This feeling was also generated when teachers gave them opportunities to improve their work and explained to them how to do so. Another teacher behavior that showed authentic care/ auténtico cariño was when there was a human relationship between the participants and the teachers. One form this took was for teachers and students to share stories about their lives outside of class. Participants explained that when a teacher took the time to tell them something meaningful about his/her life, the students felt that the teacher authentically cared for them. Table 17 shows the teacher behaviors that made participants feel that their teachers authentically cared for them.

Table 17

Teacher Behaviors: Authentic Caring/Auténtico cariño to Cause Full Student Trust/Confianza

\begin{tabular}{|c|c|c|}
\hline \multirow[b]{2}{*}{ Teacher Behaviors } & \multicolumn{2}{|c|}{ School } \\
\hline & $\begin{array}{c}\text { EHS } \\
(12 \text { students })\end{array}$ & $\begin{array}{l}\text { AHS } \\
\text { (8 students) }\end{array}$ \\
\hline Teacher comments: Good job! Great work! & $40 \%(5)$ & $25 \%(2)$ \\
\hline Teacher question: Are things okay? & $16 \%(2)$ & $25 \%(2)$ \\
\hline $\begin{array}{l}\text { Teacher question: What can you do to improve your } \\
\text { work? }\end{array}$ & $33 \%(4)$ & $38 \%(3)$ \\
\hline $\begin{array}{l}\text { Teacher advice: How to improve student's school } \\
\text { assignment }\end{array}$ & $33 \%(4)$ & $0 \%$ \\
\hline $\begin{array}{l}\text { Human relationship: Teachers and students share } \\
\text { information about their lives }\end{array}$ & $67 \%(8)$ & $25 \%(2)$ \\
\hline
\end{tabular}

Participants explained that their Spanish teachers were the ones who always showed them authentic caring/auténtico cariño, so they knew that they fully trusted them. In 
addition to treating the participants positively in their classrooms, they would design their lesson plans to include relevant topics that included studying different cultures and current events such as immigration policy. Also, the Spanish teachers provided participants with reliable information that the students brought home to their relatives. These teachers' actions built connections with their students on many levels. Participants described feeling connected to their school work and their home life. They shared that the teachers cared for what affected them in the community. This authentic care from their teachers caused them to feel trust, safe, supported, understood. They were motivated with a sense of responsibility to their schoolwork.

Another way that the Spanish teachers showed the participants authentic caring/ auténtico cariño was through sharing pictures of the places they visited in Latin America. Participants explained that they admired their teachers and called them "very open and knowledgeable of many countries." They saw their teachers as people who had experience working, living, and in contact with underrepresented communities. Participants said that they felt safe sharing some of their challenges with these teachers such as medical insurance issues, immigration appointments, health issues that included theirs and other family members. The authentic caring/auténtico cariño that the participants received from their Spanish teachers translated for many into hope and love hope that they had an ally at school and the love that they needed to feel accepted.

\section{Required Caring/Cariño Laboral}

Required caring/Cariño laboral was described by students as a feeling that their teachers cared about them in a limited way as opposed to authentic caring/auténtico 
cariño. Participants agreed that teachers who had general care for them would make sure to tell them to come to school, do their work, and do their homework. Required caring was a regular and normal caring for someone they interacted with, but did not connect or feel like connecting with. Several participants described the concept of doing the minimum: the teacher is polite, gives the assignment, and collects the work at the end of class. There is no real engagement between teacher and student that leads to trust. A participant explained:

Well, they do care for you but it is a regular type of work care, not a real feeling of care. They do not know us, they just look at how we dress, if we speak Spanish or not, and they tell us to be quiet, because they do not trust us, and that is not caring, because they do not know anything about us. They are always busy, and well, they don't make us feel good. I do not feel this type of care from a family member, it is not a welcoming feeling.

Data from participants' responses showed that very few participants felt that their teachers showed authentic caring or complete trust in them. Table 16 shows that $50 \%$ of EHS and 76\% AHS participants believed that their teachers showed a required caring for them. This impacted their relationships negatively because participants explained that they never felt completely safe and/or wanted as students in their classrooms. One participant shared, "I don't think they want to know about me and my goals. I am just there, and they are just there to teach, nothing else." $\quad$ Participants explained that for them to feel safe to learn, to ask questions, and to participate, required teacher caring was not enough on a daily basis. 


\section{Trust/Confianza}

Participants described trust/confianza as when they are completely sure that the other person has authentic caring for them, so they can feel safe and know that the person sees them as a human being - sees them as an equal in the sense that they are not viewed as less then or others are more important than they are. Participants described that if they have trust/confianza in someone, they are like family for life. They will be there for them always. But participants also shared that trust/confianza is a feeling that they know in their hearts. They explained that it is really a life connection that once put in place, it will be difficult to destroy. The participants described a very strong and very real belief that had great meaning for them. They described the concept of trust/confianza as believing in their word/ en la palabra. Confianza then represents for Latino male students honor and dignity; perceiving that their teachers felt confianza for them was the ultimate for them. One student described his feelings of confianza:

Confianza makes me want to ask for help. I can talk about what goes outside school in my life and my family. I feel my teachers are genuinely concerned of their students' well-being in the class. Feeling human like moment rather than just like a teaching moment. If someone trusts me, I feel that I can care for them. Because my teacher trusts me it helps me to achieve a greater education. She tells us her struggles and to stay motivated.

Confianza for the participants meant love, understanding, acceptance, motivation, sharing, and learning. Participants described that feeling their teachers appreciated their opinions created in them confianza to keep participating. Table 16 shows that $20 \%$ of EHS and $12 \%$ of AHS students felt full trust/confianza in their teachers.

Participants identified teacher behaviors that caused them to trust their teachers.

These included smiling and greeting them when entering the classroom, asking about 
their weekends, and allowing them to be normal in terms of letting them greet each other in Spanish. Additionally, when teachers showed their human side in the classroom by sharing simple everyday information such as if their pets were sick or if their children had a baseball/soccer game, the students felt a complete sense of trust. Table 18 lists teacher behavior that produced student trust. Select students opted to not answer the following questions.

Table 18

Teacher Behaviors That Cause Student Trust/Confianza in Teachers

\begin{tabular}{lcc}
\hline & \multicolumn{2}{c}{ School } \\
\cline { 2 - 3 } Teacher Behaviors & EHS & AHS \\
\hline Teachers greet and welcome students with smiles & $33 \%(4)$ & $25 \%(2)$ \\
Teachers ask about students' lives & $0 \%$ & $0 \%$ \\
$\begin{array}{l}\text { Teachers tell students simple things about their lives: } \\
\text { pets, children's sports events, weekend plans or events }\end{array}$ & $40 \%(5)$ & $13 \%(1)$ \\
\hline
\end{tabular}

The participants shared that feeling trust in their teacher was very necessary for them. Feeling trust meant for them to feel safe - safe to think, to participate, to feel part of the classroom, feeling en familia to collaborate. Participants explained that trust was a difficult feeling to reach. They knew that their teachers trusted them and they were not going to risk losing that trust. Participants mentioned that the trust they felt would enable them to ask for help if they needed it. Participants expressed that when teachers trusted them they moved freely in the classroom; they were not distracted watching where the teacher was or when they were going to call them out for doing something wrong. 
Participants explained that trust was reciprocal "both ways' and they would show trust in return. Students often valued when teachers shared personal life experiences:

I feel safe and like I can speak my mind. Instead of being just a student, when the teacher trusts me I feel better participating, less stress and not embarrassed if I make a mistake. Trusting my teacher has resolved many problems for me. I know I have someone that can understand me. My teacher helps me to resolve my problems.

Participants believed that trust was the foundation of their positive experiences as students at EHS. They valued feeling trusted and trusting their teachers.

Many of the factors that students identified as causing them to perceive that their teachers had negative views of them as students also were responsible for participants being unable to fully have trust/confianza in their teachers. Major factors included negative teacher comments about their work and behavior, being ignored during class, and teachers' body language and facial expressions that showed that the teachers did not welcome them. Several students explained that being or feeling singled out proved a student's point about how teachers' body language and facial expressions made them feel unwanted. One said, “Even though I didn't do something, the teacher would think it was me and point her finger at me and say, 'Please go to the main office'." The negative teacher behaviors made it near impossible for participants to develop trust in many of their teachers.

\section{RQ2: Analysis of the Participants' Responses}

Although participants did experience many positive teacher beliefs and behaviors, they experienced many negative interactions with their teachers. The lack of trust or of having no close relationships with their teachers hindered their academic progress. It 
stopped them from seeking help and often left them with a feeling of being alone, not supported, which in turn caused them to lose motivation. Many lost a sense of engagement. Participants' feelings of authentic caring/auténtico cariño and trust/confianza are essential factors for the positive engagement of Latino male students in schools in order to prevent the short circuiting of future educational aspirations at the college level.

\section{RQ3: Teacher Relationships: Impact on Participants' Academic Motivation \& Engagement}

Findings suggest that student/teacher relationships profoundly impact students' motivation and academic engagement in the classroom. Participant responses overwhelmingly identified destructive student behaviors generated by perceptions of negative student/teacher relationships. Participants described behaviors that spiraled downwards starting with not raising their hands because their teachers would not call on them to not attending classes at all to transferring to the continuation school. First, students stopped raising hands when they found that they were not called on to participate in class discussions. Next, many stated that they could not focus in class because of their perception of negative teacher attitudes towards them. Students then stopped doing assigned academic work during class. Many students stopped participating altogether and felt great anger and frustration. Students stopped caring about anything to do with the specific class and some disrupted the class. Finally, students stopped attending classes in which they had negative student/teacher relationships. Table 19, shows the percentages of the participants who described exhibiting the behaviors described above. 
Table 19

Participant Behaviors Triggered by Negative Student/Teacher Relationships

\begin{tabular}{lcc}
\hline & \multicolumn{2}{c}{ School } \\
\cline { 2 - 3 } $\begin{array}{l}\text { Repercussions of Negative Student/Teacher } \\
\text { Relationships }\end{array}$ & $\begin{array}{c}\text { EHS } \\
(12 \text { Students })\end{array}$ & $\begin{array}{c}\text { AHS } \\
\text { (8 Students) }\end{array}$ \\
\hline Students stopped raising their hands during class & $58 \%(7)$ & $87 \%(7)$ \\
$\begin{array}{l}\text { Students could not focus in class due to teachers } \\
\text { behavior }\end{array}$ & $25 \%(3)$ & $75 \%(6)$ \\
$\begin{array}{l}\text { Students stopped doing in-class assignments } \\
\text { Students stopped participating at all during class } \\
\text { time }\end{array}$ & $25 \%(3)$ & $100 \%(8)$ \\
$\begin{array}{l}\text { Students were angry and frustrated } \\
\text { Students stopped caring about anything during } \\
\text { class }\end{array}$ & $58 \%(7)$ & $50 \%(4)$ \\
Students disrupted the class through their behavior & $25 \%(3)$ & $63 \%(5)$ \\
\begin{tabular}{l} 
Students stopped attending classes \\
\hline
\end{tabular} & $25 \%(3)$ & $63 \%(5)$ \\
\hline
\end{tabular}

Not all participants exhibited negative classroom behavior motivated by poor student/teacher relationships. Instead, many developed coping skills to allow them to stay in the classroom with a minimum of negative interactions with their teachers. They explained that when they did not feel authentic caring/ auténtico cariño from their teachers, they would listen quietly to the teacher's instructions and do everything asked of them to be what they considered normal and typical students. When asked to describe what they meant by a typical student, they described a student "... who wants to be invisible, not noticed by teachers, quiet and doing work and finishing quietly." Table 20 
lists participant identified behaviors they felt and exhibited. The findings suggest that the students had to endure a thick layer of rejection and neglect, so they could fortify themselves to withstand non-caring teacher behavior. Ninety percent of EHS students remained silent during entire class periods. Ninety percent of the students waited until after class to seek help with assignments. Neither behavior is conducive to classroom learning.

Table 20

Student Responses to Teachers Who They Believe Do Not Authentically Care

\begin{tabular}{lcc}
\hline & \multicolumn{2}{c}{ School } \\
\cline { 2 - 3 } Student Responses & $\begin{array}{c}\text { EHS } \\
(12 \text { students })\end{array}$ & $\begin{array}{c}\text { AHS } \\
(8 \text { students })\end{array}$ \\
\hline Student remains silent during entire class period & $90 \%(11)$ & $38 \%(3)$ \\
Student works to be invisible in classroom & $50 \%(6)$ & $10 \%(1)$ \\
Student is afraid of the teacher & $10 \%(1)$ & $0 \%$ \\
$\begin{array}{l}\text { Student ignores distressing feelings to remain in the } \\
\text { classroom }\end{array}$ & $16 \%(2)$ & $38 \%(3)$ \\
$\begin{array}{l}\text { Student lost interest in building relationships with } \\
\text { teachers }\end{array}$ & $10 \%(1)$ & $87 \%(7)$ \\
Student seeks help outside of the classroom & $90 \%(11)$ & $25 \%(2)$ \\
Student stopped speaking Spanish in the classroom & $33 \%(4)$ & $38 \%(3)$ \\
\hline
\end{tabular}

Several AHS participants explained that knowing that they had to attend classes at EHS affected their entire day in a negative way. They did not want to go to school, so they would have to talk themselves into going. They said that they attended their classes 
with feelings that when they got to class they thought that they were going to get into a fight with their teachers. They described how they would walk into a class and either the teacher would see them and send them out to see an administrator or they would be asked for past homework. For the students to feel put on the spot was just too much, so they explained that they just left. They shared that when they did seek an opportunity to return to class, they were almost always met with a request to leave the classroom. Sixty percent of EHS students said that the teacher would set the tone of the class with them, either using a sarcastic tone or with demanding words that made the students feel powerless and angry. The AHS students shared that they felt treated unfairly by their teachers while at EHS. One hundred percent of AHS students believed that their teachers did not want them to attend their classes which made it extremely painful for them to try to belong. They explained that because they did not feel safe, welcome, or accepted in EHS classrooms, they could not focus on academics to learn. Ninety percent of the students that remained at EHS only want a high school diploma and then to disappear from the school system, while $100 \%$ of AHS students view themselves as drop-outs for being at the continuation school.

The impact of a lack of positive and/or encouraging relationships with teachers affected the AHS students to the degree that they lost hope in themselves as students. They lost hope in their ambitions by believing that they do not belong in public schools. Thinking/perceiving that teachers did not expect anything good from them for being Latinos males created an educational debt that will continue to increase if teachers are not aware of the power they have in either making students feel normal and welcome as 
learners or unwelcome as those who do not belong in educational institutions.

\section{What Motivates and Engages Latino Male Students in Schools?}

Many participants described how meaningful it was to them when teachers showed them some form of kindness in the classroom. They explained how it felt to believe that their teachers thought that they were students who belonged in the classroom. Table 21 shows a breakdown of motivating teacher behaviors and the percentage of participants that were motivated to engage in school, and most importantly, in learning because of these teacher behaviors.

Table 21

Motivating Teacher Behaviors

Teacher Behaviors $\quad \%$ of Participants

Teachers' affirmations (good job! Keep up the good work!) $\quad 80 \%$ (16)

Teachers' body language (smiles/ thumbs up) $\quad 80 \%(16)$

Teachers' cariño and confianza towards their students $\quad 100 \%(20)$

One participant explained, "When she reads my paper and looks up and smiles, it feels like so good. I just feel good." Other participants described that phrases like "Good job!" and "Keep up the good work!" made them feel motivated and happy in the classroom.

Participants explained that when they felt safe in a classroom, when they could find trust in the teacher and felt that the teacher authentically cared for them, they felt eager to participate without fear of being rejected or humiliated. Additionally, when participants found a deep connection to the subject and to the concepts being taught, they felt 
motivated and engaged. When this was the case, they explained that the teachers were not rude. They were respectful. One student shared:

I feel inclined to ask for help, I felt connected to teachers, students help each other, the more I work in the classes, the easier they will become, I like to see thumbs up, they recognized my efforts, they (teachers) show gratitude and they make me work harder, I will work harder to impress my teachers.

The above quote reflects the positive impact of feeling authentically cared for. This feeling makes the students feel motivated and engaged, as supported by a relationship of trust. They would often ask questions directed to the teachers and they would ask questions without hesitation. They explained that they did not feel less than any other students in the class. They expressed that the teachers would give them motivation and a feeling of responsibility, a feeling of respect and of duty to impress and continue a positive relationship with their teachers. The students would prove to themselves and to their teachers that they were capable of doing the work and that they would put forth much more effort in their work.

\section{Summary of Findings}

An alarming majority of participants in the study did not feel welcomed or wanted as high school students based upon their perceptions of their teachers' classroom behaviors directed at them. Participants clearly identified the teacher conduct that made them feel less then as students. These included not greeting them with a smile, failing to call on them, and commenting publicly that they would most likely fail. Participants explained that they could not trust or feel safe with teachers who treated them negatively.

The impact of the teachers' negative behaviors set off a chain reaction that led eight out of the twenty participants to enroll in the continuation school, a school that clearly 
was not designed to keep the students on a path to college. A number of the participants who opted to stay at EHS did so under circumstances that caused them to not speak during class, not ask for help, and to be afraid of their teachers. But even though twelve participants remained at EHS, only one stated his intention to continue on to college. For

eleven of them, school was a negative experience that had to be endured. It was not one that allowed them to grow as academic achievers.

The students that did feel that their teachers authentically cared for them, and so the students could trust them in turn, also identified very specific teacher behaviors. These included making them feel welcome and wanted through greeting them with smiles, asking if they were okay, and telling them ways to improve their work. But even the majority of these students did not see school as a resource for them to thrive and to believe that they should continue their education in college.

What the participants ultimately witnessed and reported was that their school was for a group of students, but they were not included. The group that the school was for were told about college, given more help with their assignments, and were greeted daily with smiles. What was so painful was that this all happened right in front of them as if they did not exist. But many of their teachers did let them know that they existed. They let them know that they existed to get into trouble, to not learn, and to not go to college.

\section{The Eight Teachers at EHS}

Without doubt the Spanish teachers (all white educators) were the most effective teachers to build relationships with the twenty participants. Forty-five percent of the students admitted that in their Spanish class they felt safe to speak up, participate, and 
most important: they felt emotionally safe to speak their native language. In this class they were not "getting in trouble", their teachers understood their expressions and dialogs and they were not scolded to help each other in the language they felt comfortable speaking. Common phrases from the students were: "I talk to everyone in the Spanish class; we are all friends there; he/she [teacher] knows we are not messing around]." The constant pain of cutting their language makes students feel emotionally unsafe. The skill of being bilingual provides these teachers the opportunity to connect and learn from their students. Sharing the same language reduced the risk of being called "troublemakers" and "getting into trouble". In addition to the Spanish teacher, the other five teachers who the students felt the connection with, embraced the moral responsibility to provide a safe space for their students. These teachers responded to their needs and put aside the demands of the institution to dedicate a personal connection to their students; they provided the human warm, the human kindness that made the Latino male students feel the connection and the respect given towards them.

Teachers that showed their auténtico cariño for their Latino male students obtained respect in return. The students valued their teachers. Some of the manifestations of authentic caring was simply that these teachers created multiple opportunities for their students and invested their time to create a place of conviviality where the teacher was willing to share and learn with and from students. Teacher learned about their students' needs and challenges so well that they adapted their teaching to the needs and interests of their students. In was in this environment that participants explained that they felt validated as students who were capable of learning. They described that they felt that 
they belonged and this feeling of belonging was constantly reinforced for them by their teachers' positive beliefs, high expectations, and supporting, encouraging behaviors.

Internalized racism came to the surface when the students shared their stories of discrimination and deficit thinking in the classrooms. Not only their academics, engagement, emotional wellness, and prosperity were at risk, they were also injected with disdain towards their Latino peers, family, background, and community. Thirty-five percent (7 students) of the twenty students expressed that "it was the troublemakers' fault" that teachers didn't like them or saw them as people who didn't care. Their body language and verbal expressions towards their parents was not good. Manifestations of seeing the Latino culture low and without strength had proven to these $35 \%$ percent of students that their better option was to reject their origins.

\section{Conclusion}

Participants' beliefs about their teachers' perceptions of them caused $40 \%$ of them to first stop participating in class, next, to stop doing work, and then to finally stop attending classes at EHS as a way to cope with feeling of being unwanted and rejected - feelings of not belonging. Negative relationships between Latino male students and their classroom teachers destroyed participants' chances for academic success. Ninety percent of participants expressed that they didn't feel safe to participate in all of their classes, to raise their hands, and/or ask questions. The majority of the students at EHS asked their friends, their peers, but not their teachers for academic support. Participants expressed that it was difficult to feel trust/confianza for and from many of their teachers because they did not have a relationship with them. 
Negative teacher beliefs, expectations, and behaviors in the classroom created negative student perceptions that affected the participants' feelings of rightfully belonging and being valued in their school. Negative expectations from their teachers caused them to view themselves as not real students. The power of the teachers' classroom behaviors - even a look or a gesture - towards the participants caused them to feel that they should not even be in class. One participant explained, "I walk into her classroom and she stares [at me] with a mean look on her face. That is my relationship with my teachers." This participant finds nothing inviting to bring him into class. Most of the time it led to his being sent to the office for defiance. Participants explained that even if a teacher did show required caring/cariño laboral for them, it was not enough to make them feel and believe that they were really welcome and accepted as real students in their classrooms by their teachers.

The opportunity of listening to the students' voices made me truly comprehend the differences between authentic caring/auténtico cariño and required caring/cariño laboral. Latino students' interpretation of cariño laboral is powerful. Eighty-five percent of participants identified that the term, cariño laboral (work love), is the type of caring that a majority of teachers exhibit to their students. They explained that this type of relationship had rules like at work: they show up, they do their work, and then they leave. There is no authentic caring. They just do what is expected of them, but if they have any problems with the routine, then there is trouble. One participant explained this concept:

...If you like your boss, everything is cool, if you hate your boss, is not cool. And your boss kind of hates you because there is tension, so it's like... "Oh, I don't even want to work for you because you don't even like me, so why should I like you and there is always a conflict. 
Auténtico cariño or authentic caring then is a complex feeling that connects and evolves through confianza/trust, but also includes challenges, respect, and compromises. There is enough trust felt so that challenges and compromises can be positively experienced by students. Confianza meant seeing the teacher as someone able to listen, to help with problems, to be made to feel less nervous in class, and to check that all was okay.

Eight teachers' names were constantly repeated among the twenty participants. Of these, four were Spanish teachers. It was the Spanish teachers who provided the participants with authentic caring/auténtico cariño and trust/confianza and provided them with meaningful and relevant assignments. The positive and productive relationships that these teachers built through their culturally responsive approaches with their Latino male students supported the participants to feel welcomed, valued, and accepted. The importance of feeling sincerity, acceptance, love, respect (for who they are, how they dress, how they talk, their physical appearance) made the students feel safe, secure, nurtured and supported to be open, to ask for help, seek help, and feel that their teachers genuinely care for them. 


\section{Chapter Five: Discussion, Recommendations, \& Conclusions}

\section{Discussion}

Findings in this study suggest that when Latino male high school students are met in their classrooms with negative teacher behaviors they often lose motivation and then disengage from their academic work which in turn short circuits their high school academic progress. Another finding suggests that positive teacher behaviors allow students to trust them, so that in turn they are motivated and then engage to do their academic work.

This study worked to identify what changes teachers can implement in their classrooms to welcome Latino male students to cause them to feel that their teachers have authentic care/ auténtico cariño and trust/confianza in and for them. These teacher changes can start to pay down the educational debt that has accumulated over decades and is owed to many disenfranchised and marginalized Latino male youth who have suffered and continue to suffer teacher rejection and hostility in high school classrooms (Ladson-Billings, 2006). This rejection and hostility often results in these students either ending their education at the high school level or dropping out altogether. Too many of these students do not continue on in college. They are being derailed in high school classes.

In California, a majority of students are Latinos. However, few Latino students graduate from high school college-ready to enroll in a four-year university, and many who are not college ready do not enroll in community colleges. One reason for this lack of college preparation is that a large number of Latino youth do not complete their high 
school education at a comprehensive school. Instead they are directed to alternative high schools such as continuation schools or court and community schools. Many of the students who are pushed into alternative schools' settings are not challenged academically and often become involved with drugs and gangs - involvements that often lead them into the criminal justice system. Those who do not make it to the alternative schools simply drop-out altogether and do not receive a high school diploma. This study was designed to identify reasons why Latino male high school students are not graduating from their comprehensive schools with the hope that change can be implemented to support and guide them in their academic pursuit of a high school diploma and for them to then take the next step to continue on to college - all as a normal pathway in their lives.

The study also viewed participants' academic engagement and motivation in relationship to their feelings about their teachers' abilities to show authentic care/cariño and required caring/ cariño laboral for them, and participants' feelings of trust/confianza in their teachers. The study sought to identify the impacts - both positive and negative of student/teacher relationships on students' motivation and engagement specifically in the classroom.

Participants' responses identified two key themes that emerged through the analysis of the data. These themes identified what hindered or helped participants to engage to be motivated to learn. Data from the study identified the theme many of the participants believed that they were treated negatively by their teachers because teachers did not see them as legitimate students, so they did not expect them to learn the material in their 
daily lessons. Participants identified teacher behaviors that led them to this conclusion. These included hostile/angry greetings, failure to include participants in the daily lessons by not inviting them or ignoring their requests to participate, and verbally connecting participants to academic failure. Participants also identified negative teacher body language as indicators such as eye rolling and pointing fingers. Many viewed their teachers' as having dismissive, fatalistic views of them because of the participants' behaviors in the classroom such as speaking in Spanish. Participants explained that when they spoke in Spanish to get help with their assignments with other students, teachers would label them as "messing around." The theme of the real student exposed an inability of the teachers to understand the motivation for the participants' actions in class. Instead, teacher behaviors often became negative reactions based on a lack of understanding of the participants' true intentions. These misinterpretations of the participants' behaviors often short circuited many participants' learning either through reprimands or asking students to leave the classroom.

Another theme that emerged from the data was that when participants believed that a teacher authentically cared for them, participants could feel complete trust in them. In turn, participants could then learn in the classroom. At the base of this theme of teacher caring are two aspects that the participants' described as authentic caring/carino and trust/confianza. When participants believed that their teachers authentically cared about them then they could feel trust and in turn feel safe in the classroom. Student feelings of authentic caring/auténtico cariño and trust/confianza supported positive 
participant/teacher relationships that led to participant motivation and engagement in their academic work.

However, participants distinguished two types of teacher caring: authentic caring/ auténtico cariño and required caring/cariño laboral. This was an important distinction because participants explained that they could not fully trust their teachers who they believed only cared for them in a general sense. While identifying caring behavior, participants' responses showed a need for them to believe in the authenticity of the caring. Teachers could not simply smile and greet them to show care. They needed to go deeper to share, for example, personal stories.

A major finding in the study identified that a majority of participants perceived that their teachers' beliefs about them were primarily negative, disrespectful, and non-caring. Seventy-five percent of AHS students and 33\% of EHS students perceived that their teachers believed that they were not capable of learning. Additionally, $58 \%$ of AHS students and $50 \%$ of EHS students believed that they did not want to learn because they spoke Spanish in the classroom. Because of these student perceived teacher beliefs, $88 \%$ of AHS students and 5\% of EHS students lost interest in building positive relationships with their teachers. This finding could illuminate part of the answer to the question, "Why do so few Latino males continue on to college?"

If a majority of Latino male students feel that they are treated negatively by their classroom teachers, they are most likely not going to be able to learn from those teachers. By extension, they will not have had the preparation necessary to successfully undertake college level work. But more pressing is the issue that the negative treatment they 
receive in their high school classrooms in fact causes them to view education in general as not for them. Initially, the classroom treatment by their teachers caused them not to engage or be motivated to learn. Next, the treatment over time cause many to give up on their learning at school altogether. Seventy-five of AHS students and 25\% of EHS students stopped attending classes. An implication of these negative experiences with public education is that they lead Latino males to conclude that education is not in their future; hence, many Latino males as influenced by their experiences in public high schools are not going to venture another encounter with learning at the community college level, the place that they can go to despite the educational debt their high schools have incurred to them. Data from the study shows that $40 \%$ of the participants transferred to the continuation high school, a school that is not on a college path, while $90 \%$ of participants said that they did not plan to continue their education in to college. The participants who did not transfer to the continuation school explained that they just wanted to earn their high school diploma and leave school as soon as possible.

An additional finding emerged from the study was that the participants saw themselves as being treated much differently than their white peers. They felt that their teachers considered and treated the white students as real students while they were troublemakers who had no desire to learn and were very difficult to teach. Participants identified specific teacher behaviors that led to their beliefs. Seventy-five percent of AHS students and $33 \%$ of EHS students believed that their teachers only helped the same group of students without helping them. Participants explained that their teachers, during class time, would talk about college plans with these select groups of students without 
including them, as if they were not going to college. Seventy-five percent of AHS students and $65 \%$ of EHS students believed that their teachers saw them as students who would not continue their education in college.

The study also found that participants linked negative teacher behaviors towards them to their own responses which ranged from questioning the teacher in class - a reaction that often led to participants being expelled from the classroom - to eight of the participants leaving EHS altogether to transfer to the continuation high school. $75 \%$ of AHS students and $25 \%$ of EHS participants reported that they disrupted their classes. These findings illustrate a loss of learning time through daily negative interactions with teachers. This in turn led to a loss of college preparation. One hundred percent of AHS students and $25 \%$ of EHS students stopped doing classroom assignments altogether. These findings show that Latino males suffer a loss of learning time and opportunities through negative interactions and relationships with their classroom teachers.

Additionally, the twelve participants who stayed at EHS articulated that they had to develop strategies such as talking themselves into going to class every day, becoming invisible in the classroom, never raising their hands or asking questions, and overcoming their fear of their teachers. Twelve percent of AHS students and 50\% of EHS students responded that they worked to be invisible in their classes. None of the AHS students and $10 \%$ of EHS students reported being fearful in their classes. Many participants shared that their daily experiences in their classrooms caused them to feel that school was not a safe place for them. These findings show a comprised solution for the participants who stayed at EHS that is far from what many saw as the behavior of real students: 
asking for help and being invited to participate. The participants' behavior showed that they did not feel wanted, but they wanted to learn, so they attended their classes and worked to complete their assignments. Because many of the students - $38 \%$ of AHS students and $41 \%$ of EHS students - remained silent during class time, they had to seek academic help outside of class. Twenty-five percent of AHS students and $90 \%$ of EHS students responded that they sought outside help to complete class assignments.

While the majority of participants did not feel authentic caring/auténtico cariño and trust/confianza, $15 \%$ of AHS students and $20 \%$ of EHS students believed that at least one of their teachers showed authentic care/ auténtico cariño for them. Their belief in their teachers authentic caring/ auténtico cariño caused 12\% of AHS students and 30\% of EHS students to have full trust in their teachers. Participants' identified teachers' behaviors that caused them to feel authentically cared for included teachers asking them if they were okay, giving them praise in the classroom, and telling them things about their own lives such as the health of their pets and the sports events of their children. Twenty-five percent of AHS students and $42 \%$ of EHS students responded that the teachers they could trust gave them praise during class. Additionally, $25 \%$ of AHS students and $25 \%$ of EHS students explained that they developed trust in their teachers through their teachers sharing personal information about their lives that included talking about their children's sporting events. These findings show that some classroom teachers did develop authentic caring relationships that were based on positive teacher behaviors.

Participants also identified that their teachers who they believed authentically cared for them engaged in other behaviors that caused them to feel that they were legitimate 
students in their classroom. These behaviors included inviting students to participate, giving them responsibilities during class activities, and asking them if they were okay. Participants identified that their Spanish teachers were the ones who they could fully trust. They explained that they felt that these teachers saw them as legitimate students. These teachers also prepared lesson plans that had connections to their culture and to issues that their family members were facing such as immigration concerns. Participants explained that the themes in these classes were ones that they take home and talked about with their families.

Although, one might feel relief in knowing exactly what some teachers did and did not do to cause participants to view themselves as legitimate students or not, there is the implication that institutionalized racism lies at the foundation of the teachers' negative classroom behaviors toward Latino males. Many of the participants made connections between their negative treatment by their teachers and their white peers' treatment between their speaking their native language, Spanish, and their perceptions of their teachers' negative reactions to them doing so. If in fact the negative treatment is a result of institutionalized racism, then it will require a focused determination to bring awareness to leadership at both the administrative and teacher level. Figure 1 represents the different types of teacher/students relationships as perceived by the students. Authentic caring is influenced by a reciprocal feeling of respect and trust, which as a result leads to academic engagement. 


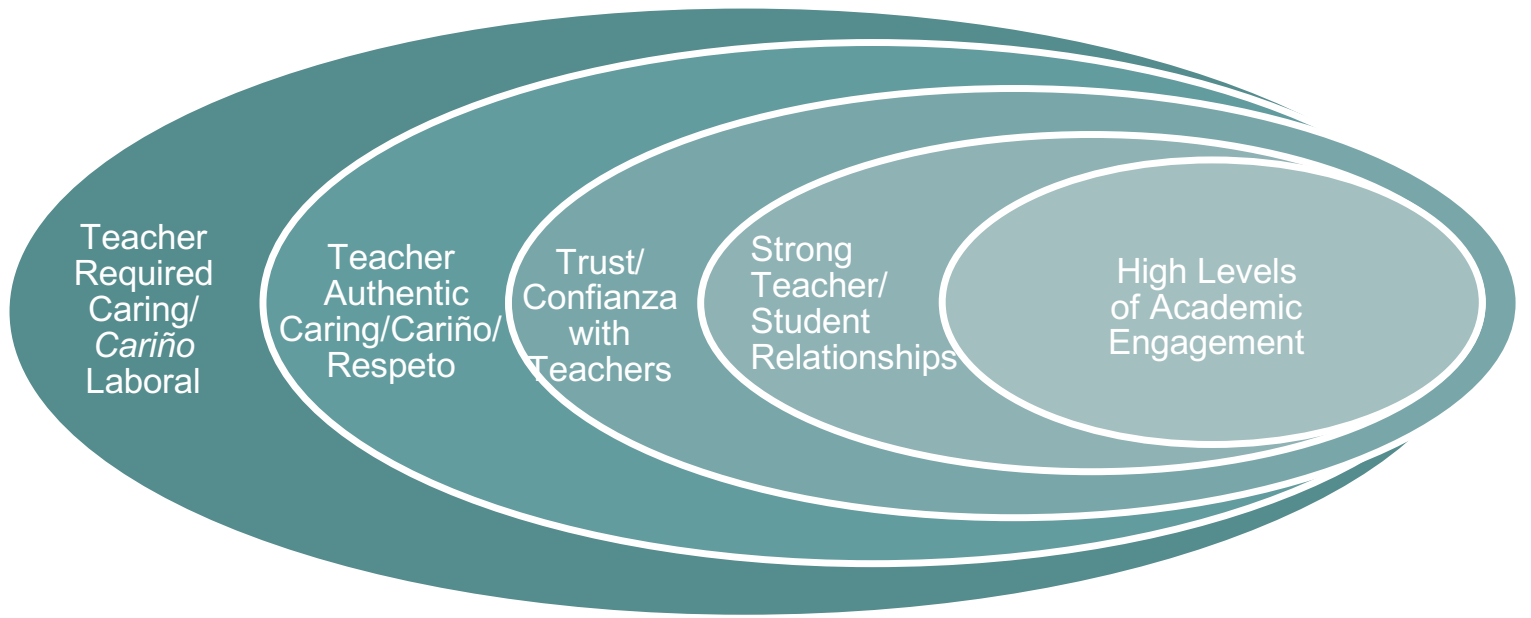

Figure 1. Conceptual framework described by nested ovals that represent the different levels of teacher-student relationships. The size of the ovals represent the ease with which the relationship is achieved. We can then compare the size of each of the first four ovals (relationship ovals) to the size of the last oval, which represents high levels of academic engagement achieved by students (outcome oval), to see the likelihood of this outcome given this relationship level. The bigger the overlap between the outcome and relationship oval the more likely it is for students to achieve high levels of academic engagement given such a relationship.

Grounded theory approach supported the development of this study's theoretical framework. This is based on the participants' experiences as students developing motivation to reach high levels of academic engagement.

\section{Recommendations}

Findings in the study suggest that a majority of participants felt unwanted and were viewed by some of their teachers as unfit to be students. Additional findings also determined that some teachers who caused participants to feel authentic care/auténtico cariño and trust/confianza from and in them provided participants with opportunities to 
build trust and develop authentic caring relationships necessary for them to feel that they too were students who belonged in their classrooms where learning was a normal and important part of their lives.

The study's aim is not to point fingers at those teachers whose behaviors caused participants to feel unwanted and uncared for so that they could not build trust in their teachers, or to give praise to those teachers who did cause participants to feel that they were wanted and authentically cared for, but instead the fundamental purpose is to provide recommendations as to how best to support Latino male students in their high school classrooms so that they feel they are legitimate students whose place is in classrooms to learn as they prepare for a college education.

Findings suggest a need to provide training for school leadership at the administrative, staff, and teacher levels. To provide effective training, time and space is needed for the administration, teachers, and staff to reflect on their daily practices and approaches to recognize that their Latino male students' perspectives about their beliefs, expectations, and behaviors have the ability to create a culture and climate of mistrust, fear, and ultimately separation that leads to many students perceiving their teachers as not including, wanting, or viewing them as real students. Again, $40 \%$ of the study's participants transferred to the continuation school thus diminishing their likelihood of continuing on to college.

Ninety percent of the participants who stayed at EHS stated that they just wanted to earn their high school diploma and then quit school altogether. To change this reality, the study's findings suggest the need for administrators, staff, and teachers to listen to and 
then hear the participants' voices. Their responses are rich sources that have the power to cause change. If teachers could understand the power they have as evidenced through the participants' voices then they could understand that their behaviors can be deciding factors if students stay in school to learn or quit because they do not feel welcome or included. It is the inclusion of the participants' voices that is key to understanding the depth of the issue and of understanding what can be done to implement change sooner than later.

Students' voices and responses in the study identified the necessity to use different methods of instruction where students learn and relate to one another, especially to their teachers. In the study, participants claimed that their favorite classes were their Spanish classes because they combined both authentically caring teachers they could trust with rigorous lesson plans that showed them that their teachers believed them to be capable students. Participants explained that their Spanish teachers provided them with authentic care/cariño, so that they could feel complete trust/confianza in return. The rich environment that they found in their EHS Spanish teachers' classrooms supported the participants to bring their best learning abilities and positive behavior to school every day, so they could engage and be motivated in class to learn.

\section{Recommendation 1: Provide Leadership Training for Administrative Staff Based on Student Identified Classroom Behaviors of Teachers and Students}

The findings suggest that there is a clear lack of understanding by their teachers of the participants' behaviors in classrooms. Many teachers interpreted the participants' behaviors as being defiant and indicative of a will not to learn. Sixty-two percent of AHS students and $42 \%$ of EHS students believed that their teachers saw them as students who 
did not want to participate positively in class. From the participants' perspectives, these teacher interpretations could not be further from the truth. The findings indicate an action-reaction misinterpretation that seemed to be unable to be stopped once it was set in motion. As the participants sought indications of their teachers' authentic caring for them, the teachers' behaviors showed them that they did not care. Eighty-seven percent of AHS students and sixty-six percent of EHS students explained that their teachers purposely did not call on them when they raised their hands in class, thus showing that they did not care about them to the point of ignoring them.

At the administrative level, leadership could facilitate an understanding of the triggers on the parts of both teachers and students that set off the often chain reaction that result in many Latino male students' perceptions that their teachers do not view them as real students and the participants' own view that they will not continue on to college. Ninetyfive percent of the participants stated that they did not plan to continue their education in college. The study revealed that teachers' behaviors in the classroom matter a lot to the success or failure of Latino males in high school and, by extension, the likelihood that they would continue on to college.

Providing leadership training at the administrative level will work to build a solid understanding of what is at stake and how to address the issues. The participants revealed that their daily treatment by their teachers in classrooms can make or break their sense of themselves as learners. By first ensuring that leadership at the administration level fully understands the issues, then a constructive plan can be developed to next work with teachers. 
Once the administrative leadership fully understands the task at hand and has developed a systematic plan for change, the next step would be to provide training for classroom teachers. With the administrative leadership fully trained, the administrative team then becomes the support system for classroom teachers. The findings suggest that participants and teachers viewed the classroom behavior issues in isolation - ships passing in the night - that did not inform the other, but often led to disruptions of learning for students and teaching for teachers. The findings suggest that a third party such as administrative leadership could act as a bridge-to-understanding to help teachers understand the dynamics of the student/teacher classroom relationships as identified in the study. If the administrative leadership can understand this dynamic, then it has the potential to develop effective training for classroom teachers with the goal of guiding teachers to an understanding of students' perspectives - to an understanding of why Latino male students would feel viewed as unwanted troublemakers who believe that their teachers do not want them in their classrooms.

\section{Recommendation 2: Teacher Training - Restorative Justice}

The findings suggest that a next step after the administration has provided teachers with training that focuses on the divide between what students and teachers perceive, should include teacher training to understand restorative practices for implementation in the classroom. These practices are based on restorative justice principles that facilitate positive communication between students and teachers. These practices have been shown to build safe classroom environments where students and teachers are supported to communicate by agreements generated by both. These agreements work to create an 
atmosphere where communication can safely take place. Restorative justice practices provide tools that include reflective practices through which teachers share with students how to repair harms. A strong point of this model is that there is much practicing, so there is time to learn the structures of communication with the end goal of teachers and students feeling safe and listened to. The structure provides a safe path that the teacher has been instructed as to how to monitor as the class works together so that if positive communication starts to derail damage can be mitigated and/or stopped.

The findings suggest that listening to students to build up trust, so students can share their viewpoints will assist the teachers to help them. Listening can address the many misinterpretations that often arise from a lack of teacher experience with students from different cultural backgrounds. These misinterpretations of student behavior often provoke unnecessary disciplinary interventions for Latino male students. Learning by listening from their students will provide teachers tools for understanding students' intent and content.

If students and teacher in classrooms can learn how to have authentic communicative interactions, then students can come to feel safe to advocate for themselves. Latino male students would have a chance to feel that they are listened to and that their opinions are valued. They will see their teachers as including them along with other students as they follow the model.

Below are some of the results schools have found through using restorative justice strategies:

1. Valuing others explicitly 
2. Acknowledging and appreciating diversity

3. Constructively challenging oppression and prejudice

4. Connecting across differences

5. Restorative debriefing after critical incidents

6. Understanding and managing anger

\section{Recommendation 3: Provide Teacher Training - Cultural Diversity of Students}

While the recommendations above are designed to provide leadership guidance and effective training for classroom teachers in regards to effective communication, a missing piece is the culturally relevant lesson plans that the findings identified in the Spanish teachers' classrooms, but were absent in other classes. Whereas participants were able to enter their Spanish classes happy and loudly greeting each other in Spanish, participants believed that teachers in other classes interpreted their behavior as not caring about their

education. Instead, they believed that they were perceived as students who just wanted to mess around. The students' and teachers' vastly different perceptions of behaviors in different classrooms at the same school point to cultural misunderstandings. One way to clear up these misunderstandings is for teachers to provide students with openings to describe their cultural norms, so teachers can understand that their behaviors are not defiant or confrontational, but culturally normal.

Additionally, the findings suggest that there is a need to focus on developing cultural approaches to curriculum development to integrate Latina/o students into the learning community. Cultural pedagogy included in lesson plans in the classroom will signal to Latina/o students that they are fully integrated members of the learning community. 
Latina/o students then would feel pride instead of ashamed of their heritage and language. Additionally, the findings strongly suggest that students would develop trust in their teachers as they witness them including them in the classroom through culturally connected curriculum. This would show a teacher's authentic caring which in turn would motivate and engage Latino males to stay in school to engage in learning as they prepare for college.

\section{Recommendations for Further Study}

Further research is needed to provide strategies to stem the flow of Latino male high school students from their comprehensive schools to continuation schools - schools that are far from keeping them on the college track. Studies are needed to bring this issue to the forefront of the national debate as to why so few Latino male students continue on to earn a four-year degree. The findings of the study point to the derailment of these students from the college track during their high school years. What further recommendations can be made to stop this from happening year in and year out?

This study's findings suggest that at one high school, Latino male students feel unwelcome and unwanted by their classroom teachers. Further studies are needed to identify if Latino male students in other public high schools across the country share these same feelings for the similar reasons. Are the findings for this study specific to this one high school or are they in fact nationwide?

Additionally, further studies are needed to determine how to most effectively support students of differing ethnic identities to feel included through curricular models and to 
take away the possibility of excluding students from learning and instead provide materials through which all students feel engaged and motivated to learn.

An area that would benefit from further study is that of school leadership at the administrative level. Studies designed to identify how administrators can become aware of and then understand the feelings of Latino male students would open a door for positive change. Such studies could provide insight into how to turn findings into action plans to address identified areas of distress to enable administrators to design effective plans to educate and train teachers. By starting at the administrative level, a school would have a sound foundation from which to support teachers and students. Without the understanding of the administration there would be next to no hope to expect teachers to become aware of and then change their negative classroom behaviors. Without the awareness of the administration, leadership could not be provided that could instigate positive change systematically through an entire school. Currently, many high schools address student behavior at the classroom level. The teacher sends the student out and the administration decides the consequence. This model does not lend itself to taking a step back to try to understand the numerous and complex issues in play. By starting at the administrative level, support would be put in place to design and implement trainings with the key purpose of guiding teachers to understand that teacher behaviors profoundly affect Latino male students in their classrooms. It is key that teachers feel supported during this process, so they will be motivated to engage in the work. The administration would need to convey respect for their teachers, so they in turn would feel safe enough to confront what could be for some of them very difficult understandings. The care of the 
administration for its teachers would in fact model the care that teachers would be trained to provide for their students. With administrators and teachers working together for positive results for students, they could go far to make public school classrooms welcoming, motivating, and engaging environments for Latino male students.

\section{Conclusion}

As a society, we need to understand how and why our public education system is and has been pushing out alarming numbers of Latino male students from their public high schools thus radically diminishing their chances of attending college. Their future lives are being negatively shaped daily in our public school classrooms. Our actions or inactions today will impact their lives and will make a difference in whether these future citizens are productive members of society or a burden to it. We need to understand how our decisions today make the difference between a life of incarceration, a life of poverty, and/or a productive fulfilling life that is firmly anchored in education. We need to understand the challenges that Latino males face and learn what to do to prevent any of them from becoming another statistic, dropping out of school, and eventually becoming what they feared the most: another stereotype.

Everything starts in the classroom. It is here where the roots are created, and it is very important for teachers of Latino youth to build foundations of authentic caring/auténtico cariño and trust/confianza. This will in turn allow students to thrive in educational environments and flourish in their chosen fields of study. If students feel cared for and attended to, if students feel a sense of belonging, if students feel a part of the system instead of being rejected by the system, students will in fact contribute and 
work for its health, regardless of color, race, or language. If the classroom can provide this unbiased environment, this mental freedom that at times seems overlooked, the youth that this classroom launches into the world will in turn provide great benefits to their communities. To be seen and treated as an equal provides a sense of belonging, and a sense of belonging allows for a creative and productive future, free of biased divisions. It all starts in the classroom, at the root of education.

This study's findings can be helpful to teachers, school staff, and other stakeholders to understand the impact of teachers' behaviors and beliefs on Latino males' future education. It is critical to understand the reasons why so many Latino males are pushed out to continuation/alternative schools and why so many ultimately dropout of school altogether. The findings were based solely on the participants' perceptions of their teachers in their classrooms. The participants honestly and with great heart revealed how their teachers made them feel and for the majority this meant that they should not be in school. Many could have said that their teachers who exhibited negative behaviors should not be teaching. Instead, they came to the conclusion, based on their teachers' behaviors, that they should not be students. Unknowingly, the participants perfectly articulated the damaging power of the education debt that EHS is amassing at the participants', Latino male students' expense. It is the payment of this debt that EHS is morally bound to address, but how can a payment be made if the school is not aware that it owes so much to so many?

Public schools are running up massive debt to historically disenfranchised students who are not welcomed as learners in their high schools. With no moral component, the 
education debt continues to grow (Ladson-Billings, 2006). As public school educators, we need to develop and foster a moral component of consciousness to realistically and fully understand the location of the human being, the student, in our public education system. This would be to take ownership for the negative treatment of millions of Latino male high school students who believe that they are not being treated as real students by a majority of classroom teachers from the moment they walk into their very first high school class. Many Latino male students believe that the system is telling them that they specifically do not belong. One student described the concept, "It's like watching a party where everyone else is having a great time, but I am not invited - I am asked to leave at the door." 


\section{References}

Arcia, E. (2006). Achievement and enrollment status of suspended students: Outcomes in a large, multicultural school district. Education and Urban Society, 38(3), 359-369.

Anyon, J. (1980). Social class and the hidden curriculum of work. Journal of Education, $67-92$.

Anzaldua, G. (2009). The gloria anzaldúa reader. Retrieved from https://ebookcentral-proquest-com.libaccess.sjlibrary.org

Anzaldúa, G. (1987). Borderlands: la frontera (Vol. 3). San Francisco: Aunt Lute.

Archambault, I., Janosz, M., Fallu, J. S., \& Pagani, L. S. (2009). Student engagement and its relationship with early high school dropout. Journal of Adolescence, 32(3), 651670.

Auerbach, S. (2002). Why do they give the good classes to some and not to others? Latino parent narratives of struggle in a college access program. Teachers College Record, 104(7), 1369-1392.

Battistich, V., Solomon, D., Watson, M., \& Schaps, E. (1997). Caring school communities. Educational Psychologist, 32(3), 137-151.

Baldwin, J. (1963). A talk to teachers. Yearbook of the National Society for the Study of Education, 107 (2), 15-20.

Bartolomé, L. I. (2008). Authentic cariño and respect in minority education: The political and ideological dimensions of love. The International Journal of Critical Pedagogy, $1(1)$.

Baumeister, R. F., \& Leary, M. R. (1995). The need to belong: desire for interpersonal attachments as a fundamental human motivation. Psychological Bulletin, 117(3), 497.

Becerra, D. (2012). Perceptions of Educational Barriers Affecting the Academic Achievement of Latino K-12 students. Children \& Schools, 34 (3), 167-177. 
Benner, A.D. and Graham, S. (2011). Latino Adolescents' Experiences of Discrimination Across the First 2 Years of High School: Correlates and Influences on Educational Outcomes. Child Development. 82 (2). 508-519.

Bernal, D. D. (2002). Critical race theory, Latino critical theory, and critical racedgendered epistemologies: Recognizing students of color as holders and creators of knowledge. Qualitative Inquiry, 8(1), 105-126.

Brewster, A. B., \& Bowen, G. L. (2004). Teacher support and the school engagement of Latino middle and high school students at risk of school failure. Child and Adolescent Social Work Journal, 21(1), 47-67.

Bonilla-Silva, E. (2017). Racism without racists: Color-blind racism and the persistence of racial inequality in America. Rowman \& Littlefield.

Bordas, J. (2013). The power of Latino leadership: Culture, inclusion, and contribution. Berrett-Koehler Publishers.

Bradley, C. L., \& Renzulli, L. A. (2011). The complexity of non-completion: Being pushed or pulled to drop out of high school. Social Forces, 90(2), 521-545.

Brown, T. M. (2007). Lost and turned out: Academic, social, and emotional experiences of students excluded from school. Urban Education, 42(5), 432-455

California Department of Education (2018). California English Language Development Test (CELDT). Retrieved from https://www.cde.ca.gov/ta/tg/el

Cameron, C. D. R. (1998). How the García cousins lost their accents: Understanding the language of Title VII decisions approving English-only rules as the product of racial dualism, Latino invisibility, and legal indeterminacy. La Raza LJ, 10, 261.

Cariño. 2017. In Real Academia Española. Retrieved August 12, 2017, from: https://www.rae.es/dictionary/cariño.

Carter, P. L. (2006). Straddling boundaries: Identity, culture, and school. Sociology of education, 79(4), 304-328. 
Cavazos-Rehg, P. A., \& DeLucia-Waack, J. L. (2009). Education, Ethnic Identity, and Acculturation as Predictors of Self-Esteem in Latino Adolescents. Journal of Counseling \& Development, 87(1), 47-54.

Child Population, by Race/Ethnicity (2016). In kidsdata.org. Retrieved from https://www.kidsdata.org/topic/33/child-population-race.

Cushman, K. (2009). SAT Bronx: A collaborative inquiry into the insider knowledge of urban youth. Theory Into Practice, 48(3), 184-190.

Daly, B. P., Shin, R. Q., Thakral, C., Selders, M., \& Vera, E. (2009). School engagement among urban adolescents of color: does perception of social support and neighborhood safety really matter? Journal of Youth and Adolescence, 38(1), 63-74.

Daniels, E. A. (2013). Fighting, loving, teaching: An exploration of hope, armed love and critical urban pedagogies (Vol. 4). Springer Science \& Business Media.

Darder, A. (2016). Critical leadership for social justice: Unveiling the dirty little secret of power and privilege. The Radical Imagine-Nation, 1(1), 41-76.

DeLuca, J. R. and Maddox, C.B. (2015). Tales from the Ethnographic Field: Navigating Feelings of Guilt and Privilege in the Research Process. Field Methods. 28(3) 284-299. doi: 10.1177/1525822X15611375.

Delpit, L. D. (1992). Education in a multicultural society: Our future's greatest challenge. The Journal of Negro Education, 61(3), 237-249.

Delpit, L. (2006). Lessons from teachers. Journal of Teacher Education, 57(3), 220-231.

Delpit, L. D. (2012). "Multiplication is for White People": Raising Expectations for Other People's Children. the new press.

De Velasco, J. R., Austin, G., Dixon, D., Johnson, J., McLaughlin, M., \& Perez, L. (2008). Alternative education options: A descriptive study of California continuation high schools. San Diego: California Alternative Education Research Project, San Diego University. 
Diamond, J. B., Randolph, A., \& Spillane, J. P. (2004). Teachers' expectations and sense of responsibility for student learning: The importance of race, class, and organizational habitus. Anthropology \& Education Quarterly, 35(1), 75-98.

Duncan-Andrade, J. (2007). Gangstas, wankstas, and ridas: Defining, developing, and supporting effective teachers in urban schools. International Journal of Qualitative Studies in Education, 20(6), 617-638.

Duncan-Andrade, J. (2009). Note to educators: Hope required when growing roses in concrete. Harvard Educational Review, 79(2), 181-194.

Durlak, J. A., Weissberg, R. P., Dymnicki, A. B., Taylor, R. D., \& Schellinger, K. B. (2011). The impact of enhancing students' social and emotional learning: A metaanalysis of school-based universal interventions. Child development, 82(1), 405-432.

Elias, M. J., Zins, J. E., Graczyk, P. A., \& Weissberg, R. P. (2003). Implementation, sustainability, and scaling up of social-emotional and academic innovations in public schools. School Psychology Review, 32(3), 303-319.

Erath, S. A., Flanagan, K. S., \& Bierman, K. L. (2008). Early adolescent school adjustment: Associations with friendship and peer victimization. Social Development, 17(4), 853-870.

Erwin, J. O. and Worrell, F. C. (2012). Assessment Practices and the Underrepresentation of Minority Students in Gifted and Talented Education. Journal of Psychoeducational Assessment. 30(1) 74-87.

Fernández, L. (2002). Telling stories about school: Using critical race and Latino critical theories to document Latina/Latino education and resistance. Qualitative Inquiry, $8(1), 45-65$.

Dropouts by Race \& Gender. (2018). In California Department of Education. Retrieved from https://www.cde.ca.gov/

Flanagan, C., A., \& Stout, M. (2010). Developmental Patterns of Social Trust between Early and Late Adolescence: Age and school climate effects. Journal of Research on Adolescence, 20(3), 748-773. 
Flannery, M. E. (2015). The School-to-Prison Pipeline: Time to Shut it Down. NEA Today, 33 (4), 42-45.

Ford, D. Y. (2012). Culturally different students in special education: Looking backward to move forward. Exceptional Children, 78(4), 391-405.

Freire, P. (2000). Pedagogy of the oppressed (30th anniversary ed.). New York: Continuum.

Fry, R. (2003). High School Dropout Rates for Latino Youth. ERIC Digest.

Fry, R. A. (2010). Hispanics, high school dropouts and the GED. Washington, DC: Pew Hispanic Center.

Furrer, C., \& Skinner, E. (2003). Sense of relatedness as a factor in children's academic engagement and performance. Journal of Educational Psychology, 95(1), 148.

Gandara, P. C., \& Contreras, F. (2009). The Latino education crisis: The consequences of failed social policies. Harvard University Press.

Goddard, R. D., Salloum, S. J., and Berebitsky, D. (2009) Trust as a mediator of the relationships between poverty, racial composition, and academic achievement: Evidence from Michigan's public elementary schools. Educational Administration Quarterly, 45 (2), 292-311.

Gordon, R., Della Piana, L., \& Keleher, T. (2001). Zero tolerance: A basic racial report card. Zero tolerance: Resisting the drive for punishment in our schools, 165-175.

Grana, R. A., Black, D., Sun, P., Rohrbach, L. A., Gunning, M., \& Sussman, S. (2010). School disrepair and substance use among regular and alternative high school students. Journal of School Health, 80(8), 387-393.

Green, T.L. (2017). Community-based equity audits: A practical approach for educational leaders to support equitable community-school improvements. Educational Administration Quarterly, 53(1), 3-39. 
Greenberg, M. T., Weissberg, R. P., O'brien, M. U., Zins, J. E., Fredericks, L., Resnik, H., \& Elias, M. J. (2003). Enhancing school-based prevention and youth development through coordinated social, emotional, and academic learning. American Psychologist, 58(6-7), 466.

Gregory, A., \& Ripski, M. B. (2008). Adolescent trust in teachers: Implications for behavior in the high school classroom. School Psychology Review, 37(3), 337.

Gregory, A., Skiba, R. J., \& Noguera, P. A. (2010). The achievement gap and the discipline gap: Two sides of the same coin? Educational Researcher, 39(1), 59-68.

Gross, B., \& Gross, R. (1969). Radical School Reform.

Howard, G. R. (2007). As diversity grows, so must we. Educational Leadership, 64(6), 16.

Johnson, T., Boyden, J. E., \& Pittz, W. J. (2001). Racial Profiling and Punishment in US Public Schools: How Zero Tolerance Policies and High Stakes Testing Subvert Academic Excellence and Racial Equity. Research Report [and] Executive Summary.

Katz, S. R. (1999). Teaching in tensions: Latino immigrant youth, their teachers, and the structures of schooling. Teachers College Record, 100(4), 809-840.

Kelly, D. M. (1993). Last chance high: How girls and boys drop in and out of alternative schools. Yale University Press.

Kohl, H. (1969). A Harlem class writes. Radical school reform, 330-346.

Kunc, N. (1992). The need to belong: Rediscovering Maslow's hierarchy of needs.

Ladson-Billings, G. (1995). Toward a theory of culturally relevant pedagogy. American Educational Research Journal, 32(3), 465-491.

Ladson-Billings, G. (2006). From the achievement gap to the education debt: Understanding achievement in US schools. Educational Researcher, 35(7), 3-12.

Ladson-Billings, G. (2007). Pushing past the achievement gap: An essay on the language of deficit. The Journal of Negro Education, 316-323. 
Landsman, J. G. and Lewis, C. W. (2012). White teachers/ diverse classrooms: Creating inclusive schools, building on students' diversity, and providing true educational equity. Stylus Publishing, LLC.

Lea, J. (2000). The Macpherson Report and the question of institutional racism. The Howard Journal of Criminal Justice, 39(3), 219-233.

Loera, G., Rueda, R., \& Oh, Y. J. (2015). Learning and motivational characteristics of urban Latino high school youth. Urban Education, 0042085915602536.

López, F. A. (2016). Culturally Responsive Pedagogies in Arizona and Latino Students' Achievement. Teachers College Record, 118(5), n5.

Mallett, R. K., Mello, Z. R., Wagner, D. E., Worrell, F., Burrow, R. N., \& Andretta, J. R. (2011). Do I belong? It depends on when you ask. Cultural Diversity and Ethnic Minority Psychology, 17(4), 432.

Martinez, S. (2009). A system gone berserk: How are zero-tolerance policies really affecting schools? Preventing school failure: alternative education for children and youth, 53(3), 153-158.

Merriam, S. B., \& Tisdell, E. J. (2015). Qualitative research: A guide to design and implementation. John Wiley \& Sons.

Miles, M. B., Huberman, A. M., Huberman, M. A., \& Huberman, M. (1994). Qualitative data analysis: An expanded sourcebook. sage.

Mills, C. W. (2000). The sociological imagination. Oxford University Press

Nave, B. (2015). Student-Centered Learning: Nine Classrooms in Action. Harvard Education Press. 8 Story Street First Floor, Cambridge, MA 02138.

Noddings, N. (2013). Caring: A relational approach to ethics and moral education. Univ of California Press.

Noguera, P. A. (2003). The trouble with Black boys: The role and influence of environmental and cultural factors on the academic performance of African American males. Urban Education, 38(4), 431-459.

Noguera, P. A. (2009). The trouble with black boys: ...And other reflections on race, equity, and the future of public education. John Wiley \& Sons. 
Orfield, G., Losen, d., Wald, J., \& Swanson, C. B. (2004) Losing our future: How minority youth are being left behind by the graduation rate crisis. Civil Rights Project at Harvard Univeristy (The).

Pizarro, M. (2005). Chicanas and Chicanos in school: Racial profiling, identity battles, and empowerment (Vol. 11). University of Texas Press.

Reagan, T. (2005). Non-Western educational traditions (3rd . ed.). Lawrence: New Jersey.

Rios, V. M. (2011). Punished: Policing the lives of Black and Latino boys. NYU Press.

Robinson, V. (2011). Student-centered leadership (Vol. 15). John Wiley \& Sons.

Rose, M. (1995). Possible lives: The promise of public education in America (pp. 2-3). Boston: Houghton Mifflin Company.

Rowe, M. B. (1986). Wait time: slowing down may be a way of speeding up!. Journal of teacher education, 37(1), 43-50.

Sánchez, B., Colón, Y., \& Esparza, P. (2005). The role of sense of school belonging and gender in the academic adjustment of Latino adolescents. Journal of Youth and Adolescence, 34(6), 619-628.

School to prison pipeline. (n.d.). In American Civil Liberties Union. Retrieved from https://www.aclu.org/issues/juvenile-justice/school-prison-pipeline/school-prisonpipeline

Schwartz, S. J., Zamboanga, B. L., \& Jarvis, L. H. (2007). Ethnic identity and acculturation in Hispanic early adolescents: Mediated relationships to academic grades, prosocial behaviors, and externalizing symptoms. Cultural Diversity and Ethnic Minority Psychology, 13(4), 364.

Sealey-Ruiz, Y., \& Greene, P. (2011). Embracing urban youth culture in the context of education. The Urban Review, 43(3), 339-357.

Senge, P. M., Cambron-McCabe, N., Lucas, T., Smith, B., \& Dutton, J. (2012). Schools that learn (updated and revised): A fifth discipline field book for educators, parents, and everyone who cares about education. Crown Business. 
Solomona, R. P., Portelli, J. P., Daniel, B. J., \& Campbell, A. (2005). The discourse of denial: How white teacher candidates construct race, racism and 'white privilege'. Race Ethnicity and Education, 8(2), 147-169.

Sosa, T., \& Gomez, K. (2012). Connecting teacher efficacy beliefs in promoting resilience to support of Latino students. Urban Education, 47(5), 876-909.

Tinkler, B. (2002). A Review of Literature on Hispanic/Latino Parent Involvement in K12 Education.

Trueba, H. (1993). Culture and language: The ethnographic approach to the study of learning environments. Language and culture in learning: Teaching Spanish to native speakers of Spanish, 26-44.

Tschannen-Moran, M., \& Hoy, W. K. (2000). A multidisciplinary analysis of the nature, meaning, and measurement of trust. Review of Rducational research, 70(4), 547-593.

Valenzuela, A. (1999). Subtractive schooling: Issues of caring in education of USMexican youth. State University of New York Press.

Verdugo, R. R. (2002). Race-ethnicity, social class, and zero-tolerance policies: The cultural and structural wars. Education and Urban Society, 35(1), 50-75.

Vygotsky, L. (1978). Interaction between learning and development. Readings on the Development of Children, 23(3), 34-41.

Wald, J., \& Losen, D. J. (2003). Defining and redirecting a school-to-prison pipeline. New directions for youth development, 2003(99), 9-15.

Walton, G. M., \& Cohen, G. L. (2007). A question of belonging: race, social fit, and achievement. Journal of Personality and Social Psychology, 92(1), 82.

Weiner, L. (2006). Challenging deficit thinking. Educational Leadership, 64(1), 42.).

Weissman, M. (2015). Prelude to prison: Student perspectives on school suspension. Syracuse University Press. 


\section{APPENDIX}

\section{Appendix A: Background Survey/Encuesta}

1. What is your age? ¿Cuól es su edad?

2. What is the primary language spoken at your home? ¿Cuál es su lengua materna?

3. What is your ethnicity? ¿Cuál su grupo étnico? Please circle your ethnicity: Por favor circule su grupo étnico: Blanco Hispano Latino Indígena ¿De donde? Otro

4. Please tell me if you are new to the school system in the United States (U.S) or if you have attended since Kindergarten. Por favor dígame si usted es nuevo en el sistema educativo de los Estados Unidos o si usted ha asistido desde el Kinder a una escuela de los Estados Unidos?

5. Are you an English Language Learner student? Está considerado un alumno aprendiz de inglés?

6. Who do you live with? ¿Con quién vive usted? 


\section{Appendix B: Interview Questions}

RQ1: How do Latino male students' perceptions of teacher beliefs, expectations, and behaviors toward Latino students, impact their relationships with these teachers?

1. Are there any adults on campus you feel you can trust and be yourself with, without feeling self- conscious? What is it about these adults that makes you feel accepted and part of your school community? How do these adults make you feel supported? What do adults on campus do and/or say to you that makes you feel you cannot trust them? What is it about these adults that makes you feel unaccepted and not part of your school community?

2. Do you have a favorite class? Please explain why. Please discuss your interactions with your teacher, classmates and other class components that make you feel safe and able to learn. Please discuss what makes you feel unsafe and disrupts your learning. What is your least favorite class? Please explain why. What makes it difficult for you to participate in this class? What happens in this class that cause it to become your least favorite? What does your teacher do that makes you feel unmotivated? What do your classmates do? What do you do in this class? In what percentage of your classes do you feel this way?

3. Have you ever felt that you were treated differently from other students at your school? If so, please describe. Describe the interactions that made you feel that you were treated differently. Why do you think they treated you differently? Who made you feel this, and what did they say to you? What did they do? What did they say to you that made you feel you were being treated differently? When did this happen? Why did this happen? Does being treated differently affects your motivation in the classroom? How often do you believe this happens? Why do you think/feel that it happened? If this has happened, please describe the situation. Please include where, when, how and why? What percentage of times do you feel treated differently?

4. Have you been sent to see the principal/assistant principal for discipline issues? Have you been suspended or at risk of being suspended? Why were you sent to see the principal or assistant principal? How did that encounter make you feel as a student? Did anyone make you feel safe? Who made you feel safe during the 
ordeal? What did they do? Did anyone make you feel unsafe? What did they say to you to make feel unsafe? What did they do to make you feel unsafe?

5. What beliefs do your teachers have about you and other Latino students? How have they shown you these beliefs?

6. What expectations do your teachers have for you and other Latino students? How have they shown you these expectations?

RQ2: How do Latino male students' perceptions of teacher cariño and confianza impact their relationships with these teachers?

1. What does confianza mean for you? Tell me of a teacher(s) who inspires you to have confianza at this school? What does your teacher do for you to have confianza in him/her? What do you do when you are with this teacher that is different because of the confianza you feel for him/her? Tell me of a teacher that you do not feel confianza with? What happened that makes you not feel confianza? Did they say or do something that is not supporting confianza?

2. What are some characteristics of a teacher that would inspire you to feel confianza to ask questions in class? Confianza to ask for help? Confianza to tell them what you need? Confianza to share about you, your life, and your challenges? Give me examples of situations in which you have had confianza with a teacher (s) or an adult in this school? How many adults do you feel confianza with in this school? Please tell me how you feel when you are around the people you do not feel confianza with.

3. Can you think of teachers that you feel confianza with to share some of your challenges? How do you know who to have confianza in? What do you share with these teachers? How do feel in these classes due the confianza you feel for your teachers?

4. Do you feel your teachers have confianza towards you? What do they do that shows you that they have confianza in you? What does a teacher do so you do not have confianza in them?

5. What does cariño mean for you? Tell me of a teacher who shows you cariño. Tell me what your teacher does so you have/feel cariño towards them? Tell me of 
a teacher who you cannot feel this cariño. Tell me why? And tell me what happened that makes you unable to feel cariño for this teacher?

6. What are some characteristics of a teacher that inspire you to feel cariño? Tell me of a teacher(s) that shows cariño for you? Give me examples of situations in which the cariño you feel for a teacher made you feel motivated to attend school(s). How many adults do you feel cariño for at this school? What percentage of your teachers do you feel cariño?

7. Tell me what it is more important confianza or cariño or both? Do you feel confianza and cariño for a teacher(s)? What percentage of your teachers at this school have your confianza and cariño? And how many teachers do you believe feel confianza and cariño for you?

RQ3: How do these Latino male students' perceptions and relationships impact their academic motivation and academic engagement?

1. When you feel that a teacher cares for you, does this affect/promote your participation in class? Do you feel that your teacher cares if you ask questions in class? Do you raise your hand in all of your classes? Why or why not? Does it affect your willingness to ask for help or to seek support regarding an assignment/homework?

2. Is there a class in which you are attentive? How is your grade in that class? What is the difference between this class and others? Does the teacher influence your motivation and engagement? Do you feel your teacher has high expectations for you in the class? How is your relationship with your teacher in this class? What makes you participate in this class? What makes you not participate in the class?

3. What do you like least about school? Do you skip classes often? If you do, what class or classes do you choose to skip? Why? When you skip class/classes does your teacher call your parents? Does he/she call you? Does he/she approach you and ask the reason you missed class? What can your teacher do to motivate you to attend class? What does he/she do that causes you feel unmotivated to engage in this class? What do you believe can change to improve the relationship and your motivation as well? 
4. Do your teachers recognize your hard work in class, that you attend class, and have the desire to learn? Have you ever been recognized for your efforts by your teacher? Do you feel ignored in your class? If so, why do you think/feel that it happened? If this has happened, please describe the situation.

5. How many teachers do you feel connected to at this school? How do these teachers make you to feel connected? Why are these teachers different? Tell me what they do that makes you feel that they care for you? What does a teacher do that causes you not to feel connected to your school?

6. Do your relationships, or lack of relationships, with your teachers affect your motivation to improve in your classes? Do good relationships with teachers affect your motivation to learn and get good grades? Does this affect how you view yourself as a student now and your motivation in moving forward?

\section{Appendix B (Español): Encuesta}

RQ1: ¿Cómo las percepciones de los estudiantes latinos sobre las creencias, expectativas y comportamientos de los maestros hacia los estudiantes latinos impactan sus relaciones con estos maestros?

1. ¿Hay adultos en el campus en los que sientes que puedes confiar y ser tú mismo, sin sentirte cohibido? ¿Qué hay en estos adultos que te hace sentir aceptado y parte de tu comunidad escolar? ¿Cómo te hacen sentir estos adultos? ¿Qué hacen y dicen los adultos en el campus que te hacen sentir que no puedes confiar en ellos? ¿Qué hay en estos adultos que te hace sentir no aceptado y no parte de tu comunidad escolar?

2. ¿Tienes una clase favorita? Por favor explica por qué. Discuta sus interacciones con su profesor, compañeros de clase y otros componentes de la clase que lo hagan sentir seguro y capaz de aprender. Por favor, discuta qué te hace sentir inseguro e interrumpe tu aprendizaje. ¿Cuál es tu clase menos favorita? Por favor explica por qué. ¿Qué te dificulta participar en esta clase? ¿Qué sucede en esta clase que hace que se convierta en tu menos favorito? ¿Qué hace tu maestro que te hace sentir desmotivado? ¿Qué hacen tus compañeros de clase? ¿Qué haces en esta clase? ¿En qué porcentaje de tus clases te sientes así? 
3. ¿Alguna vez has sentido que te trataron de manera diferente a otros estudiantes en tu escuela? Si es así, por favor describe. Describe las interacciones que te hicieron sentir que te trataron de manera diferente. ¿Por qué crees que te trataron de manera diferente? ¿Quién te hizo sentir esto y qué te dijeron? ¿Qué hicieron? ¿Qué te dijeron que te hizo sentir que te estaban tratando de manera diferente? ¿Cuándo esto pasó? ¿Por qué pasó esto? ¿Ser tratado de manera diferente afecta tu motivación en el aula? ¿Con qué frecuencia crees que esto sucede? ¿Por qué piensas / siento que sucedió? Si esto sucedió, por favor describe la situación. Por favor incluya dónde, cuándo, cómo y porqué. ¿Qué porcentaje de veces te sientes tratado de manera diferente?

4. ¿Le han enviado a ver al director / subdirector por cuestiones de disciplina? ¿Has sido suspendido o estás en riesgo de ser suspendido? ¿Por qué te enviaron a ver al director o subdirector? ¿Cómo te hizo sentir ese encuentro como estudiante? ¿Alguien te hizo sentir seguro? ¿Quién te hizo sentir seguro durante la dura prueba? ¿Qué hicieron? ¿Alguien te hizo sentir inseguro? ¿Qué te dijeron para hacerte sentir inseguro? ¿Qué hicieron para hacerte sentir inseguro?

5. ¿Qué creencias tienen tus maestros sobre ti y otros estudiantes latinos? ¿Cómo te han mostrado estas creencias?

6. ¿Qué expectativas tienen tus maestros para ti y para otros estudiantes latinos? ¿Cómo te han mostrado estas expectativas?

RQ2: ¿Cómo impactan las percepciones de los estudiantes latinos sobre el maestro cariño y confianza en sus relaciones con estos docentes?

1. ¿Qué significa confianza para ti? ¿Dime de un maestro (s) que te inspire a tener confianza en esta escuela? ¿Qué hace tu maestro para que tengas confianza en él / ella? ¿Qué haces cuando estás con este profesor que es diferente debido a la confianza que sientes por él / ella? ¿Cuéntame de un maestro con el que no sientas confianza? ¿Qué sucedió que hace que no sientas confianza? ¿Dijeron o hicieron algo que no respalda la confianza?

2. ¿Cuáles son algunas características de un maestro que te inspirará a sentir confianza para hacer preguntas en clase? ¿Confianza para pedir ayuda? ¿Confianza para decirles lo que necesitas? ¿Confianza para compartir acerca de usted, su vida y sus desafíos? Dame ejemplos de situaciones en las que has tenido confianza con un maestro (s) o un adulto en esta escuela. ¿Con cuántos adultos te 
sientes confiado en esta escuela? Por favor, dime cómo te sientes cuando estás cerca de las personas con las que no sientes confianza.

3. ¿Puedes pensar en profesores con los que sientas confianza para compartir algunos de tus desafíos? ¿Cómo sabes en quién tener confianza? ¿Qué compartes con estos profesores? ¿Cómo te sientes en estas clases debido a la confianza que sientes por tus profesores?

4. ¿Sientes que tus maestros tienen confianza contigo? ¿Qué hacen ellos que te muestra que tienen confianza en ti? ¿Qué hace un maestro para que no tengas confianza en ellos?

5. ¿Qué significa cariño para ti? Cuéntame de un maestro que te muestra cariño. ¿Dime qué hace tu profesor para que tengas / sientas cariño hacia ellos? Cuéntame de un maestro que no puedes sentir este cariño. ¿Dime por qué? ¿Y dime qué pasó que te hace incapaz de sentir cariño por este maestro?

6. ¿Cuáles son algunas características de un maestro que te inspiran a sentir cariño? ¿Cuéntame de un maestro (s) que te muestre cariño? Dame ejemplos de situaciones en las que el cariño que sientes por un maestro te hace sentir motivado para asistir a la escuela (s). ¿Para cuántos adultos sientes cariño en esta escuela? ¿Qué porcentaje de tus maestros sientes cariño?

7. ¿Dime qué es más importante confianza o cariño o ambos? ¿Sientes confianza y cariño por un maestro (s)? ¿Qué porcentaje de tus profesores en esta escuela tienen tu confianza y cariño? ¿Y cuántos profesores crees que te sientan confianza y cariño?

RQ3: ¿Cómo impactan las percepciones y relaciones de estos estudiantes latinos sobre su motivación académica y compromiso académico?

1. Cuando sientes que un maestro se preocupa por ti, ¿esto afecta / promueve tu participación en clase? ¿Sientes que a tu maestra le importa si haces preguntas en clase? ¿Levantas tu mano en todas tus clases? ¿Por qué o por qué no? ¿Afecta su deseo de pedir ayuda o buscar apoyo con respecto a una tarea / tarea?

2. ¿Hay una clase en la que estás atento? ¿Cómo está tu calificación en esa clase? ¿Cuál es la diferencia entre esta clase y otras? ¿El profesor influye en tu motivación y compromiso? ¿Sientes que tu maestro tiene grandes expectativas para ti en la clase? ¿Cómo es tu relación con tu maestro en esta clase? ¿Qué te hace participar en esta clase? ¿Qué te hace no participar en la clase?

3. ¿Qué es lo que menos te gusta de la escuela? ¿Te saltas las clases a menudo? Si lo haces, ¿qué clase o clases eliges omitir? ¿Por qué? Cuando te saltas la clase / clases ¿tu maestra llama a tus padres? ¿Él / ella te llama? ¿Él / ella se le acerca y 
le pregunta la razón por la que se perdió la clase? ¿Qué puede hacer tu maestro para motivarte a asistir a clase? ¿Qué hace él / ella que te hace sentir desmotivado para participar en esta clase? ¿Qué crees que puede cambiar para mejorar la relación y tu motivación también?

4. ¿Sus maestros reconocen su arduo trabajo en clase, que asiste a clase y tiene el deseo de aprender? ¿Alguna vez ha sido reconocido por sus esfuerzos por su maestro? ¿Te sientes ignorado en tu clase? Si es así, ¿por qué piensas / siento que sucedió? Si esto sucedió, por favor describe la situación.

5. ¿Con cuántos maestros te sientes conectado en esta escuela? ¿Cómo te hacen estos profesores para sentirte conectado? ¿Por qué son estos profesores diferentes? Dime qué hacen que te hace sentir que te quieren. ¿Qué hace un maestro que hace que no te sientas conectado con tu escuela?

6. ¿Sus relaciones, o la falta de relaciones, con sus profesores afectan su motivación para mejorar en sus clases? ¿Las buenas relaciones con los docentes afectan su motivación para aprender y obtener buenas calificaciones? ¿Afecta esto la forma en que se ve a sí mismo como estudiante ahora y su motivación para seguir adelante? 